NUREG/CR-6446

BMI-2194

\title{
Fracture Toughness Evaluations of TP304 Stainless Steel Pipes
}

\author{
Technical Report \\ January 1994-November 1996
}

Manuscript Completed: January 1997

Date Published: February 1997

Prepared by

D. L. Rudland, F. W. Brust, G. M. Wilkowski

Battelle

305 King Avenue

Columbus, OH 43201

M. E. Mayfield, NRC Project Manager

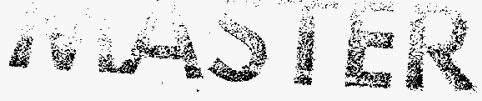

\section{Prepared for}

Division of Engineering Technology

Office of Nuclear Regulatory Research

U.S. Nuclear Regulatory Commission

Washington, DC 20555-0001

NRC Job Code D2060 


\section{DISCLAMMER}

Portions of this document may be illegible in electronic image products. Images are produced from the best available original document. 


\section{DISCLAIMER}

This report was prepared as an account of work sponsored by an agency of the United States Government. Neither the United States Government nor any agency thereof, nor any of their employees, make any warranty, express or implied, or assumes any legal liability or responsibility for the accuracy, completeness, or usefulness of any information, apparatus, product, or process disclosed, or represents that its use would not infringe privately owned rights. Reference herein to any specific commercial product, process, or service by trade name, trademark, manufacturer, or otherwise does not necessarily constitute or imply its endorsement, recommendation, or favoring by the United States Government or any agency thereof. The views and opinions of authors expressed herein do not necessarily state or reflect those of the United States Government or any agency thereof. 


\section{ABSTRACT}

In the IPIRG-1 program, the J-R curve calculated for a 16-inch nominal diameter, Schedule 100 TP304 stainless steel (DP2-A8) surface-cracked pipe experiment (Experiment 1.3-3) was considerably lower than the quasi-static, monotonic J-R curve calculated from a C(T) specimen (A8-12a). The results from several related investigations conducted to determine the cause of the observed toughness difference are:

(1) Chemical analyses on sections of Pipe DP2-A8 from several surface-cracked pipe and material property specimen fracture surfaces indicate that there are two distinct heats of material within Pipe DP2-A8 that differ in chemical composition. (2) SEN(T) specimen experimental results indicate that the toughness of a surface-cracked specimen is highly dependent on the depth of the initial crack. In addition, the J-R curves from the SEN(T) specimens closely match the J-R curve from the surface-cracked pipe experiment. (3) C(T) experimental results suggest that there is a large difference in the quasi-static, monotonic toughness between the two heats of DP2-A8, as well as a toughness degradation in the lower toughness heat of material (DP2-A8II) when loaded with a dynamic, cyclic $(R=-0.3)$ loading history. 


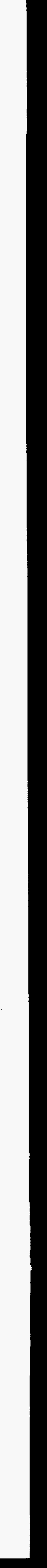


EXECUTIVE SUMMARY $\ldots \ldots \ldots \ldots \ldots \ldots \ldots \ldots \ldots \ldots \ldots \ldots \ldots \ldots \ldots \ldots \ldots \ldots \ldots \ldots \ldots \ldots \ldots$

ACKNOWLEDGMENTS $\ldots \ldots \ldots \ldots \ldots \ldots \ldots \ldots \ldots \ldots \ldots \ldots \ldots \ldots \ldots \ldots \ldots \ldots \ldots \ldots$

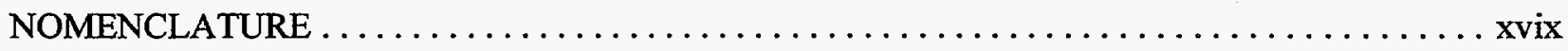

PREVIOUS REPORTS $\mathbb{N}$ SERIES $\ldots \ldots \ldots \ldots \ldots \ldots \ldots \ldots \ldots \ldots \ldots \ldots \ldots \ldots \ldots \ldots \ldots \ldots \ldots$

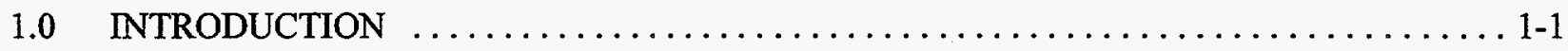

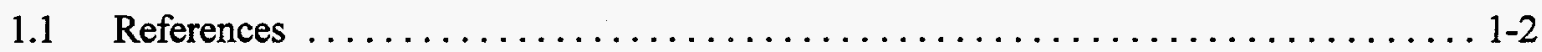

2.0 PREVIOUS MATERIAL CHARACTERIZATION OF PIPE DP2-A8 $\ldots \ldots \ldots \ldots \ldots \ldots 2-1$

2.1 Chemical Analyses . . . . . . . . . . . . . . . . . . . . . .

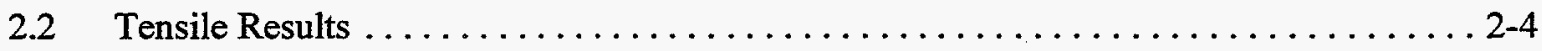

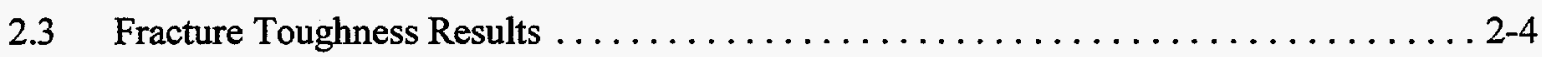

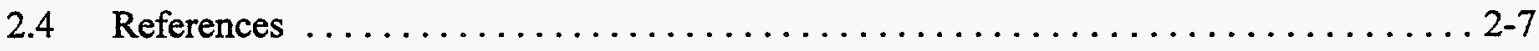

3.0 RESOLUTION OF THE TOUGHNESS DISCREPANCY BETWEEN C(T) SPECIMEN AND SURFACE-CRACKED PIPE SPECIMEN $\ldots \ldots \ldots \ldots \ldots \ldots \ldots$.

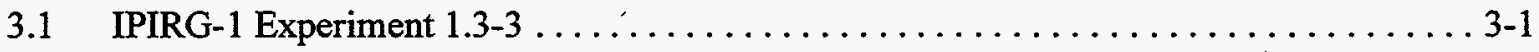

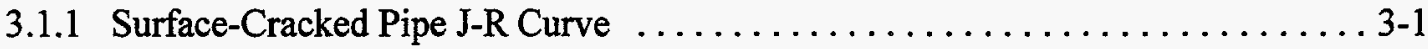

3.1.2 Predictions of Maximum Experimental Stress . . . . . . . . . . . . . . 3

3.1.3 Possible Explanations for Toughness and Maximum

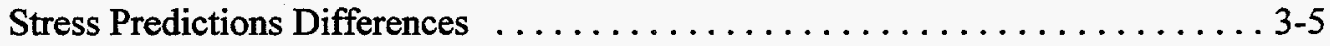

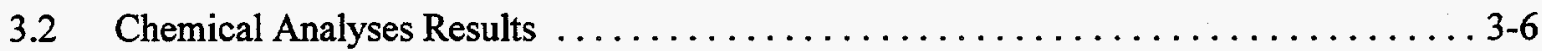

3.3 Single-Edge Notched Tensile Specimen Experiments $\ldots \ldots \ldots \ldots \ldots \ldots \ldots \ldots$

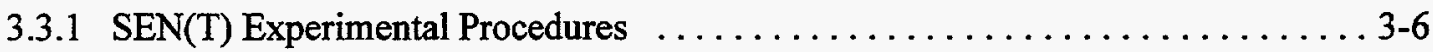

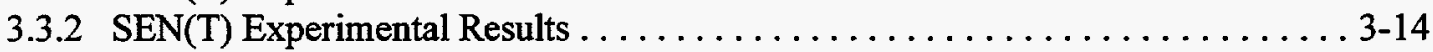

3.3.3 J-R Curves for the SEN(T) Specimens . . . . . . . . . . . . . . $3-14$

3.4 Compact Tension Specimen Experiments $\ldots \ldots \ldots \ldots \ldots \ldots \ldots \ldots \ldots \ldots \ldots \ldots$

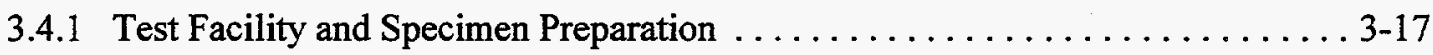

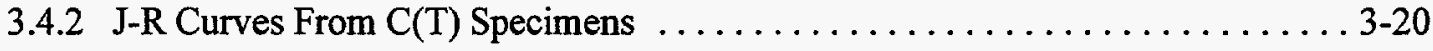

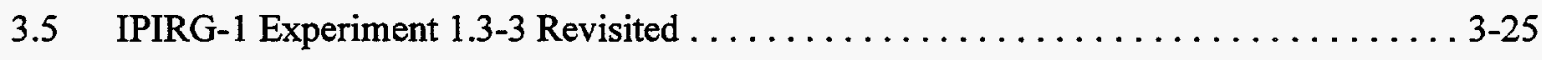




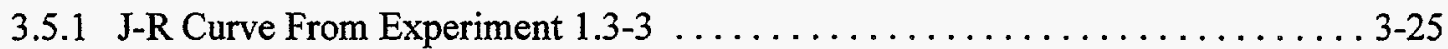

3.5.2 Predictions of Maximum Experimental Stress . . . . . . . . . . . . 3-26

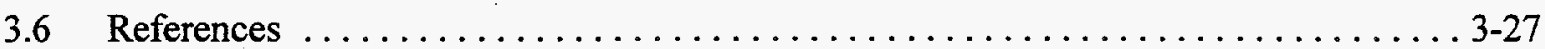

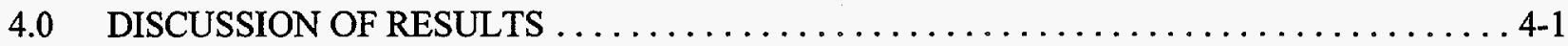

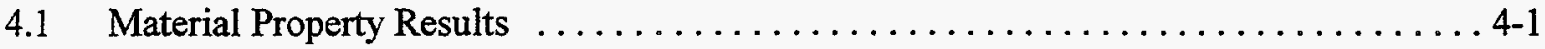

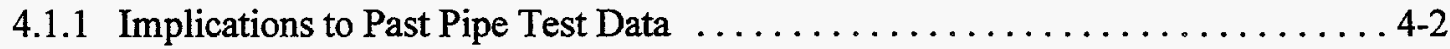

4.1 .2 Implications to ASME Section XI and LBB $\ldots \ldots \ldots \ldots \ldots \ldots \ldots \ldots \ldots \ldots \ldots \ldots$

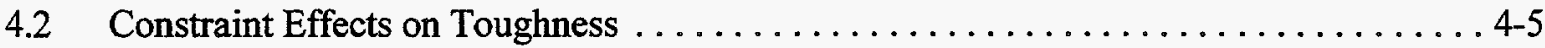

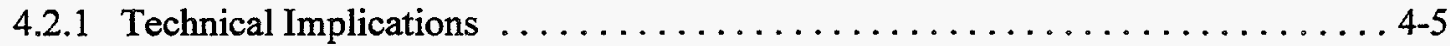

4.3 Dynamic and Cyclic Effects on Toughness $\ldots \ldots \ldots \ldots \ldots \ldots \ldots \ldots \ldots \ldots$

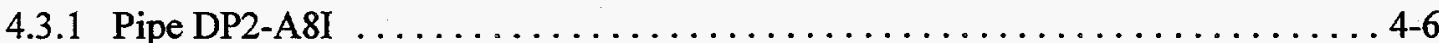

4.3 .2 Pipe DP2-A8II . . . . . . . . . . . . . . . . . . . . . . . . 4-7

4.3.3 Predictions of Maximum Experimental Stress . . . . . . . . . . . . . . . 4-8

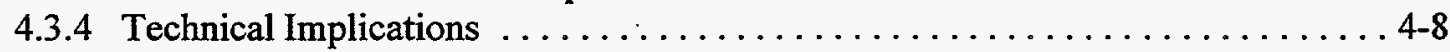

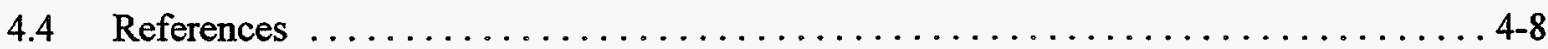

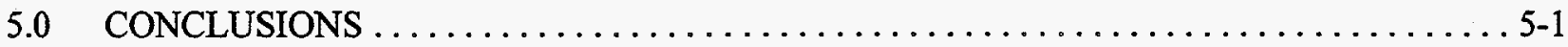

APPENDIX A: ANALYSIS OF SEN(T) SPECIMENS MACHINED FROM PIPE DP2-A8II . . . . A-1

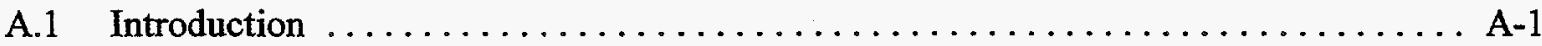

A.1.1 Unique Effects of Fixed Grip Conditions on the SEN(T) $\ldots \ldots \ldots \ldots \ldots$ A-1

A.2 Experimental Crack Growth Measurement $\ldots \ldots \ldots \ldots \ldots \ldots \ldots \ldots \ldots \ldots \ldots$ A -4

A.3 Finite Element Analysis - General Considerations $\ldots \ldots \ldots \ldots \ldots \ldots \ldots \ldots \ldots$ A-5

A.4 SEN(T) J-estimation Scheme $\ldots \ldots \ldots \ldots \ldots \ldots \ldots \ldots \ldots \ldots \ldots \ldots \ldots \ldots \ldots \ldots \ldots$

A.5 Analysis Results for Monotonic Loading $\ldots \ldots \ldots \ldots \ldots \ldots \ldots \ldots \ldots \ldots \ldots$

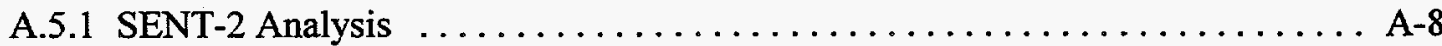

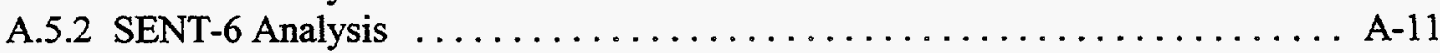

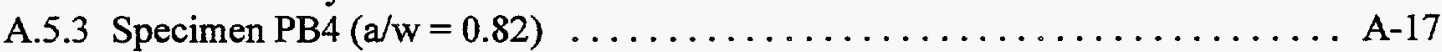

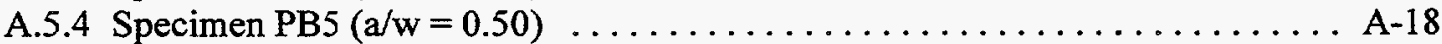

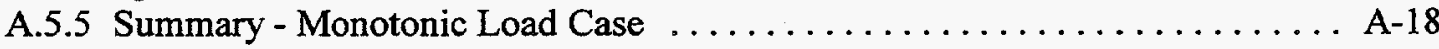




\section{CONTENTS}

Page

A.6 Analysis Results for Cyclick Loading, SENT-4 $(a / w=0.635) \ldots \ldots \ldots \ldots \ldots$ A-21

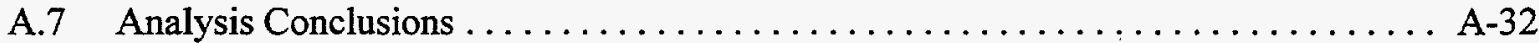

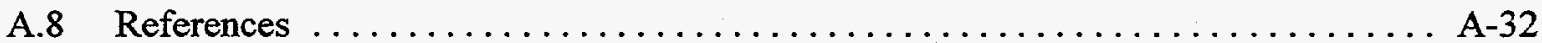

APPENDIX B: LISTING OF ALL DP2-A8 SPECIMENS $\ldots \ldots \ldots \ldots \ldots \ldots \ldots \ldots \ldots \ldots$ B-1 


\section{CONTENTS}

\section{LIST OF TABLES}

2.1 Full-scale pipe experiments on Pipe DP2-A8 with cracks in the base metal

2.2 Tensile specimens machined from Pipe DP2-A8 $\ldots \ldots \ldots \ldots \ldots \ldots \ldots \ldots \ldots \ldots \ldots \ldots \ldots \ldots$

2.3 Fracture toughness specimens machined from Pipe DP2-A8 $\ldots \ldots \ldots \ldots \ldots \ldots \ldots \ldots$

2.4 Chemical analysis from data record books containing Pipe DP2-A8 $\ldots \ldots \ldots \ldots \ldots \ldots$

2.5 Tensile properties of Pipe DP2-A8 (ASTM A358, Type 304 stainless steel) $\ldots \ldots \ldots \ldots 2-5$

2.6 Summary of $\mathrm{J}_{\mathrm{i}}$ and $\mathrm{dJ} / \mathrm{da}$ values for Pipe DP2-A8 $\ldots \ldots \ldots \ldots \ldots \ldots \ldots \ldots \ldots \ldots \ldots \ldots \ldots$

3.1 $\mathrm{J}_{\mathrm{i}}$ values for Experiment $1.3-3$ from Reference $3.2 \ldots \ldots \ldots \ldots \ldots \ldots \ldots \ldots \ldots \ldots \ldots \ldots \ldots \ldots$

3.2 Material property constants used in the maximum stress predictions $\ldots \ldots \ldots \ldots \ldots \ldots .4$

3.3 Fracture ratios for experiments on Pipe DP2-A8 $\ldots \ldots \ldots \ldots \ldots \ldots \ldots \ldots \ldots \ldots \ldots \ldots$

3.4 Chemical analysis results for specimens manufactured from Pipe DP2-A8 $\ldots \ldots \ldots \ldots .7$

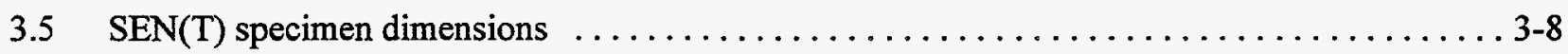

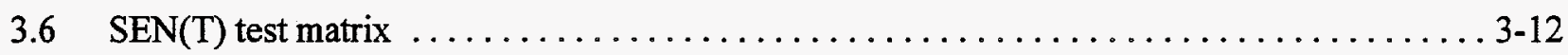

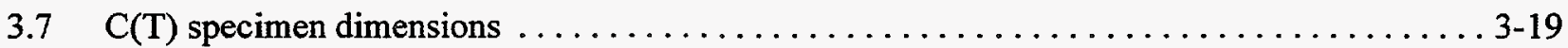

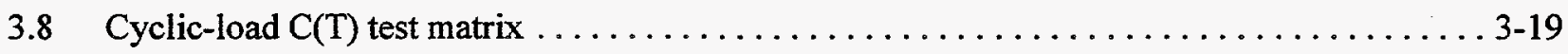

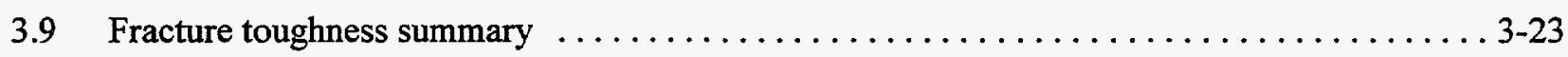

$3.10 \mathrm{~J}$-estimation scheme analyses of IPIRG pipe system experiments that

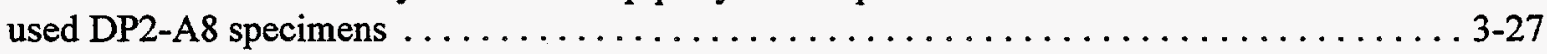

4.1 Average chemical compositions for Pipe DP2-A8 $\ldots \ldots \ldots \ldots \ldots \ldots \ldots \ldots \ldots \ldots \ldots \ldots$

4.2 Tensile and fracture toughness summary for Pipe DP2-A8 $\ldots \ldots \ldots \ldots \ldots \ldots \ldots \ldots \ldots$-2

4.3 Specimen listing by heat of Pipe DP2-A8 $\ldots \ldots \ldots \ldots \ldots \ldots \ldots \ldots \ldots \ldots \ldots \ldots \ldots \ldots \ldots \ldots$

4.4 Compact tension specimen loading histories $\ldots \ldots \ldots \ldots \ldots \ldots \ldots \ldots \ldots \ldots \ldots \ldots$

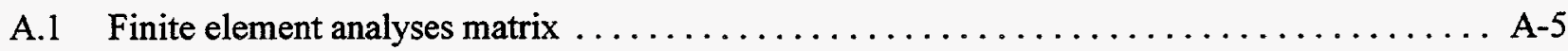

B.1 Full-scale pipe experiments with crack in base metal $\ldots \ldots \ldots \ldots \ldots \ldots \ldots \ldots \ldots$ B-1 


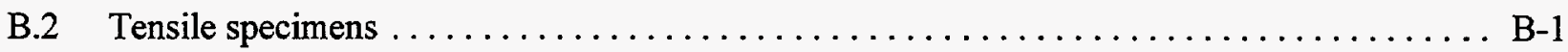

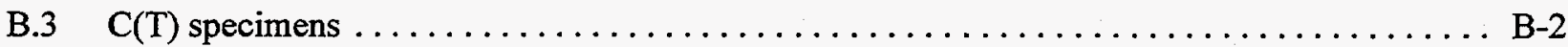

B.4 Single-edge notched specimens $\ldots \ldots \ldots \ldots \ldots \ldots \ldots \ldots \ldots \ldots \ldots \ldots \ldots \ldots \ldots \ldots \ldots$ 


\section{CONTENTS}

\section{LIST OF FIGURES}

2.1 Engineering stress-strain curves at 288 C (550 F) for Pipe DP2-A8 (A358 Type 304

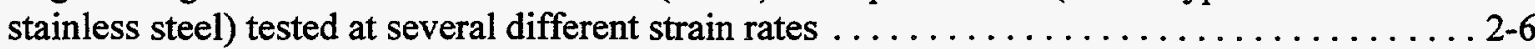

2.2 J-resistance curves for compact specimens from Pipe DP2-A8 (A358 Type 304 stainless steel) tested at $288 \mathrm{C}(550 \mathrm{~F})$

3.1 Crack section moment-rotation behavior from the IPIRG-1 stainless steel base metal experiment (1.3-3)

3.2 Comparison of the modified J-R curve from the pipe experiment with the quasi-static, monotonic $\mathrm{C}(\mathrm{T})$ specimen $\mathrm{J}-\mathrm{R}$ curve

3.3 Schematic illustration of SEN(T) testing arrangement

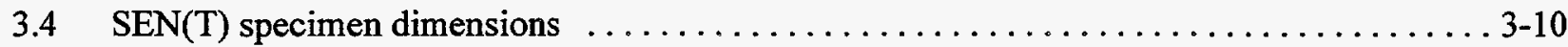

3.5 Photograph of SEN(T) experimental setup $\ldots \ldots \ldots \ldots \ldots \ldots \ldots \ldots \ldots \ldots \ldots \ldots \ldots \ldots \ldots$

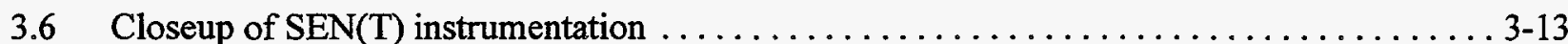

3.7 Load-displacement record for $\mathrm{SEN}(\mathrm{T})$ specimens $\ldots \ldots \ldots \ldots \ldots \ldots \ldots \ldots \ldots \ldots \ldots \ldots$

3.8 Comparison of SEN(T) J-R curves calculated using the Ahmad J-estimation scheme and the finite element method

$3.9 \mathrm{~J}_{\mathrm{i}}$ versus crack depth for a variety of specimens $\ldots \ldots \ldots \ldots \ldots \ldots \ldots \ldots \ldots \ldots \ldots \ldots \ldots \ldots$

3.10 Schematic illustration of direct-current electric potential method employed at Battelle to monitor crack growth in $\mathrm{C}(\mathrm{T})$ tests $\ldots \ldots \ldots \ldots \ldots \ldots \ldots \ldots \ldots \ldots$

$3.11 \mathrm{~J}-\mathrm{R}$ curves from $\mathrm{C}(\mathrm{T})$ specimens machined from Pipe DP2-A8I $\ldots \ldots \ldots \ldots \ldots \ldots \ldots .21$

$3.12 \mathrm{~J}-\mathrm{R}$ curves from $\mathrm{C}(\mathrm{T})$ specimens machined from Pipe DP2-A8II $\ldots \ldots \ldots \ldots \ldots \ldots \ldots .21$

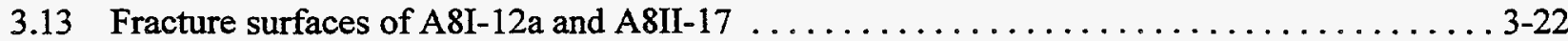

3.14 Engineering stress-strain curves at $288 \mathrm{C}(550 \mathrm{~F})$ for A358 Type 304 stainless steel pipe (DP2-A8) tested at several different strain rates $\ldots \ldots \ldots \ldots \ldots \ldots \ldots \ldots \ldots \ldots \ldots \ldots$

3.15 Several J-R curves for comparison with Experiment $1.3-3 \ldots \ldots \ldots \ldots \ldots \ldots \ldots \ldots \ldots \ldots \ldots$

4.1 Sensitivity analyses using DP2-A8I and DP2-A8II material properties $\ldots \ldots \ldots \ldots \ldots \ldots$

A.1 Illustration of surface-cracked pipe and SEN(T) applied displacements $\ldots \ldots \ldots \ldots \ldots \ldots$ A-2 
A.2 Deformed shape in SEN(T) FEM analysis, (a) Uniform applied stress,

(b) Uniform (fixed grip) applied displacement $\ldots \ldots \ldots \ldots \ldots \ldots \ldots \ldots \ldots \ldots \ldots \ldots \ldots$

A.3 FEM mesh used for some of the analyses, crack tip mesh refinement is

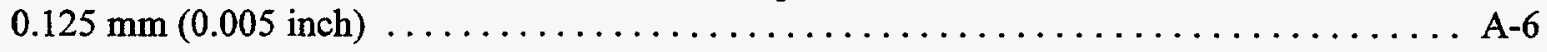

A.4 Total load-line displacement versus crack growth from Experiment SENT-2. Note that, due to symmetry of the model, only one-half of this displacement was applied in the

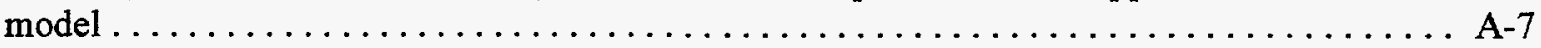

A.5 Load-displacement predictions, SENT-2 $\ldots \ldots \ldots \ldots \ldots \ldots \ldots \ldots \ldots \ldots \ldots \ldots$

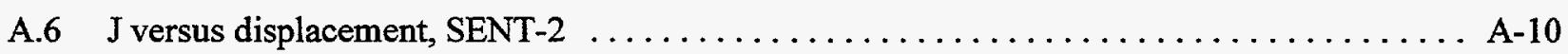

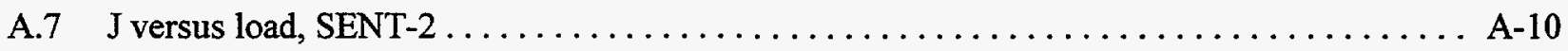

A.8 J-R curves, SENT-2 $\ldots \ldots \ldots \ldots \ldots \ldots \ldots \ldots \ldots \ldots \ldots \ldots \ldots \ldots \ldots \ldots \ldots \ldots \ldots \ldots \ldots \ldots$

A.9 Analysis results with no crack growth, SENT-2, (a) J versus displacement,

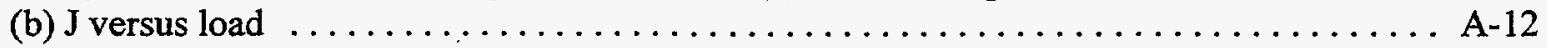

A.10 Displacement versus crack growth experimental record used as input for

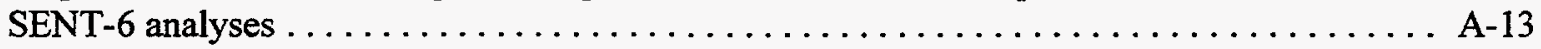

A.11 Predicted load displacement curve, SENT $-6 \ldots \ldots \ldots \ldots \ldots \ldots \ldots \ldots \ldots \ldots \ldots \ldots \ldots$

A.12 J versus load-line displacement, SENT $-6 \ldots \ldots \ldots \ldots \ldots \ldots \ldots \ldots \ldots \ldots \ldots \ldots \ldots$

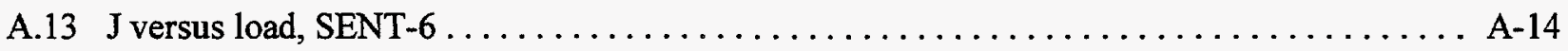

A.14 Predicted J-R curves compared with Experiment SENT-6; the experimental

$\mathrm{J}$ values were calculated from the load-displacement curve based on the method

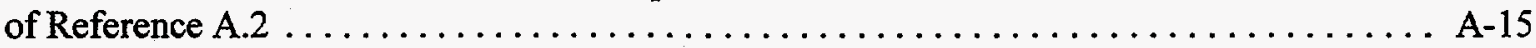

A.15 Analysis results with no crack growth, SENT-6, (a) J versus load-line displacement

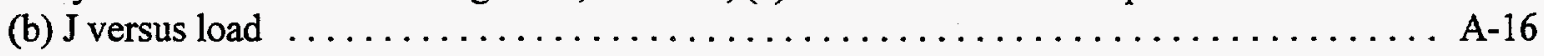

A.16 Predicted load versus load-line displacement curve for Specimen PB4 $\ldots \ldots \ldots \ldots \ldots$ A-17

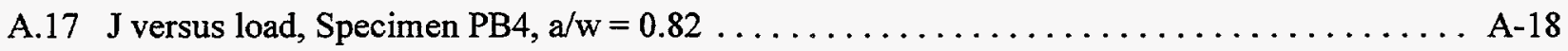

A.18 Load-displacement curve, Specimen PB5, a/w $=0.5 \ldots \ldots \ldots \ldots \ldots \ldots \ldots \ldots \ldots$

A.19 J-integral versus displacement, Specimen $\mathrm{PB} 5, \mathrm{a} / \mathrm{w}=0.5 \ldots \ldots \ldots \ldots \ldots \ldots \ldots$

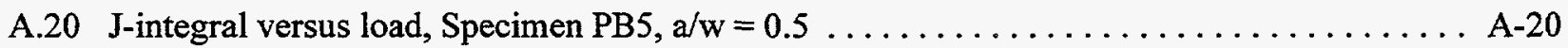


A.21 Load versus displacement comparison, no crack growth

A.22 J-integral versus load comparison, no crack growth

A.23 Experimental displacement versus crack growth for SENT-4, used as input to analysis

A.24 Predicted load-displacement curve SENT-4, no contact permitted

A.25 Predicted versus experimental load-displacement curve, SENT-4, no contact permitted

(a) First $3 \frac{1}{2}$ cycles, (b) Cycles 4 to 6

A.26 Predicted versus experimental load-displacement curve, SENT-4; contact permitted

A.27 Predicted versus experimental load-displacement curve near the compressive peaks,

SENT-4; contact permitted

A.28 Comparison of load-displacement predictions between the contact and no-contact plane stress solutions, SENT-4

A.29 Predicted versus experimental load-displacement curve, plane strain, SENT-4

A.30 Predicted versus experimental load-displacement curve over the first three cycles, plane strain, SENT-4 .

A.31 J-resistance curves, SENT-4

A.32 J-resistance curves for SENT-2 and SENT-4, plane stress; the SENT-4 analysis included contact

A.33 J versus displacement, SENT-4, plane stress, contact permitted

A.34 J versus load, SENT-4, plane stress, contact permitted A-31

A.35 Crack profiles, 8th load and unload cycle, SENT-4, plane stress A-32 


\section{EXECUTIVE SUMMARY}

In the First International Piping Integrity Research Group (IPIRG-1) program, a 16-inch nominal diameter, Schedule 100 TP304 stainless steel pipe (DP2-A8) containing a 180-degree internal surface crack was loaded in a pipe system with an increasing-amplitude single-frequency forcing function (IPIRG-1 Experiment 1.3-3). The test was conducted at PWR conditions [288 C (550 F) and 15.5 MPa $(2,250 \mathrm{psi})]$. This load history produced an effective stress ratio $\left[\left(\sigma_{\mathrm{B}_{\min }}+\sigma_{\mathrm{m}}\right) /\left(\sigma_{\mathrm{B}_{\max }}+\sigma_{\mathrm{m}}\right)\right]$ of -0.2 for this experiment. The J-R curve calculated for this experiment was appreciably lower than the J-R curve calculated from a standard quasi-static, monotonic $C(T)$ specimen. Experience at the time led to the conclusion that the differences in the J-R curves were due to a cyclic toughness degradation occurring due to the compressive plasticity present during the cyclic event.

In the Second International Piping Integrity Research Group (IPIRG-2) program, a series of cyclic compact tension specimen experiments were conducted to determine the mechanisms causing the toughness degradation. In that investigation, specimens were machined from both a TP304 stainless (DP2-A23) and an A106 Grade B carbon steel (DP2-F30) and were tested with a range of different stress ratios. The stainless steel tested showed no toughness degradation at a stress ratio of -0.3 , while the carbon steel, which had a much lower quasi-static, monotonic toughness than the stainless steel, showed a slight toughness degradation at a stress ratio of -0.3 . Since the work in IPIRG-2 suggests that the toughness of a stainless steel would not be reduced by a stress ratio of -0.3 , and yet the IPIRG- 1 experiment showed a large toughness degradation as compared with the quasi-static, monotonic J-R curve, laboratory experiments and associated analyses were conducted to determine the reasons for this difference in toughness.

\section{Observation From the Chemical Analyses Conducted on Pipe DP2-A8}

The IPIRG-1 and IPIRG-2 pipe-system experiments were conducted using Pipe DP2-A8. Pipe DP2-A8 was originally shipped to Battelle in three $5.74 \mathrm{~m}$ (18.83 feet) lengths from the Electric Power Research Institute (EPRI). At that time, it was assumed that the lengths of pipe all had the same chemical composition and mechanical properties and therefore, the lengths of pipe were not individually labeled to distinguish one length of Pipe DP2-A8 from another.

In this investigation, a series of chemical analyses were conducted on sections of pipe and test specimen fracture surfaces to verify that all lengths of Pipe DP2-A8 had the same composition. The results from these chemical analyses suggest that there are two distinct heats of material within the original three lengths of pipe. The chemical analyses data showed two distinct chemical compositions that consistently group together based on manganese, sulphur, silicon, nickel and chrome content. These two heats of material were given the designations DP2-A8I and DP2-A8II. Note that the pipe material used in Experiment 1.3-3 came from heat DP2-A8II, while the companion quasi-static, monotonic $C(T)$ specimen came from heat DP2-A8I.

Quasi-static, monotonic J-R curves from these two heats of material showed appreciably different toughness response. The $J$ value at crack initiation $\left(J_{i}\right)$ for Pipe DP2-A8II was 36 percent less than the $J_{i}$ value for Pipe DP2-A8I. Also the dJ/da value for Pipe DP2-A8II was 45 percent lower than the $\mathrm{dJ} / \mathrm{da}$ 
Executive Summary

value for Pipe DP2-A8I. Even though the difference in toughness response between the heats of Pipe DP2-A8 was great, the difference in tensile properties was minimal.

The large difference in toughness and chemical composition between the heats of Pipe DP2-A8 could have large implications to both past pipe test data, ASME code calculations, and the U.S. NRC leak-beforebreak draft standard review plan 3.6.3. To assess the impact of A8I versus A8II materials, a series of sensitivity analyses was performed which was aimed at determining the difference in moment predictions when using the different DP2-A8 material properties. The results of these sensitivity calculations imply that some stainless steel base metals may have maximum loads that are below the limit-load solution for both the surface-cracked and through-wall-cracked pipe cases. Therefore, the ASME Section XI Appendix $C$ approach should be reconsidered, where perhaps a Z-factor is needed for some stainless steel base metals. Also, since the ASTM standards on chemical composition have not kept up with the capabilities of the steel-making industry, a statistical study of stainless steel chemical compositions and toughness data is advisable. This task could help to determine optional chemical composition limits that could be used in future code or regulatory changes, as well as guidelines for future plant material selection.

\section{Constraint Effects on Toughness}

In addition to the difference in chemical composition and quasi-static, monotonic toughness, the difference in crack-tip constraint between the $\mathrm{C}(\mathrm{T})$ specimen and the surface-cracked pipe could have caused the different toughness response between Experiment 1.3-3 and the standard $C(T)$ experiment. In order to investigate this, a series of single-edge notched tensile [SEN(T)] specimen experiments were conducted. All SEN(T) specimens were machined from material DP2-A8II and were conducted with both quasi-static, monotonic and quasi-static, cyclic loading histories.

Estimates of the J-integral were made for this geometry using two methods, i.e., the finite element method and the Ahmad J-estimation scheme method. Even though the finite element method gave good predictions of the experimental loads for both the monotonic and cyclicly loaded specimens, the J-values calculated were a factor of 2 lower than the J-values calculated from the Ahmad scheme for the monotonic case. Since there has been no verification data using the Ahmad scheme for deeply flawed high toughness SEN(T) specimens, it was concluded that the Ahmad scheme needs to be revised to account for hightoughness and high strain-hardening steels, such as TP304.

The J-R curves calculated from the finite element method results indicate that the toughness of an SEN(T) specimen is highly dependent on the depth of the initial crack. The deeper the initial flaw, the lower the $\mathrm{J}$-values at crack initiation. The J-R curve for the dynamic, cyclic $(\mathrm{R}=-0.2)$ Experiment 1.3-3 $(a / t=0.66)$ was very similar to the J-R curves from the SEN(T) specimens tested with quasi-static, $\mathrm{R}=-1(\mathrm{a} / \mathrm{t}=0.63)$ load history and the deeply flawed quasi-static, monotonic $\mathrm{SEN}(\mathrm{T})$ specimen $(\mathrm{a} / \mathrm{t}=0.72)$. However, no dynamic, cyclic $\mathrm{SEN}(\mathrm{T})$ specimen experiments were conducted for comparison purposes. It is possible that the difference in J-R response between the J-R curve for Experiment 1.3-3 and the SEN $(T)$ specimens could be due to the combined dynamic and cyclic effects on toughness.

\section{Dynamic and Cyclic Effects on Toughness}

A series of compact tension specimen experiments was conducted on both the DP2-A8I and DP2-A8II material to investigate the effects of quasi-static, cyclic and dynamic, cyclic loading histories on the 
toughness of these materials. Note, again, that the DP2-A8I material had a much higher quasi-static, monotonic toughness at both crack initiation and during crack growth than the quasi-static monotonic toughness for the DP2-A8II material.

Under quasi-static, cyclic $(R=-0.3$ and -1$)$ loading, the behavior of both materials was similar. For $R=-0.3$, up to $5 \mathrm{~mm}(0.2$ inches) of crack extension, neither material had a change in the resistance as compared with the quasi-static, monotonic resistance. After $5 \mathrm{~mm}(0.2$ inches) of crack growth, the DP2-A8I material showed a slight decrease in toughness while the DP2-A8II material showed no change in toughness as compared with the quasi-static, monotonic resistance. However, at $R=-1$, both materials showed a large decrease in toughness as compared with the quasi-static, monotonic resistance. At $5 \mathrm{~mm}$ (0.2 inches), each material showed a decrease of about 70 percent of their respective monotonic resistances. However, the dynamic, cyclic $(R=-0.3)$ behaviors differed between the two materials. For the DP2-A8I material, the resistance at both crack initiation and during crack growth for the dynamic, $R=-0.3$ loading, showed a slight decrease as compared to the dynamic, monotonic resistance for that material. This trend was expected since the results from Task 3 of the IPIRG- 2 program indicated that for $R=-1$ loading, there was no interaction between the dynamic and cyclic effects on toughness. In fact, an estimate of the dynamic, cyclic toughness was made by multiplying the percent change in toughness due to the dynamic and cyclic effects to the quasi-static, monotonic resistance.

Results from the dynamic, cyclic $(R=-0.3)$ experiments conducted on the DP2-A8II material indicate that the resistance at both crack initiation and during crack growth were decreased as compared with both the quasi-static, and dynamic monotonic resistances. Noticeably, the trends established in Task 3 of the IPIRG-2 program do not seem to be valid for the A8II specimens tested at $R=-0.3$. The amount of interaction between cyclic and dynamic effects on toughness may be related to the materials quasi-static monotonic toughness since it has been shown (in Task 3 of IPIRG-2 program) that lower toughness materials appear to be more sensitive to intermediate stress ratios than higher toughness materials. However, a detailed study of this interaction was beyond the scope of this investigation.

In order to make accurate maximum experimental stress predictions, it is necessary to use the most appropriate material properties in the analyses. In a pipe-system experiment, where cyclic effects may be a factor (as in Experiment 1.3-3), the appropriate dynamic, cyclic properties should be used. Only when it has been proven that no interaction between the dynamic and cyclic effects on toughness exists can the quasi-static, cyclic and dynamic, monotonic resistances be used with certainty to make an estimate of the dynamic, cyclic fracture resistance. 



\section{ACKNOWLEDGMENTS}

The technical work described in this report was funded entirely by Battelle. The writing of this document and the publishing of the work as an NRC document was funded through the IPIRG-2 program, which is coordinated by the U.S. Nuclear Regulatory Commission's Electrical, Materials, and Mechanical Engineering Branch of the Office of Nuclear Regulatory Research under Contract No. NRC-04-91-063 to Battelle.

The authors would like to thank Mr. Michael Mayfield, USNRC program manager, for his support in publishing this work. We would also like to express our appreciation for the support and interest of the IPIRG-2 Technical Advisory Group (TAG) members.

We would like to thank others at Battelle who have helped in these efforts. Those who have contributed include: Mr. Mark Fleming, Mr. Tom Kilinski, Mr. G. Wall, Mr. J. Anthony, Mr. E. Blakesley, Mr. M. Oliver, Mr. P. Held, and Mr. D. Roberts. We also would like to recognize Mrs. V. Kreachbaum and Ms. Brenda Fuller for their assistance in preparing this report and Dr. A. Hopper and Mr. P. Scott for their editorial assistance. 



\section{NOMENCLATURE}

\section{SYMBOLS}

A

a

$\mathbf{a}_{i}$

b

B

$\mathrm{B}_{\mathrm{N}}$

C

$\mathrm{C}_{3}$

c

$\mathrm{D}_{\mathrm{i}}$

D。

D

d

E

$\mathbf{f}_{1}$

$\mathrm{H}$

I

J

$\mathrm{J}_{\mathrm{D}}$

$\mathrm{J}_{\text {elastic }}$

$\mathbf{J}_{\mathrm{i}}$
Maximum amplitude of sinusoidal displacement for Subtask 1.3 forcing function

Crack depth

Initial crack depth

Subtask 1.3 forcing function parameter

Specimen thickness

Net thickness at side-grooves for $C(T)$ and SEN(T) specimens

Contact permitted in $\mathrm{FE}$ analysis

J-R curve power law fit constant

Distance from neutral bending axis

Inside pipe diameter

Outside pipe diameter

Nominal pipe diameter

Displacement

Elastic modulus

Geometry factor for Ahmad J-estimation scheme

Distance between grips for SEN(T) specimens

Area moment of inertia

J-integral fracture parameter

$\mathrm{J}$ based on deformation theory

Elastic component of $\mathrm{J}$

$\mathrm{J}$ at crack initiation 
$\mathrm{J}_{\mathrm{Ic}}$

$\mathrm{J}_{\mathrm{m}}$

$J_{\text {plastic }}$

K

1

M

$\mathrm{m}$

n

NC

$\mathrm{n}_{\mathrm{i}}$

$\mathrm{p}$

$\mathrm{p}_{\mathrm{i}}$

$P_{\min }$

$\mathrm{P}_{\max }$

$\mathbf{R}$

r

$\mathbf{R}_{\text {effective }}$

$\mathbf{R}_{\mathbf{m}}$

$\mathrm{S}$

SF

$\mathrm{S}_{\mathrm{u}}$

$\mathrm{S}_{\mathrm{y}}$

$\mathrm{t}$

$\mathrm{U}_{\mathrm{x}}, \mathrm{U}_{\mathrm{y}}, \mathrm{U}_{\mathrm{z}}$
Plane strain J at crack initiation by ASTM E813

Modified form of J

Plastic component of J

LEFM stress intensity factor fracture parameter

SEN(T) distance from crack plane

Moment

J-R curve power law exponent

Ramberg-Osgood parameter

No contact permitted in a FE analysis

Constant in Ahmad J-estimation scheme

Pressure

Constant in Ahmad J-estimation scheme

Minimum load per cycle

Maximum load per cycle

Stress or load ratio, i.e., minimum stress (load)/maximum stress (load)

J-R curve power law constant

Effective stress ratio for a pipe system experiment

Mean pipe radius

System 1.3 forcing function ramp parameter

Safety factor

ASME Section III ultimate strength

ASME Section III yield strength

Pipe wall thickness

Displacements in $\mathrm{X}, \mathrm{Y}$, and $\mathrm{Z}$ directions 
$\epsilon$

$\epsilon_{\mathrm{o}}$

$v$

$\eta$

$\sigma_{\mathrm{B}}$

$\sigma_{\mathrm{B} \min }$

$\sigma_{\mathrm{B} \max }$

$\sigma_{0}$

$\sigma_{u}$

$\sigma_{\mathrm{y}}$

$\omega$

$\xi_{1}$

Specimen width

Spacing of EP probes

Ramberg-Osgood parameter

Inside displacement

Outside displacement

Displacement per cycle

Change in crack length or depth, i.e., crack growth

Crack growth due to cyclic loading

Crack growth due to monotonic loading

Change in $d-c$ electric potential

Change in $\mathrm{J}$

Strain

Ramberg-Osgood parameter

Poisson's ratio

Geometric constant used in general analytical procedure where $J_{\text {plastic }}$ is calculated using experimental load, displacement, and crack growth data

Bending Stress

Minimum Bending stress

Maximum bending

Ramberg-Osgood parameter

Ultimate strength

Yield strength

Forcing function frequency in radians/second

Geometry function in Ahmad J-estimation scheme 
Nomenclature

\section{ACRONYMS AND INITIALISMS}

\begin{tabular}{|c|c|}
\hline ABAQUS & Finite element code \\
\hline ANL & Argonne National Laboratories \\
\hline ASME & American Society of Mechanical Engineers \\
\hline ASTM & American Society for Testing and Materials \\
\hline BWR & Boiling Water Reactor \\
\hline $\mathrm{CC}$ & Complex Crack \\
\hline CMOD & Crack-mouth-opening displacement \\
\hline COD & Crack-opening displacement \\
\hline CS & Carbon steel \\
\hline $\mathrm{C}(\mathrm{T})$ & Compact (Tension) \\
\hline CTOA & Crack-tip-opening angle \\
\hline$d-c$ & Direct current \\
\hline d-c EP & Direct-current electric potential \\
\hline $\mathrm{dJ} / \mathrm{da}$ & Change in $\mathrm{J}$ for a change in crack length \\
\hline DPZP & Dimensionless plastic zone parameter \\
\hline $\mathrm{DP}^{3} \mathrm{II}$ & Degraded Piping Program - Phase II \\
\hline DRB & Data Record Book \\
\hline DSA & Dynamic strain aging \\
\hline DTRC & David Taylor Research Center \\
\hline Dyn & Dynamic \\
\hline
\end{tabular}

EDM

Electric Discharge Machining 
EP

EPFM

EPRI

FEA

FEM

GE

ID

IPIRG-1

IPIRG-2

J-R

$\mathrm{J}_{\mathrm{D}}-\mathrm{R}$

$\mathrm{J}_{\mathrm{m}}-\mathrm{R}$

LBB

LBB.ENG2

L-C

LEFM

L-T

LVDT

LWR

MTS

NRC

NRC-NRR

NRCPIPE
Electric potential

Elastic-plastic fracture mechanics

Electric Power Research Institute, USA

Finite element analysis

Finite element method

General Electric

Identification

First International Piping Integrity Research Group

Second International Piping Integrity Research Group

J-resistance (curve)

$\mathrm{J}$-resistance based on deformation theory form of $\mathrm{J}$

J-resistance based on modified form of $\mathrm{J}$

Leak-Before-Break

A J-estimation scheme

Orientation that indicates crack plane is normal to longitudinal axis $(\mathrm{L})$ and crack growth direction is circumferential (C)

Linear elastic fracture mechanics

Orientations code that indicates crack plane is normal to longitudinal rolling direction $(\mathrm{L})$ and crack growth direction is transverse (T) to plate rolling directions

Linear variable differential transformer

Light water reactor

Supplier of servo-hydraulic equipment

Nuclear Regulatory Commission

Nuclear Regulatory Commission - Office of Nuclear Reactor Regulation

J-estimation scheme computer program 
Nomenclature

NRC-RES Nuclear Regulatory Commission - Office of Nuclear Reactor Research

NSC Net-Section-Collapse

OD Outside diameter

PC Personal Computer

PIFRAC Piping fracture mechanic database

PVP Pressure Vessel and Piping

PWR Pressurized Water Reactor

QS Quasi-static

RT Room temperature

SC Surface crack

SC.TKP A finite length surface crack J-estimation scheme based on thick-wall formulations

SEN(T) Single-edge Notched Tensile Specimen

SEN(B) Single-edge Notched Bend Specimen

SMTS Specified minimum tensile strength

SMYS Specified minimum yield strength

SS

Stainless steel

SSE

Safe shutdown earthquake

TAG

Technical Advisory Group

TWC

Through-wall crack

U.S.

United States

USNRC

United States Nuclear Regulatory Commission 


\section{PREVIOUS REPORTS IN SERIES}

\section{Reports from this Program}

"Summary of Results from the IPIRG-2 Round-Robin Analyses," NUREG/CR-6337, BMI-2186, January 1996.

"The Effect of Cyclic and Dynamic Loads on Carbon Steel Pipe," NUREG/CR-6438, BMI-2188, February 1996.

"Design of the IPIRG-2 Simulated Seismic Forcing Function," NUREG/CR-6439, BMI-2189, February 1996.

"Deterministic and Probabilistic Evaluations for Uncertainty in Pipe Fracture Parameters in Leak-BeforeBreak and In-Service Flaw Evaluations," NUREG/CR-6443, BMI-2191, June 1996.

"Fracture Behavior of Circumferentially Surface-Cracked Elbows," NUREG/CR-6444, BMI-2192, December 1996.

"Development of a J-Estimation Scheme for Internal Circumferential and Axial Surface Cracks in Elbows," NUREG/CR-6445, BMI-2193, June 1996.

"The Effect of Cyclic and Dynamic Loading on the Fracture Resistance of Nuclear Piping Steels," NUREG/CR-6440, BMI-2190, December 1996.

\section{Reports from the IPIRG-1 Program}

"Evaluation and Refinement of Leak-Rate Estimation Models," NUREG/CR-5128, BMI-2164, Revision 1, June 1994.

"Loading Rate Effects on Strength and Fracture Toughness of Pipe Steels Used in Task 1 of the IPIRG Program," Topical Report, NUREG/CR-6098, BMI-2175, October 1993.

"Stability of Cracked Pipe Under Inertial Stresses," NUREG/CR-6233, BMI-2177, Volume 1, August 1994.

\section{Previous Related Documents from NRC's Short Cracks in Piping and Piping Welds Program}

"Short Cracks in Piping and Piping Welds," First Semiannual Report, NUREG/CR-4599, BMI-2173, Vol. 1, No. 1, March 1991. 
Previous Reports in Series

"Short Cracks in Piping and Piping Welds," Second Semiannual Report, NUREG/CR-4599, BMI-2173, Vol. 1, No. 2, April 1992.

"Short Cracks in Piping and Piping Welds," Third Semiannual Report, NUREG/CR-4599, BMI-2173, Vol. 2, No. 1, September 1992.

"Short Cracks in Piping and Piping Welds," Fourth Semiannual Report, NUREG/CR-4599, BMI-2173, Vol. 2, No. 2, February 1993.

"Short Cracks in Piping and Piping Welds," Fifth Semiannual Report, NUREG/CR-4599, BMI-2173, Vol. 3, No. 1, October 1993.

"Short Cracks in Piping and Piping Welds," Sixth Semiannual Report, NUREG/CR-4599, BMI-2173, Vol. 3, No. 2, March 1994.

"Short Cracks in Piping and Piping Welds," Progress Report, NUREG/CR-4599, BMI-2173, Vol. 4, No. 1, April 1995.

"Assessment of Short Through-Wall Circumferential Cracks in Pipes," NUREG/CR-6235, BMI-2178, April 1995.

"Fracture Behavior of Short Circumferential Short-Surface-Cracked Pipe," NUREG/CR-6298, BMI-2183, November 1995.

"Fracture Evaluations of Fusion Line Cracks in Nuclear Pipe Bimetallic Welds," NUREG/CR-6297, BMI-2182, April 1995.

"Effect of Dynamic Strain Aging on the Strength and Toughness of Nuclear Ferritic Piping at LWR Temperatures," NUREG/CR-6226, BMI-2176, October 1994.

"Effects of Toughness Anisotropy and Combined Loading on Fracture Behavior of Ferritic Nuclear Pipe," NUREG/CR-6299, BMI-2184, April 1995.

"Refinement and Evaluation of Crack-Opening Analyses for Circumferential Through-Wall Cracks in Pipes," NUREG/CR-6300, April 1995.

"Probabilistic Pipe Fracture Evaluations for Leak-Rate Detection Applications," NUREG/CR-6004, BMI-2174, April 1995.

"Stainless Steel Submerged Arc Weld Fusion Line Toughness," NUREG/CR-6251, BMI-2180, April 1995.

"Validity Limits in J-Resistance Curve Determination: Volume 1: An Assessment of the $\mathrm{J}_{\mathrm{M}}$ Parameter," NUREG/CR-6264, BMI-2181, Vol. 1, February 1995.

"Validity Limits in J-Resistance Curve Determinations: Volume 2: A Computational Approach to Ductile Crack Growth Under Large-Scale Yielding Condition," NUREG/CR-6264, BMI-2181, Vol. 2, February 1995. 


\section{Previous Related Documents from NRC's Degraded Piping Program}

\section{- Phase I Reports}

"The Development of a Plan for the Assessment of Degraded Nuclear Piping by Experimentation and Tearing Instability Fracture Mechanics Analysis," NUREG/CR-3142, Vols. 1 and 2, June 1983.

\section{Previous Related Documents from NRC's Degraded Piping Program - Phase II Reports}

"Degraded Piping Program - Phase II," Semiannual Report, NUREG/CR-4082, BMI-2120, Vol. 1, Oct. 1984.

"Degraded Piping Program - Phase II," Semiannual Report, NUREG/CR-4082, BMI-2120, Vol. 2, June 1985.

"Degraded Piping Program - Phase II," Semiannual Report, NUREG/CR-4082, BMI-2120, Vol. 3, March 1986.

"Degraded Piping Program - Phase II," Semiannual Report, NUREG/CR-4082, BMI-2120, Vol. 4, July 1986.

"Degraded Piping Program - Phase II," Semiannual Report, NUREG/CR-4082, BMI-2120, Vol. 5, Dec. 1986.

"Degraded Piping Program - Phase II," Semiannual Report, NUREG/CR-4082, BMI-2120, Vol. 6, April 1988.

"Degraded Piping Program - Phase II," Semiannual Report, NUREG/CR-4082, BMI-2120, Vol. 7, March 1989.

“Degraded Piping Program - Phase II," Semiannual Report, NUREG/CR-4082, BMI-2120, Vol. 8, March 1989.

"NRC Leak-Before-Break (LBB.NRC) Analysis Method for Circumferentially Through-Wall Cracked Pipes Under Axial Plus Bending Loads," Topical Report, NUREG/CR-4572, BMI-2134, March 1986.

"Elastic-Plastic Finite Element Analysis of Crack Growth in Large Compact Tension and Circumferentially Through-Wall-Cracked Pipe Specimen--Results of the First Battelle/NRC Analysis Round Robin," Topical Report, NUREG/CR-4573, BMI-2135, September 1986.

"An Experimental and Analytical Assessment of Circumferential Through-Wall Cracked Pipes Under Pure Bending," Topical Report, NUREG/CR-4574, BMI-2136, June 1986.

"Predictions of J-R Curves With Large Crack Growth From Small Specimen Data," Topical Report, NUREG/CR-4575, BMI-2137, September 1986. 
Previous Reports in Series

"An Assessment of Circumferentially Complex-Cracked Pipe Subjected to Bending," Topical Report, NUREG/CR-4687, BMI-2142, September 1986.

"Analysis of Cracks in Stainless Steel TIG Welds," Topical Report, NUREG/CR-4806, BMI-2144, November 1986.

"Approximate Methods for Fracture Analyses of Through-Wall Cracked Pipes," Topical Report, NUREG/CR-4853, BMI-2145, January 1987.

"Assessment of Design Basis for Load-Carrying Capacity of Weld-Overlay Repair," Topical Report, NUREG/CR-4877, BMI-2150, February 1987.

"Analysis of Experiments on Stainless Steel Flux Welds," Topical Report, NUREG/CR-4878, BMI-2151, February 1987.

"Experimental and Analytical Assessment of Circumferentially Surface-Cracked Pipes Under Bending," Topical Report, NUREG/CR-4872, BMI-2149, April 1987.

\section{Other Related Program Reports}

"Validation of Analysis Methods for Assessing Flawed Piping Subjected to Dynamic Loading," NUREG/CR-6234, ANL-94/22, BMI-2178, August 1994. 


\subsection{INTRODUCTION}

In industry, quasi-static, monotonic material properties are normally used in the piping fracture analyses. In some cases, piping systems may experience both dynamic and cyclic loadings, possibly due to a seismic event. In these cases, the predictions made using quasi-static material properties may overpredict the actual in-service loads at failure. Therefore, it is necessary to understand the cyclic and dynamic effects on nuclear piping materials, and to use the appropriate material properties in making load-carrying capacity predictions.

In the IPIRG-1 program (Ref. 1.1), a 16-inch nominal diameter, Schedule 100, Type 304 stainless steel pipe (DP2-A8) with an internal surface crack was tested using a single-frequency forcing function (IPIRG-1 Experiment 1.3-3). This experiment, conducted at $288 \mathrm{C}(550 \mathrm{~F})$ with an internal pressure of 15.5 $\mathrm{MPa}(2,250 \mathrm{psi})$, had a minimum-to-maximum stress ratio, $\mathrm{R}_{\text {effective }}{ }^{*}$, of -0.2 . When the J-resistance curve calculated from this experiment was compared with the quasi-static, monotonic C(T) J-R curve of the same material, it was found that the pipe J-R curve was considerably lower than the J-R curve calculated from the $C(T)$ specimen. The results and analysis of this experiment can be found in Reference 1.2. The conclusion from this reference was that the differences in J-R curves may have been due to the effects of cyclic loading on the toughness of the material.

Also in the IPIRG-1 program, a series of material property experiments were conducted on material from Pipe DP2-A8 in order to characterize the quasi-static and dynamic, stress-strain and fracture toughness response. It was shown that only a small change in strength and an increase in toughness occurred with an increasing strain rate. This behavior due to dynamic loading is typical of austenitic materials (Ref. 1.3).

In the IPIRG-2 program, an extensive study was performed to determine the mechanisms behind the toughness degradation due to cyclic loading, and to determine the effects of combined cyclic and dynamic loading. It was found that the mechanics of void and crack tip sharpening aided in the toughness degradation process. However, the toughness degradation due to cyclic loading was found to be a function of the material's quasi-static, monotonic toughness. In that investigation (Ref. 1.4), the stainless steel tested (a 6-inch nominal diameter TP304 pipe, DP2-A23) showed no toughness degradation at crack initiation or during crack growth at a stress ratio of -0.3 and a cyclic plastic history "similar to that in the pipe test. In addition, the results from Reference 1.4 indicated that the effects of cyclic and dynamic loading on the toughness of nuclear piping steels may be related to the material's yield-to-ultimate strength ratio and the combined dynamic, cyclic $(R=-1)$ effect on toughness can be predicted by multiplying the percentage change in toughness due to cyclic and dynamic loading by the quasi-static, monotonic resistance, i.e., there was no interaction between the cyclic $(R=-1)$ and dynamic effects on the fracture toughness of the steels investigated.

*

$$
\mathbf{R}_{\text {effective }}=\left(\sigma_{B_{\min }}+\sigma_{m}\right) /\left(\sigma_{B_{\max }}+\sigma_{m}\right)
$$

** $\delta_{\text {cyc }} / \delta_{i}=0.1$, where $\delta_{\text {cyc }}$ is the displacement per cycle and $\delta_{i}$ is the displacement at crack initiation in a monotonic experiment. The inverse of the normalized plastic displacement increment is the number of cycles to crack initiation if no cyclic degradation exists. 
The differences between the documented C(T) J-R curves and the J-R curves calculated from the pipesystem experiment (Experiment 1.3-3) on Pipe DP2-A8 may be due several factors. The first possibility is that the differences between the $C(T)$ and pipe J-R curves may be due to an inherent difference in material properties of Pipe DP2-A8. This pipe was originally shipped to Battelle in three lengths from the same source, and although there was no mill data, it was assumed that the pipes came from the same heat. Since material characterization was not performed on each length of pipe, it is possible that the material properties were different for each length of pipe. A series of chemical analyses performed on the past material property specimens, as well as on the material from the pipe experiments are presented.

Second, the difference in constraint between the $C(T)$ and the surface-cracked pipe geometry may be causing the differences in the J-R curves. The $C(T)$ specimen is a much higher constrained geometry than a surface-cracked pipe. It has been shown in a previous study (Ref. 1.5) that the single-edge notched tensile specimen geometry models the constraint in a surface-cracked pipe better than the $C(T)$ specimen geometry. This report will discuss the results from a series of monotonic and cyclic single-edge notched tensile specimens conducted to study the effects of cyclic loading and crack geometry on the toughness of Pipe DP2-A8.

Finally, since the pipe-system experiment was a dynamic, cyclic experiment, the effects of this loading history may have caused the differences in the toughness values. The report also discusses the effects of dynamic and cyclic loading by presenting the results from a series of quasi-static, monotonic; quasi-static, cyclic; and dynamic, cyclic C(T) experiments conducted from specimens machined from Pipe DP2-A8.

The remainder of this report is divided into four sections. Section 2 reviews the previously documented material characterization of Pipe DP2-A8 by listing all pipe and material property specimens machined from these lengths of pipe. This section then recaps the general material property results documented in many of the data record books on pipe experiments conducted with this material. Section 3 discusses each of the possible reasons for the differences between the $C(T)$ and pipe J-R curves. A brief description of the analysis of Experiment 1.3-3 and predictions of experimental moments using the material properties in Section 2 are presented, followed by the chemical analyses, SEN(T), and C(T) results. Finally, Section 3 concludes by revisiting the analysis of Experiment 1.3-3 based on the new toughness results presented in this report. Section 4 contains a discussion of the technical results and the implication of these results to the past large-scale piping programs and to the ASME code criteria. Section 5 presents the general conclusions from this investigation.

\subsection{References}

1.1 Scott, P., and others, "The IPIRG-1 Pipe System Fracture Tests: Experimental Results," PVP Vol. 280, pp 135-151, June 1994.

1.2 Olson, R., Scott, P., Marschall, C., and Wilkowski, G., "Comparison of Fracture Toughness Values from an IPIRG-1 Large-Scale Pipe System Test and C(T) Specimens on Wrought TP304 Stainless Steel,"ASME PVP, Vol. 280, pp 241-254, June 1994. 
1.3 Marschall, C. M., Landow, M. P., and Wilkowski, G. M., "Loading Rate Effects on Strength and Fracture Toughness of Pipe Steels Used in Task 1 of the IPIRG Program," NUREG/CR-6098, BMI2175, October 1993.

1.4 Rudland, D., and others, "The Effects of Cyclic and Dynamic Loading on the Fracture Resistance of Nuclear Piping Steels," NUREG/CR-6440, BMI-2190, December 1996.

1.5 Wilkowski, G. M., and others, "Degraded Piping Program - Phase II," Semi-Annual Report: April 1985 - September 1985, NUREG/CR-4082, Vol. 3, March 1986. 



\subsection{PREVIOUS MATERIAL CHARACTERIZATION OF PIPE DP2-A8}

On February 3, 1981, three $5.74 \mathrm{~m}$ (18.83 feet) lengths of 16-inch nominal diameter, Schedule 100, Type 304 stainless steel pipe were shipped to Battelle Columbus Laboratories by the Electric Power Research Institute (EPRI) to verify the net-section yield concept for circumferentially cracked stainless steel pipe. These lengths of pipe were later given the Battelle designation DP2-A8. From these original lengths of pipe, two full-scale pipe experiments were conducted under an EPRI contract (Ref. 2.1), i.e., Experiments EPRI-8T and EPRI-13S. In addition, these lengths of pipe were used to generate full-scale experimental pipe test data in the Degraded Piping Program (Ref. 2.2), and the First and Second International Piping Integrity Research Group (IPIRG-1 and IPIRG-2) programs (Refs. 2.3 and 2.4). Table 2.1 lists all of the full-scale pipe experiments conducted using Pipe DP2-A8 with cracks in the base metal.

Table 2.1 Full-scale pipe experiments on Pipe DP2-A8 with cracks in the base metal

\begin{tabular}{cccc}
\hline $\begin{array}{c}\text { Experiment } \\
\text { Number }\end{array}$ & Crack Type $^{(\mathrm{a})}$ & Loading History & Program \\
\hline EPRI-8T & TWC pipe & Quasi-static bending & EPRI \\
EPRI-13S & SC pipe & Quasi-static bending & EPRI \\
$4114-3$ & CC pipe & Quasi-static bending & Degraded Piping \\
$4114-4$ & CC pipe & Quasi-static bending & Degraded Piping \\
$1.3-3$ & SC pipe & Single Frequency & IPIRG-1 \\
$1-1$ & SC pipe & Simulated Seismic & IPIRG-2 \\
\hline
\end{tabular}

(a) $\mathrm{TWC}=$ Through-wall crack, $\mathrm{SC}=$ surface crack, and $\mathrm{CC}=$ complex crack.

In addition to the full-scale pipe experiments shown in Table 2.1, a full range of material characterization experiments were conducted from specimens machined from pipe DP2-A8. Tables 2.2 and 2.3, show the tensile, compact tension, and 3-point bend specimens that were machined from Pipe DP2-A8. Note that the specimens shown in these tables come directly from the most recent revision of the PIFRAC database (Ref. 2.5).

\subsection{Chemical Analyses}

The chemical analyses listed in every data record book for pipe experiments using Pipe DP2-A8 are shown in Table 2.4 . 
Also shown in Table 2.4 are the specification maximums for TP304 stainless steel from the ASTM specifications. For the most part, this material's chemical composition falls within the ASTM specification for TP304 stainless steel; however, it is slightly low in Ni and Cr.

Table 2.2 Tensile specimens machined from Pipe DP2-A8

\begin{tabular}{lll}
\hline Specimen ID & Loading History & Program \\
\hline A8-1-1 & Quasi-static & Degraded Piping \\
A8-1-2 & Quasi-static & Degraded Piping \\
A8-1-4 & Quasi-static & Degraded Piping \\
A8-35 & Quasi-static & Degraded Piping \\
A8-36 & Quasi-static & Degraded Piping \\
A8-37 & Quasi-static & Degraded Piping \\
A8-38 & Quasi-static & Degraded Piping \\
A8-39 & Quasi-static & Degraded Piping \\
A8-40 & Quasi-static & Degraded Piping \\
A8-101 & Dynamic, 1/sec & IPIRG-1 \\
A8-102 & Dynamic, 1/sec & IPIRG-1 \\
A8-103 & Dynamic, 10/sec & IPIRG-1 \\
A8-104 & Dynamic, 10/sec & IPIRG-1 \\
A8-105 & Quasi-static & IPIRG-1 \\
\hline
\end{tabular}


Table 2.3 Fracture toughness specimens machined from Pipe DP2-A8

\begin{tabular}{llll}
\hline Specimen ID & Specimen Type & Loading History & Program \\
\hline A8-2 & 3-point bend bar & Quasi-static, monotonic & Degraded Piping \\
A8-3 & 3-point bend bar & Quasi-static, monotonic & Degraded Piping \\
A8-41 & Compact Tension & Quasi-static, monotonic & Degraded Piping \\
A8-42 & Compact Tension & Quasi-static, monotonic & Degraded Piping \\
A8-43 & Compact Tension & Quasi-static, monotonic & Degraded Piping \\
A8-44 & Compact Tension & Quasi-static, monotonic & Degraded Piping \\
A8-47 & Compact Tension & Quasi-static, monotonic & Degraded Piping \\
A8-48 & Compact Tension & Quasi-static, monotonic & Degraded Piping \\
A8-49 & Compact Tension & Quasi-static, monotonic & Degraded Piping \\
A8-52 & Compact Tension & Quasi-static, monotonic & Degraded Piping \\
A8-54 & Compact Tension & Quasi-static, monotonic & Degraded Piping \\
A8-55 & Compact Tension & Quasi-static, monotonic & Degraded Piping \\
A8-56 & Compact Tension & Quasi-static, monotonic & Degraded Piping \\
A8-57 & Compact Tension & Quasi-static, monotonic & Degraded Piping \\
A8-71 & Compact Tension & Quasi-static, monotonic & Degraded Piping \\
A8-72 & Compact Tension & Quasi-static, monotonic & Degraded Piping \\
A8-9a & Compact Tension & Dynamic, monotonic & IPIRG-1 \\
A8-10a & Compact Tension & Dynamic, monotonic & IPIRG-1 \\
A8-11a & Compact Tension & Dynamic, monotonic & IPIRG-1 \\
A8-12a & Compact Tension & Quasi-static, monotonic & IPIRG-1 \\
\hline
\end{tabular}


Table 2.4 Chemical analysis from data record books containing Pipe DP2-A8

\begin{tabular}{ccccccccccccc}
\hline & \multicolumn{10}{c}{ Percent } \\
\cline { 2 - 11 } & $\mathbf{C}$ & $\mathbf{M n}$ & $\mathbf{P}$ & $\mathbf{S}$ & $\mathbf{S i}$ & $\mathbf{N i}$ & $\mathbf{C r}$ & $\mathbf{M o}$ & $\mathbf{T i}$ & $\mathbf{C b}$ & $\mathbf{C u}$ \\
\hline $\begin{array}{c}\text { DRB } \\
\text { DP2-A8 }\end{array}$ & 0.055 & 1.25 & 0.019 & 0.000 & 0.70 & 7.70 & 17.00 & 0.02 & 0.03 & 0.02 & 0.12 \\
$\begin{array}{c}\text { ASTM } \\
(\mathbf{m a x})\end{array}$ & 0.08 & 2.00 & 0.045 & 0.030 & 0.75 & $\mathbf{8 - 1 2 ^ { ( \mathbf { a } ) }}$ & $18-20^{(\mathbf{a})}$ & - & - & - & - \\
\hline
\end{tabular}

(a) Minimum-maximum range.

\subsection{Tensile Results}

Table 2.5 and Figure 2.1 show the documented tensile results from Reference 2.6. This figure shows that there is a 4 percent difference in ultimate strength between the quasi-static stress-strain curves. Also, there is a minimal change in strength as the strain rate is increased by five orders of magnitude. Note, that Specimen A8-39 and A8-40 were manufactured during the Degraded Piping Program and are round bar specimens, while Specimen A8-101, -102, -103, -104 and -105 were manufactured in the IPIRG-1 program and were flat, pin-loaded specimens.

\subsection{Fracture Toughness Results}

Table 2.6 and Figure 2.2 show the J-R results for Pipe DP2-A8 from Reference 2.6. Note that the term dynamic in this figure corresponds to a tests where crack initiation occurred in 0.2 seconds. Under dynamic loading, the $\mathrm{J}$ at crack initiation for this material was increased approximately 40 percent as compared with the quasi-static resistance. After $8 \mathrm{~mm}$ ( 0.315 inches) of crack extension, the dynamic resistance was 15 percent higher than the quasi-static resistance. These trends are typical of stainless steel piping materials. 
Table 2.5 Tensile properties of Pipe DP2-A8 (ASTM A358, Type 304 stainless steel)

\begin{tabular}{|c|c|c|c|c|c|c|c|c|}
\hline \multirow[b]{2}{*}{ Spec. Ident. No. } & \multicolumn{2}{|c|}{ Temperature, } & \multirow{2}{*}{$\begin{array}{c}\text { Strain } \\
\text { Rate, } \mathbf{s}^{-1}\end{array}$} & \multicolumn{2}{|c|}{$\begin{array}{c}\text { 0.2-Percent } \\
\text { Offset Yield } \\
\text { Strength, }\end{array}$} & \multicolumn{2}{|c|}{$\begin{array}{l}\text { Ultimate } \\
\text { Tensile } \\
\text { Strength, }\end{array}$} & \multirow[t]{2}{*}{$\begin{array}{c}\text { Elongation, } \\
\text { Percent in } \\
25.4 \mathrm{~mm} \\
(1.0 \text { inch }) \\
\end{array}$} \\
\hline & $\mathbf{C}$ & $\mathbf{F}$ & & & ksi & MPa & ksi & \\
\hline $\mathrm{A} 8-48^{(\mathrm{a})}$ & 22 & 72 & $4 \times 10^{-4}$ & 287 & 41.6 & 698 & 101.2 & 79.4 \\
\hline$A 8-35^{(a)}$ & 22 & 72 & $4 \times 10^{-4}$ & 295 & 42.8 & 743 & 107.8 & 75.9 \\
\hline$A 8-36^{(a)}$ & 22 & 72 & $4 \times 10^{-4}$ & 303 & 43.9 & 736 & 106.7 & 74.3 \\
\hline$A 8-37^{(a)}$ & 149 & 300 & $4 \times 10^{-4}$ & 225 & 32.6 & 481 & 69.8 & 43.5 \\
\hline$A 8-38^{(a)}$ & 149 & 300 & $3 \times 10^{-4}$ & 202 & 29.3 & 476 & 69.1 & 54.8 \\
\hline A8-105 & 288 & 550 & $5 \times 10^{-4}$ & $200^{(b)}$ & 29.0 & 443 & 64.3 & 45.7 \\
\hline$A 8-39^{(a)}$ & 288 & 550 & $3 \times 10^{-4}$ & 180 & 26.1 & 461 & 66.8 & 45.0 \\
\hline$A 8-40^{(a)}$ & 288 & 550 & $4 \times 10^{-4}$ & 171 & 24.8 & 456 & 66.2 & 47.0 \\
\hline A8-100 & 288 & 550 & 1 & N.D. & N.D. & 430 & 62.4 & 47.0 \\
\hline A8-101 & 288 & 550 & 1 & $200^{(\mathrm{b})}$ & 29.0 & 420 & 60.9 & 47.1 \\
\hline A8-102 & 300 & 572 & 1 & $190^{(b)}$ & 27.5 & 423 & 61.3 & 46.5 \\
\hline A8-103 & 288 & 550 & 10 & $200^{(b)}$ & 29.0 & 429 & 62.2 & 49.8 \\
\hline A8-104 & 288 & 550 & 10 & $194^{(b)}$ & 28.1 & 423 & 61.4 & 50.8 \\
\hline SA358 TP304 & 22 & 72 & QS & $207^{(c)}$ & $30.0^{(c)}$ & $517^{(\mathrm{d})}$ & $75.0^{(d)}$ & - \\
\hline SA358 TP304 & 288 & 550 & QS & $130^{(e)}$ & $18.8^{(\mathrm{e})}$ & $438^{(f)}$ & $63.5^{(t)}$ & - \\
\hline
\end{tabular}

(a) Round-bar, threaded-ends specimen; all others were flat, pin-loaded specimens.

(b) Approximate value only, due to uncertainties in stress-strain curves at small strains.

(c) Specified minimum yield strength (SMYS) at room temperature from ASME Section II.

(d) Specified minimum tensile strength (SMTS) at room temperature from ASME Section II.

(e) $\mathrm{S}_{\mathrm{y}}$ at $288 \mathrm{C}(550 \mathrm{~F})$ from ASME Section II.

(f) $S_{u}$ at $288 \mathrm{C}(550 \mathrm{~F})$ from ASME Section II. 


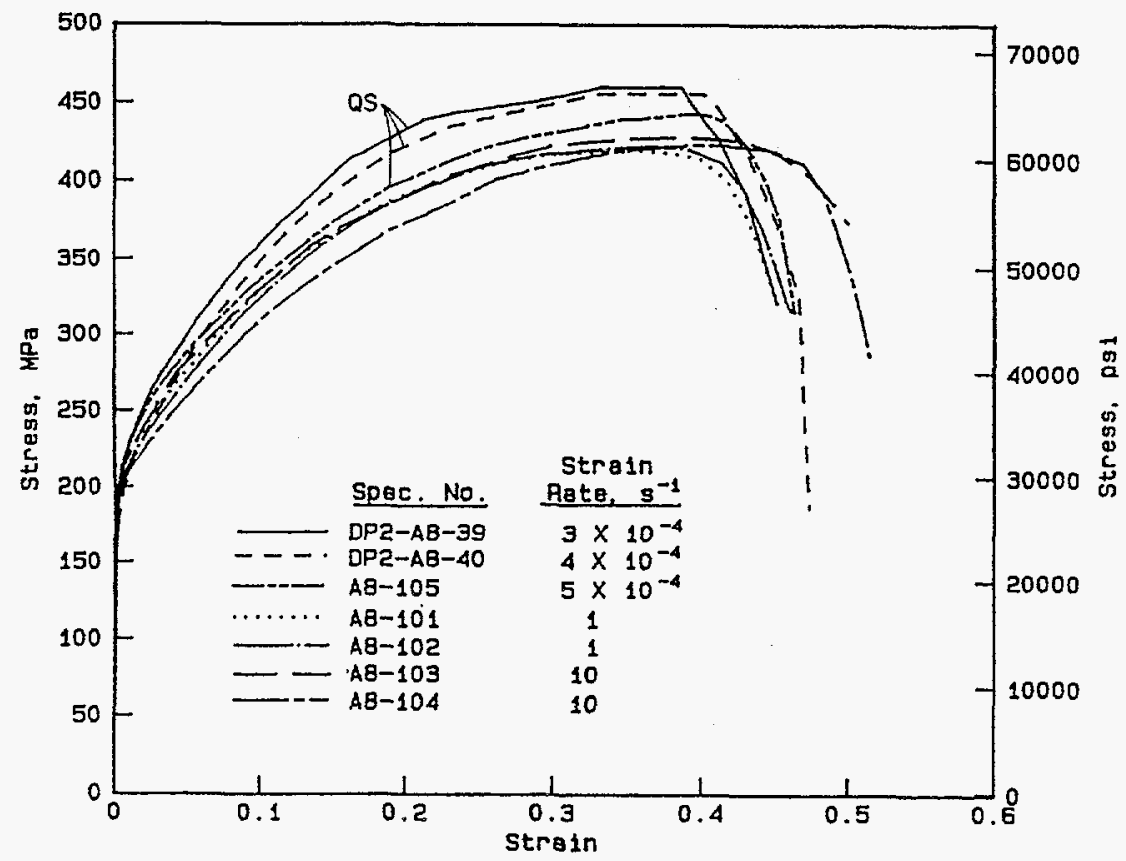

Figure 2.1 Engineering stress-strain curves at 288 C (550 F) for Pipe DP2-A8 (A358 Type 304 stainless steel) tested at several different strain rates

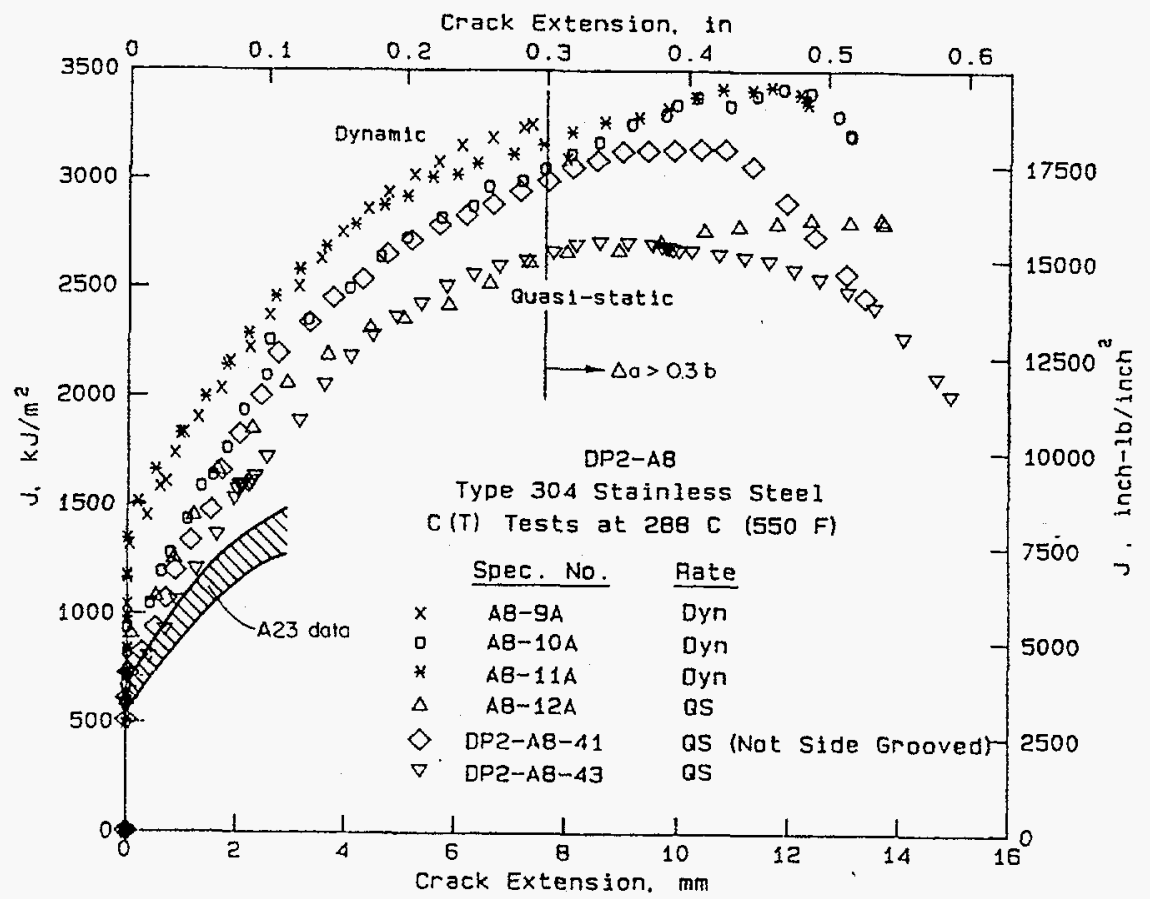

Figure 2.2 J-resistance curves for compact specimens from Pipe DP2-A8 (A358 Type 304 stainless steel) tested at $288 \mathrm{C}(550 \mathrm{~F})$ 
Table 2.6 Summary of $J_{i}$ and $d J / d a$ values for Pipe DP2-A8

\begin{tabular}{|c|c|c|c|c|c|c|}
\hline \multirow{2}{*}{$\begin{array}{l}\text { Spec. } \\
\text { Ident. } \\
\text { No. } \\
\end{array}$} & \multirow{2}{*}{$\begin{array}{c}\text { Percent } \\
\text { Side-grooves } \\
\end{array}$} & \multirow[b]{2}{*}{ Rate } & \multicolumn{2}{|c|}{$\mathbf{J}$ at Initiation } & \multicolumn{2}{|c|}{$\mathbf{d J} / \mathbf{d a ^ { ( a ) }}$} \\
\hline & & & $\mathbf{k J} / \mathbf{m}^{2}$ & in-lb/in ${ }^{2}$ & $\mathbf{M J} / \mathbf{m}^{3}$ & in-lb/in ${ }^{3}$ \\
\hline A8-41 & 0 & QS & 710 & 4,050 & 610 & 88,500 \\
\hline A8-43 & 20 & QS & 623 & 3,555 & 524 & 76,000 \\
\hline A8-12A & 20 & QS & 854 & 4,875 & 481 & 69,720 \\
\hline A8-9A & 20 & Dyn & 1,302 & 7,430 & 500 & 72,470 \\
\hline A8-10A & 20 & Dyn & 943 & 5,385 & 566 & 82,060 \\
\hline A8-11A & 20 & Dyn & 1,399 & 7,985 & 388 & 56,320 \\
\hline
\end{tabular}

(a) Calculated between $0.15 \mathrm{~mm}$ and $1.5 \mathrm{~mm}$ (0.006 inch and 0.06 inch).

\subsection{References}

2.1 Kanninen, M. F., and others, "Instability Predictions for Circumferentially Cracked Type 304 Stainless Steel Pipes Under Dynamic Loadings," Final Report on EPRI Project T118-2, by Battelle Columbus Laboratories, EPRI Report Number NP-2347, April 1982.

2.2 Wilkowski, G. M., and others, "Degraded Piping Program - Phase II, Summary of Technical Results and Their Significance to Leak-Before-Break and In-Service Flaw Acceptance Criteria," March 1984 - January 1989, by Battelle Columbus Division, NUREG/CR-4082, Vol. 8, March 1989.

2.3 Scott, P., and others, "The IPIRG-1 Pipe System Fracture Tests: Experimental Results," PVP Vol. 280, pp 135-151, June 1994.

2.4 Scott, P., and others, "IPIRG-2 Task 1 - Pipe System Experiments with Circumferential Cracks in Straight-Pipe Locations," NUREG/CR-6389, January 1997.

2.5 Wilkowski, G. M., and others, "Short Cracks in Piping and Piping Welds," Seventh Program Report, March 1993 - December 1994, NUREG/CR-4599, Vol. 4, No. 1, April 1995.

2.6 Marschall, C. M., Landow, M. P., and Wilkowski, G. M., "Loading Rate Effects on Strength and Fracture Toughness of Pipe Steels Used in Task 1 of the IPIRG Program," NUREG/CR-6098, BMI-2175, October 1993. 



\subsection{RESOLUTION OF THE TOUGHNESS DISCREPANCY BETWEEN C(T) SPECIMEN AND SURFACE-CRACKED PIPE SPECIMEN}

\subsection{IPIRG-1 Experiment 1.3-3}

In the IPIRG-1 program, five cracked-pipe and one uncracked-pipe system experiments were conducted. These experiments were conducted at nominal pressurized water reactor (PWR) conditions, i.e., $15.5 \mathrm{MPa}$ $(2,250 \mathrm{psi})$ pressure and $288 \mathrm{C}(550 \mathrm{~F})$. The crack in each of the experiments was an internal circumferential surface crack with a crack length approximately 50 percent of the pipe circumference, and a depth of approximately 66 percent of the wall thickness. Reference 3.1 contains the details of the pipe system loop and the associated experiments.

Experiment 1.3-3 was a typical pipe-system test conducted on TP304 stainless steel pipe, DP2-A8. The actuator displacement-time history was an increasing amplitude sinusoidal displacement function with an increasing displacement ramp superimposed. The equation of motion for the actuator was:

$$
U_{x}=S t+A\left[1-e^{-b t}\right] \sin (\omega t)
$$

where

$$
\begin{array}{ll}
\mathrm{U}_{\mathrm{x}^{-}} & =\text {actuator displacement } \\
\mathrm{t} & =\text { time } \\
\mathrm{S}, \mathrm{A}, \mathrm{b} & =\text { equation constants } \\
\omega \quad & =24.82 \mathrm{rad} / \sec (3.95 \mathrm{~Hz})
\end{array}
$$

The moment-rotation response for this experiment is shown in Figure 3.1. This pipe system experienced nine cycles of loading and unloading before maximum load. Surface-crack penetration occurred on the final loading cycle.

\subsubsection{Surface-Cracked Pipe J-R Curve}

The fracture toughness of this material was evaluated directly from the pipe experiment using several different procedures to confirm the results. The details of these analyses can be found in Reference 3.2 and the results can be found in Table 3.1.

In additions to the $\mathrm{J}_{\mathrm{i}}$ values, the $\mathrm{J}-\mathrm{R}$ curve for this pipe experiment was estimated using the SC.TNP $\mathrm{J}$-estimation scheme. This curve was generated by modifying the $\mathrm{J}_{\mathrm{i}}$ and $\mathrm{dJ} / \mathrm{da}$ values from the quasi-static, monotonic $\mathrm{C}(\mathrm{T})$ experiment (A8I-12a) until the predicted moment-rotation response matched the experimental moment-rotation response. This calculated J-R curve is shown in Figure 3.2. Also included in this figure is the J-R curve from the quasi-static, monotonic $\mathrm{C}(\mathrm{T})$ experiment (A8I-12a, from Table 2.6 and Figure 2.2). Clearly, the J-R curve for the pipe-system experiment is much lower than the $C(T)$ specimen J-R curve. 


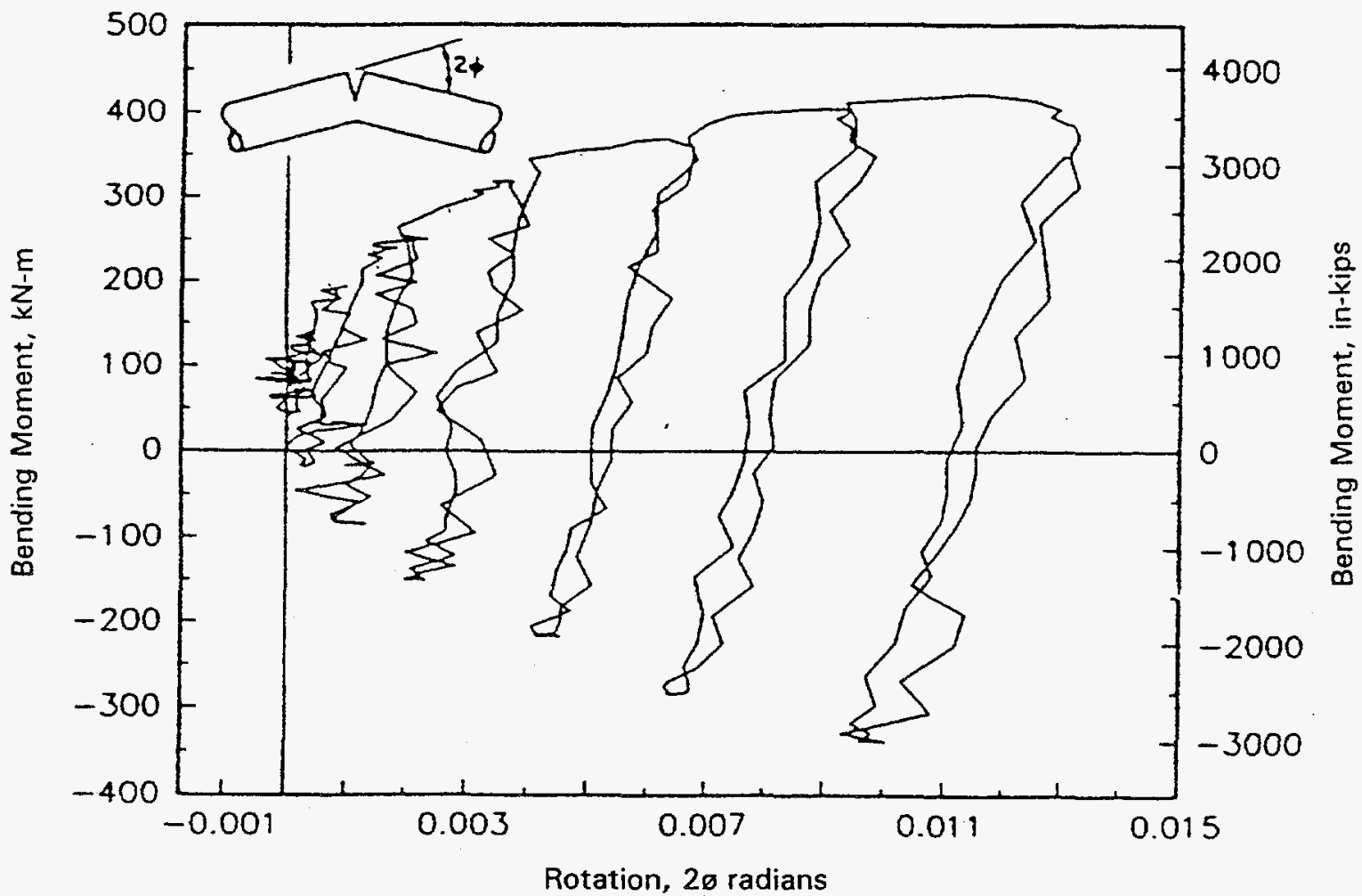

Figure 3.1 Crack section moment-rotation behavior from the IPIRG-1 stainless steel base metal pipe-system experiment (1.3-3)

Table 3.1 $J_{i}$ values for Experiment 1.3-3 from Reference 3.2

\begin{tabular}{lc}
\hline \multicolumn{1}{c}{ Method of Calculation } & $\mathbf{J}_{\mathbf{i}}, \mathbf{k J} / \mathbf{m}^{\mathbf{2}}$ \\
\hline SC.TNP J-estimation scheme & 215 \\
Surface-cracked pipe $\eta$-factor analysis & 145 \\
DPZP analysis & $<145$ \\
\hline
\end{tabular}




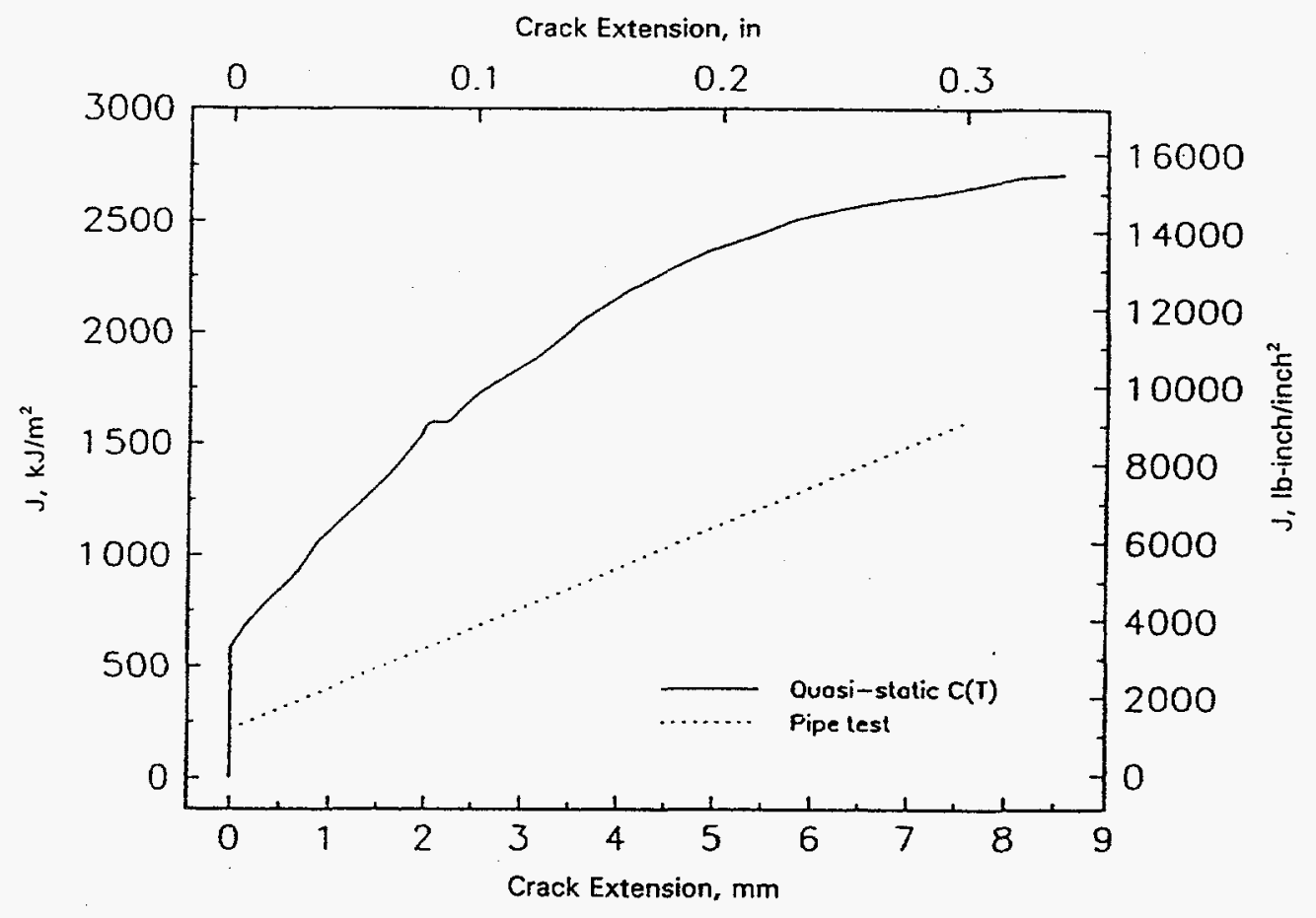

Figure 3.2 Comparison of the modified J-R curve from the pipe experiment with the quasi-static, monotonic $C(T)$ specimen $J-R$ curve

\subsubsection{Predictions of Maximum Experimental Stress}

This section will compare maximum experimental stress predictions for the surface-cracked pipe experiments shown in Table 2.1 using a variety of fracture prediction analyses. The analysis methods considered include:

Simple limit-load analyses such as the Net-Section-Collapse (NSC) analysis (Ref. 3.3)

Dimensionless-Plastic-Zone-Parameter (DPZP) analysis (Ref. 3.4) and

Various J-estimation scheme analyses such as SC.TNP1 (Ref. 3.5), SC.TNP2 (Ref. 3.6), SC.ENG1 (Ref. 3.6), and SC.ENG2 (Ref. 3.6).

Details of each of these fracture analysis methods can be found in the appropriate reference. A summary of the analysis methods and details pertaining to definition of flaw size and appropriate material properties can be found in Reference 3.7.

The quasi-static stress-strain curve and the appropriate J-R curve (dynamic J-R curve was used for the analysis of dynamically loaded pipe, while the quasi-static J-R curve was used in the analysis of quasistatically loaded pipe) were used in these analyses. The constants used in these analyses can be found in Table 3.2. The stress-strain curve constants are based on the Ramberg-Osgood relationship. 
Table 3.2 Material property constants used in the maximum stress predictions

\begin{tabular}{|c|c|c|c|c|c|c|c|c|c|c|}
\hline \multirow[b]{2}{*}{$\begin{array}{c}\text { Experiment } \\
\text { ID }\end{array}$} & \multicolumn{5}{|c|}{ Stress-Strain Data } & \multirow[b]{2}{*}{$\begin{array}{c}\text { Specimen } \\
\text { ID }\end{array}$} & \multicolumn{3}{|c|}{ J-R Curve Data ${ }^{(a)}$} & \multirow[b]{2}{*}{$\begin{array}{c}\text { Specimen } \\
\text { ID }\end{array}$} \\
\hline & $\begin{array}{c}\sigma_{y} \\
\text { MPa }\end{array}$ & $\begin{array}{c}\sigma_{u}, \\
\text { MPa }\end{array}$ & $\epsilon_{0}$ & $\alpha$ & $\mathbf{n}$ & & $\begin{array}{c}\mathbf{J}_{\mathbf{i}}, \\
\mathbf{k J} / \mathbf{m}^{2}\end{array}$ & $\underset{\mathrm{kJ} / \mathrm{m}^{2}}{\mathrm{C}_{3}}$ & $\mathbf{m}$ & \\
\hline EPRI-13S & 295 & 743 & 0.00162 & 3.93 & 5.07 & A8-35 & 2,277 & 1,292 & 0.502 & (b) \\
\hline $1.3-3$ & 171 & 456 & 0.000936 & 5.34 & 4.17 & A8-40 & 1,302 & 510 & 0.739 & A8-9a \\
\hline $1-1$ & 171 & 456 & 0.000936 & 5.34 & 4.17 & A8- 40 & 1,302 & 510 & 0.739 & $A 8-9 a$ \\
\hline
\end{tabular}

(a) $\mathrm{J}=\mathrm{J}_{\mathrm{i}}+\mathrm{C}_{3}(\Delta \mathrm{a} / \mathrm{r})^{\mathrm{m}}$, where $\mathrm{r}=1.0 \mathrm{~mm}$.

(b) Average fit for Specimens A8a-1, A8a-2, and A8a-3.

In addition to Experiment 1.3-3, two other experiments were analyzed for comparison purposes.

Experiment EPRI-13S was a room temperature quasi-static bend test on circumferentially surface-cracked section of Pipe DP2-A8, while Experiment 1-1 was tested under the same conditions as Experiment 1.3-3 except a simulated seismic forcing function was used in place of a single-frequency forcing function.

Details of these experiments and their respective analyses can be found in Reference 3.7.

In calculating the fracture ratios for these experiments (i.e., the ratio of experimental-to-predicted maximum stress), the bending stress terms were calculated by converting the bending moments to bending stresses through a simple strength of material formulation $(\mathrm{Mc} / \mathrm{I})$, where $\mathrm{c}$ is the outside pipe radius and $\mathrm{I}$ is the moment of inertia. The membrane stress term was calculated using the simple thin-wall Barlow equation (PR/2t), but using the outside diameter as per Section III of the ASME code instead of the inside radius.

Table 3.3 contains the results of these analyses. Also included in this table are the average values of the fracture ratio for each of the analysis methods taken from Reference 3.6. These average values were taken from the analysis of 16 surface-cracked pipe experiments under tension and bending.

Table 3.3 Fracture ratios for experiments on Pipe DP2-A8

\begin{tabular}{cccccccc}
\hline & & \multicolumn{7}{c}{ Eracture Ratio $^{(\mathbf{(})}$} \\
\cline { 3 - 7 } $\begin{array}{c}\text { Experiment } \\
\text { Number }\end{array}$ & $\begin{array}{c}\text { Effective Stress } \\
\text { Ratio (R) }^{(\mathbf{b})}\end{array}$ & NSC & DPZP & SC.TNP1 & SC.TNP2 & SC.ENG1 & SC.ENG2 \\
\hline EPRI 13S & 1.0 & 1.144 & 1.144 & 1.008 & 1.316 & 1.324 & 1.522 \\
$1.3-3$ & -0.2 & 0.975 & 0.975 & 0.816 & 1.066 & 1.055 & 1.225 \\
$1-1$ & -0.5 & 1.156 & 1.156 & 0.999 & 1.291 & 1.222 & 1.403 \\
Ref. 3.6 & & 0.92 & 1.05 & 1.100 & 1.410 & 1.390 & 1.650 \\
\hline
\end{tabular}

(a) Fracture ratio $=\left(\sigma_{\mathrm{B}_{\text {expt }}}+\sigma_{\mathrm{m}}\right) /\left(\sigma_{\mathrm{B}_{\text {analysis }}}+\sigma_{\mathrm{m}}\right)$.

(b) $\mathrm{R}_{\text {effective }}=\left(\sigma_{\mathrm{B}_{\min }}+\sigma_{\mathrm{m}}\right) /\left(\sigma_{\mathrm{B}_{\max }}+\sigma_{\mathrm{m}}\right)$. 
From Table 3.3, the fracture ratios from the J-estimation scheme analyses for Experiments EPRI 13S and 1-1 fall close to the average values from Reference 3.6. However, the ratios for Experiment 1.3-3 are much lower than the average values in all cases, which is expected since the J-R curve used in the analysis is much higher than the one calculated for the pipe experiment.

\subsubsection{Possible Explanations for Toughness and Maximum Stress Predictions Differences}

There are several possible explanations for the differences observed between the behavior of Experiment 1.3-3 and the other experimental results. First, the unusual behavior of Experiment 1.3-3 may be caused by an inherent difference in the material properties of Pipe DP2-A8. As discussed in Section 2, three lengths of this pipe were originally shipped to Battelle by EPRI. Since it was assumed that all three lengths of pipe came from the same heat, the different lengths were not given a unique label. Therefore, it is uncertain which length of pipe the material characterization specimens and the pipe experiment test section came from. A series of chemical analyses was conducted to verify if the three lengths of pipe had the same chemical composition. These results are given in Section 3.2.

Second, the effect of constraint on the toughness of the material may be explain the behavior of Experiment 1.3-3. In Figure 3.2, the J-R curve from the pipe experiment is compared with that of a quasistatic, monotonically loaded $C(T)$ specimen. The $C(T)$ specimen is a much higher constrained geometry than a surface-cracked-pipe geometry. It stands to reason then that a J-R curve calculated from a C(T) specimen should have a lower toughness than the surface-cracked pipe because of this constraint difference. However, the constraint is a function of both the specimen and crack geometry, i.e., a longer crack in a specimen will be constrained differently than a short crack in the same geometry.

In the Degraded Piping program (Ref. 3.8), the single-edge notched tensile [SEN(T)] specimen was shown to have similar constraint as a surface-cracked pipe. Therefore, to address the constraint issue, a series of quasi-static, monotonic and quasi-static, cyclic SEN(T) experiments were conducted. These specimens were machined from Pipe DP2-A8. The results of these experiments are given in Section 3.3

Another possible cause for the behavior observed in Experiment 1.3-3 is the effect of a dynamic, cyclic loading history on the fracture toughness of this material. In Table 3.3, Experiment 1-1, which was a simulated-seismic, pipe-system experiment, had an effective stress ratio of -0.5 , yet the calculated fracture ratios were similar to the average values shown in Reference 3.6 (all experiments in Ref. 3.6 were conducted with monotonic load histories). As discussed in the IPIRG-2, Task 1 final report (Ref. 3.7), the cycles prior to maximum load in Experiment 1-1 were primarily elastic (with one large amplitude cycle to maximum moment), which is a direct function of the seismic load history applied. Experiment 1.3-3, which had a more positive stress ratio $(R=-0.2)$ than Experiment $1-1$, had a significant amount of plasticity in the cycles prior to maximum load. Therefore, since the toughness degradation due to cyclic loading is related to the amount of compressive plasticity (Ref. 3.9), it can be expected that the fracture ratios calculated for Experiment 1.3-3 would be lower than those calculated for Experiment 1-1. 
In order to verify that the dynamic, cyclic $(R=-0.2)$ loading history of Experiment 1.3-3 would reduce the apparent toughness of the material as compared to quasi-static, monotonic loading, a series of $C(T)$ specimens were conducted. Both quasi-static, cyclic and dynamic, cyclic C(T) experiments were conducted. The results of these experiments are given in Section 3.4.

\subsection{Chemical Analyses Results}

A series of chemical analyses were performed on tested specimens to determine if the chemical compositions of the specimen could explain the behavior of Experiment 1.3-3. Sections of the fracture surfaces for both Experiment 1.3-3 and 1-1 were tested as well as several material property specimen tested both in this investigation and past piping programs. The results of these analyses are shown in Table 3.4.

The data in Table 3.4 show two distinct chemical compositions that consistently group together based on manganese, sulphur, silicon, nickel, and chromium contents, which are labeled using a new pipe numbering system, i.e., DP2-A8I and DP2-A8II. Although all of the compositions shown in Table 3.4 fall within the ASTM specification for TP304 stainless steel, the data in Table 3.4 suggest that the three lengths of stainless steel pipe donated to Battelle by EPRI, which were thought to come from a single heat and were labeled as DP2-A8 are really from two different heats that have different chemistries.

\subsection{Single-Edge Notched Tensile Specimen Experiments}

\subsubsection{SEN(T) Experimental Procedures}

This section describes the experimental SEN(T) procedures developed and used during the course of this work. The original work performed on monotonically loaded SEN(T) specimens was part of the Degraded Piping Program (Ref. 3.8). Figure 3.3 shows a schematic illustration of the specimen arrangement used in the Degraded Piping program. The specimen is held by hydraulic grips that prevent rotation of the specimen within the grips as the test proceeds. The fixed-grip condition was used since it better simulated the rotational restrictions that would occur in surface-cracked pipe. In order to minimize end effects from the gripped ends on the crack front, the distance from the notch to the grips is set at a minimum of $2 \mathrm{~B}$, where $B$ is the specimen thickness. The maximum value of dimension $B$, which depends on the pipe geometry and on specimen width, w, can be estimated from the following equation:

$$
\mathrm{B}_{\max }=2\left[\mathrm{tD}_{\mathrm{i}}\left(1-\frac{\mathrm{w}}{\mathrm{t}}\right)+\mathrm{t}^{2}\left(1-\frac{\mathrm{w}}{\mathrm{t}^{2}}\right)\right]^{0.5}
$$

where $t$ is the pipe thickness, and $D_{i}$ is the pipe inside diameter. 
Table 3.4 Chemical analysis results for specimens manufactured from Pipe DP2-A8

\begin{tabular}{|c|c|c|c|c|c|c|c|c|c|}
\hline & $\begin{array}{c}\text { Exp. 1.3-3 } \\
\text { Fracture } \\
\text { Surface }\end{array}$ & $\begin{array}{c}\text { Exp. 1-1 } \\
\text { Fracture } \\
\text { Surface }\end{array}$ & $\begin{array}{c}C(T) \\
\text { Specimen } \\
\mathbf{A 8 - 1 2 \mathbf { a } ^ { ( \mathrm { a } ) }}\end{array}$ & $\begin{array}{c}\text { C(T) } \\
\text { Specimen } \\
\text { A8-17 } \\
\text { (a) }\end{array}$ & $\begin{array}{c}\text { SEN(T) } \\
\text { Specimen } \\
\text { SENT-2 }\end{array}$ & $\begin{array}{c}\text { C(T) } \\
\text { Specimen } \\
\text { A8-44 }\end{array}$ & $\begin{array}{c}\text { Tensile } \\
\text { Specimen } \\
\text { A8-39 }\end{array}$ & $\begin{array}{c}\text { Tensile } \\
\text { Specimen } \\
\text { A8-105 }\end{array}$ & $\begin{array}{c}\text { Maximum } \\
\text { ASTM } \\
\text { Allowables }\end{array}$ \\
\hline $\mathbf{C}$ & 0.041 & 0.051 & 0.056 & 0.042 & 0.041 & 0.057 & 0.055 & 0.047 & 0.08 \\
\hline Mn & 1.79 & 1.37 & 1.38 & 1.73 & 1.79 & 1.37 & 1.36 & 1.79 & 2.00 \\
\hline $\mathbf{P}$ & 0.020 & 0.020 & 0.022 & 0.025 & 0.019 & 0.023 & 0.024 & 0.024 & 0.045 \\
\hline $\mathbf{S}$ & 0.019 & 0.001 & 0.002 & 0.017 & 0.019 & 0.001 & 0.002 & 0.022 & 0.030 \\
\hline $\mathbf{S i}$ & 0.31 & 0.63 & 0.62 & 0.38 & 0.31 & 0.58 & 0.64 & 0.35 & 0.75 \\
\hline $\mathbf{N i}$ & 8.97 & 8.03 & 7.94 & 8.75 & 8.92 & 8.01 & 8.05 & 9.05 & $8-12^{(c)}$ \\
\hline $\mathrm{Cr}$ & 18.57 & 17.95 & 17.99 & 18.61 & 18.57 & 18.01 & 18.01 & 18.54 & $18-20^{(\mathrm{c})}$ \\
\hline Mo & 0.28 & 0.19 & 0.19 & 0.27 & 0.28 & 0.19 & 0.17 & 0.27 & \\
\hline $\mathbf{T i}$ & - & - & $<0.01$ & $<0.01$ & - & 0.010 & 0.012 & $<0.01$ & \\
\hline $\mathrm{Cb}$ & - & - & $<0.05$ & $<0.05$ & - & $<0.05$ & $<0.05$ & $<0.05$ & \\
\hline $\mathbf{C u}$ & - & - & 0.090 & 0.26 & - & 0.08 & 0.10 & 0.35 & \\
\hline $\begin{array}{l}\text { New } \\
\text { Pipe } \\
\text { No. }\end{array}$ & DP2-A8II & DP2-A8I & DP2-A8I & DP2-A8II & DP2-A8II & DP2-A8I & DP2-A8I & DP2-A8II & \\
\hline
\end{tabular}

(a) Experimental results discussed in Section 3.4 .
(b) Experimental results discussed in Section 3.3.

(c) Minimum-maximum allowables. 
The specimens tested in this study were machined from TP304 stainless steel pipe material, Battelle pipe number DP2-A8II (see Table 3.4). This Schedule 100 pipe had a 16-inch nominal diameter. The SEN(T) specimens were machined from the pipe thickness without flattening and were in the L-R orientation, i.e., loads were applied in the direction of the pipe axis and the crack growth was radial through the original pipe wall thickness. As shown in Figure 3.4, the specimen design and dimensions are similar to those used in the Degraded Piping Program.

The starter crack was machined using electric-discharge machining (EDM) and had a scalloped crack front in order to provide a fatigue precrack of reasonably uniform depth. Figure 3.4 shows the specimen and crack dimensions. The specimens were precracked under cyclic loading $(R=0.1)$ until an $\mathrm{a} / \mathrm{w}$ of approximately 0.6 was achieved. This deep starter flaw was needed in order to minimize yielding of the uncracked material. In order to investigate the effect of an unusually deep crack, Specimen SENT-6 was precracked to an a/w of 0.71 . After precracking, the specimens were side grooved with a blunt notch in order to provide a stress state that would allow straight crack front growth during ductile tearing. The dimensions for the side grooving are shown in Figure 3.4. They were chosen from past experience with SEN(T) specimens in the Degraded Piping Program. Table 3.5 shows the specific SEN(T) specimen dimensions.

Each specimen was tested in a $22.2 \mathrm{kN}(50,000 \mathrm{lb})$ servo-hydraulic test frame equipped with hydraulic grips. Figure 3.5 is a photograph of the test setup. All specimens were tested at quasi-static rates, i.e., crack initiation occurred in about 10 minutes in the monotonic-load tests. The identical displacement rate was then used for the cyclic-load tests.

Direct-current electric potential (d-c EP) was used to monitor crack growth during these tests. This method of crack initiation detection and crack growth measurement has been used with favorable results in both the IPIRG-1 (Ref. 3.1) and Degraded Piping Programs (Ref. 3.8). The load cell in the servo-hydraulic test machine was electrically isolated to prevent a current path through the load train. The potential leads were stainless steel wires in order to reduce thermally induced voltages that can arise from dissimilar

Table 3.5 SEN(T) specimen dimensions

\begin{tabular}{|c|c|c|c|c|c|c|c|c|c|c|}
\hline \multirow[b]{2}{*}{ Specimen } & \multicolumn{2}{|c|}{$\mathbf{w}$} & \multicolumn{2}{|c|}{$\mathbf{B}$} & \multicolumn{2}{|c|}{$\mathbf{B}_{\mathrm{N}}$} & \multicolumn{2}{|c|}{$\mathbf{H}^{(\mathfrak{a})}$} & \multicolumn{2}{|c|}{$\mathbf{a}_{i}$} \\
\hline & $\mathbf{m m}$ & inch & $\mathbf{m m}$ & inch & mm & inch & $\mathrm{mm}$ & inch & $\mathbf{m m}$ & inch \\
\hline SENT-2 & 19.1 & 0.75 & 38.2 & 1.50 & 30.5 & 1.20 & 152.4 & 6.00 & 11.8 & 0.46 \\
\hline SENT-3 & 19.1 & 0.75 & 38.2 & 1.50 & 30.6 & 1.20 & 152.4 & 6.00 & 11.2 & 0.44 \\
\hline SENT-4 & 19.2 & 0.76 & 38.1 & 1.50 & 30.7 & 1.21 & 152.4 & 6.00 & 12.1 & 0.48 \\
\hline SENT-5 & 19.1 & 0.75 & 38.2 & 1.50 & 30.8 & 1.21 & 152.4 & 6.00 & 12.1 & 0.48 \\
\hline SENT-6 & 19.1 & 0.75 & 38.2 & 1.50 & 30.5 & 1.20 & 152.4 & 6.00 & 13.6 & 0.54 \\
\hline
\end{tabular}

(a) $\mathrm{H}$ is the distance between the hydraulic grips. 

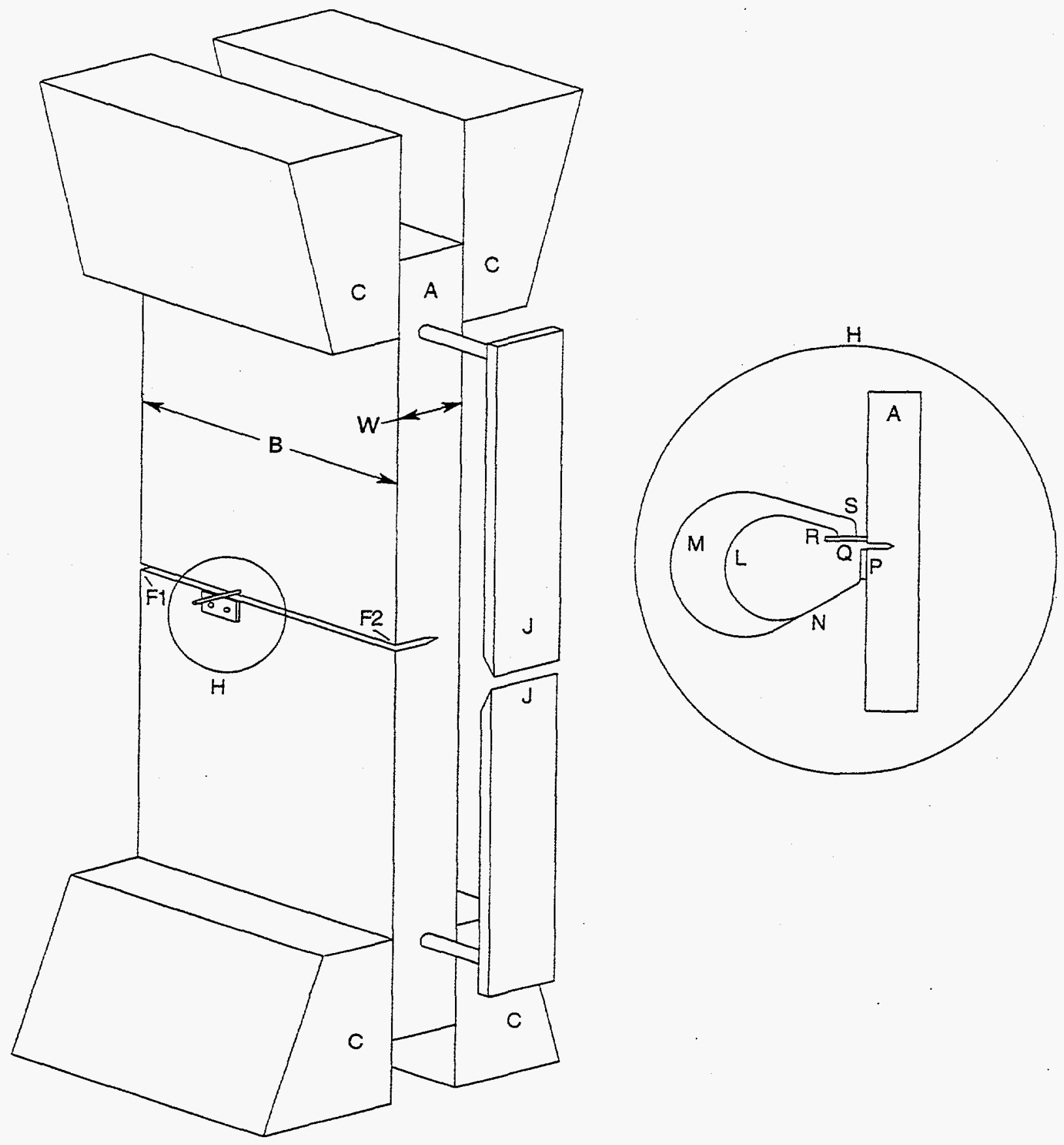

Figure 3.3 Schematic illustration of SEN(T) testing arrangement 

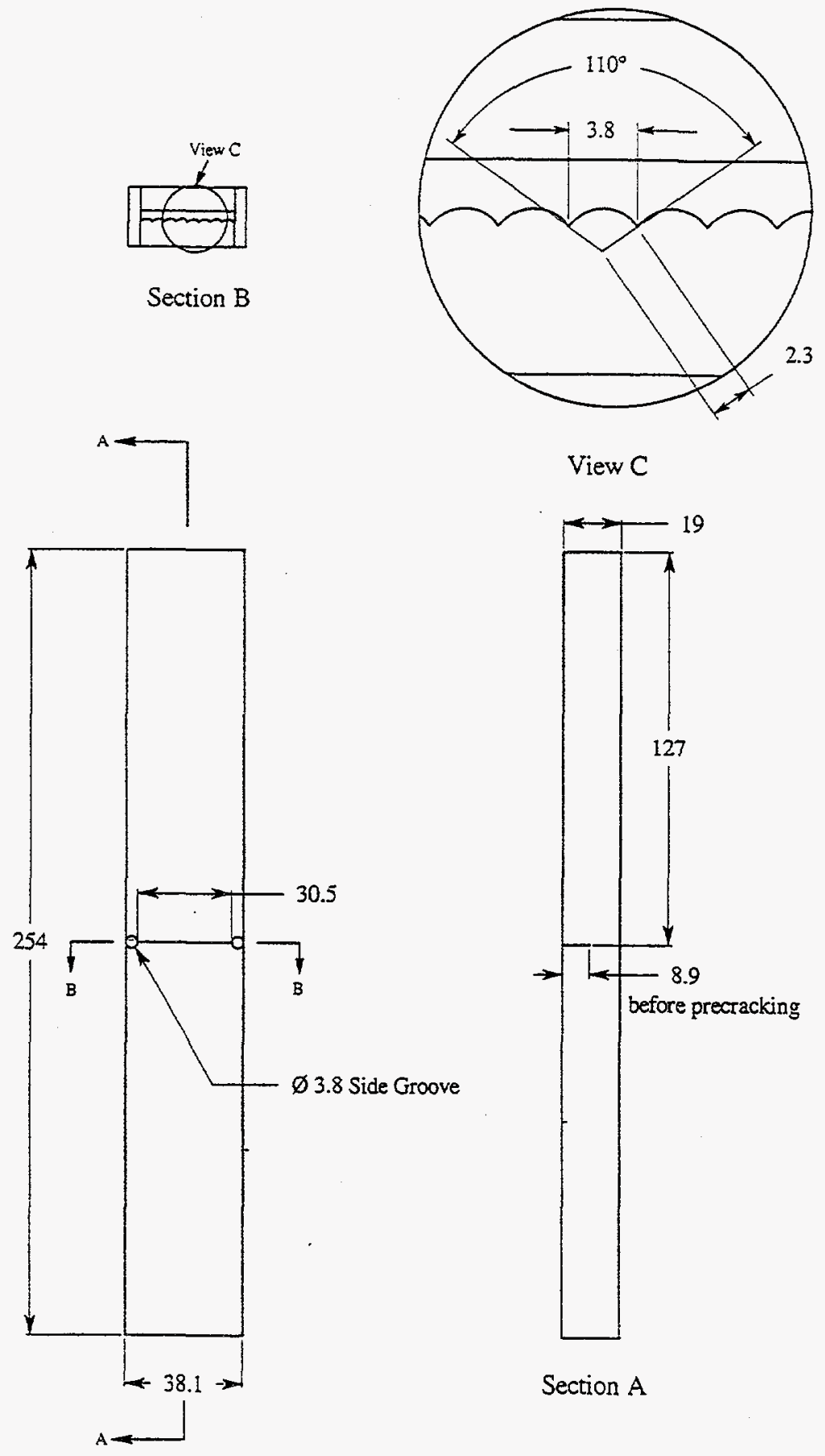

Section A

All dimensions in millimeters, to convert to inches divide by 25.4

Figure 3.4 SEN(T) specimen dimensions 


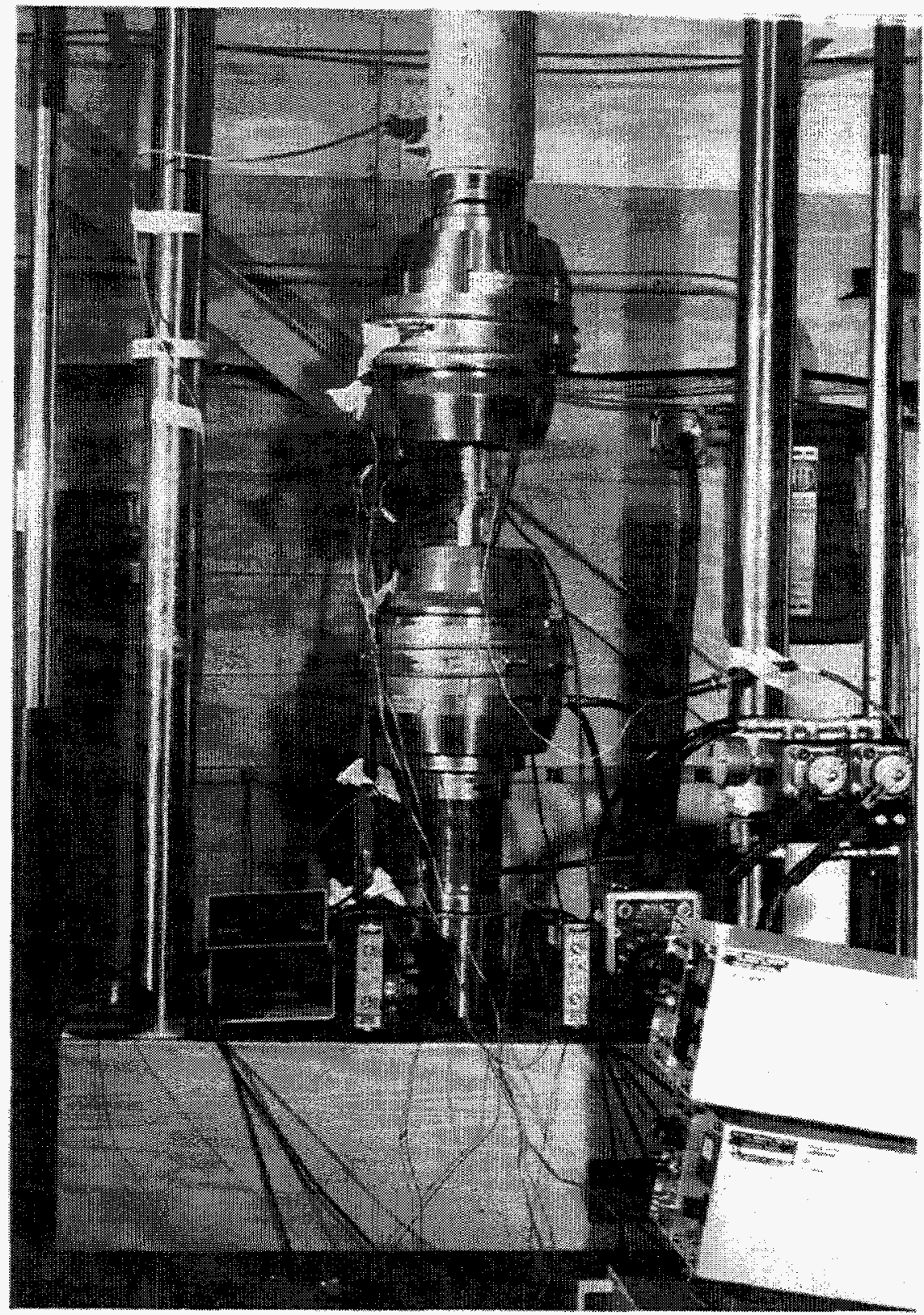

Figure 3.5 Photograph of SEN(T) experimental setup 
materials in contact. As shown in Figure 3.3, the potential leads were placed at locations F1 and F2 in order to detect an average crack front in the specimens where the crack front might not be straight. The direct-current magnitude was adjusted to give a potential of about $400 \mu \mathrm{V}$ at the start of the tests. The tests continued until a $400 \mu \mathrm{V}$ shift in the electric potential was observed, or until the load dropped to 50 percent of the maximum load. The procedure for calculating the crack extension from the d-c EP data can be found in Appendix A.

Displacements were measured at four locations. Ram displacement was measured using the LVDT stroke indicator of the test machine. Load-line displacement was measured between the arms labeled " $\mathrm{J}$ " in Figure 3.3, using a high temperature MTS clip gage. Displacements at the notch mouth were measured with a dual clip gage, as shown in Figure 3.3. The dual clip gage employed electric-resistance strain gages in a bridge circuit. The two clip gages were fastened together at location " $\mathrm{N}$ " and attached with screws to Block "P", which previously had been welded to the specimen. The free ends of the dual clip gage were allowed to rest at Points " $R$ " and "S" against Post " $Q$," which was also welded to the specimen. This block and post were placed as close to the crack mouth as possible so that an accurate crack-mouthopening displacement could be measured. The distance between Points " $R$ " and " $S$ " was set at $12.7 \mathrm{~mm}$ ( 0.5 inch), where Point " $\mathrm{S}$ " was $3.8 \mathrm{~mm}(0.15 \mathrm{inch})$ from the specimen face. Using these displacements, the amount of bending or rotation in the specimen as the crack advanced could be determined. $A$ photograph of the instrumented specimen is shown in Figure 3.6.

All specimens were tested at $288 \mathrm{C}(550 \mathrm{~F})$. To achieve this temperature, one heater tape was wrapped around the specimen above the notch and one below the notch. Temperature was controlled within $3 \mathrm{C}$ (5 F) using a Chromel/Alumel Type $\mathrm{K}$ thermocouple spot welded to the specimen near the notch and an Omega DC7000 temperature controller.

Table 3.6 shows the test matrix for the SEN(T) specimens. In Table 3.6, $R$ is the stress ratio, which is defined as the minimum experimental load divided by the maximum experimental load per cycle $\left(\mathrm{P}_{\min } / \mathrm{P}_{\max }\right), \delta_{\text {cyc }}$ is the plastic displacement per cycle, and $\delta_{\mathrm{i}}$ is the load-line displacement at crack initiation in the monotonic-load test (SENT-2). The value of 0.1 for $\delta_{\text {cyc }} / \delta_{i}$ was chosen to match that in the TWC pipe experiments conducted as part of Subtask 1-2 of the IPIRG-1 program.

Table 3.6 SEN(T) test matrix

\begin{tabular}{lcc}
\hline Specimen ID & Stress Ratio, $\mathbf{R}\left(\mathbf{P}_{\min } / \mathbf{P}_{\mathbf{m a x}}\right)$ & $\delta_{\mathbf{c y c}} / \delta_{\mathbf{i}}$ \\
\hline SENT-2 & 1 & N/A \\
SENT-3 & -0.3 & 0.1 \\
SENT-4 & -1 & 0.1 \\
SENT-5 & -0.8 & 0.1 \\
SENT-6 & 1 & N/A \\
\hline
\end{tabular}



C(T) SPECIMEN AND SURFACE-CRACKED PIPE SPECIMEN

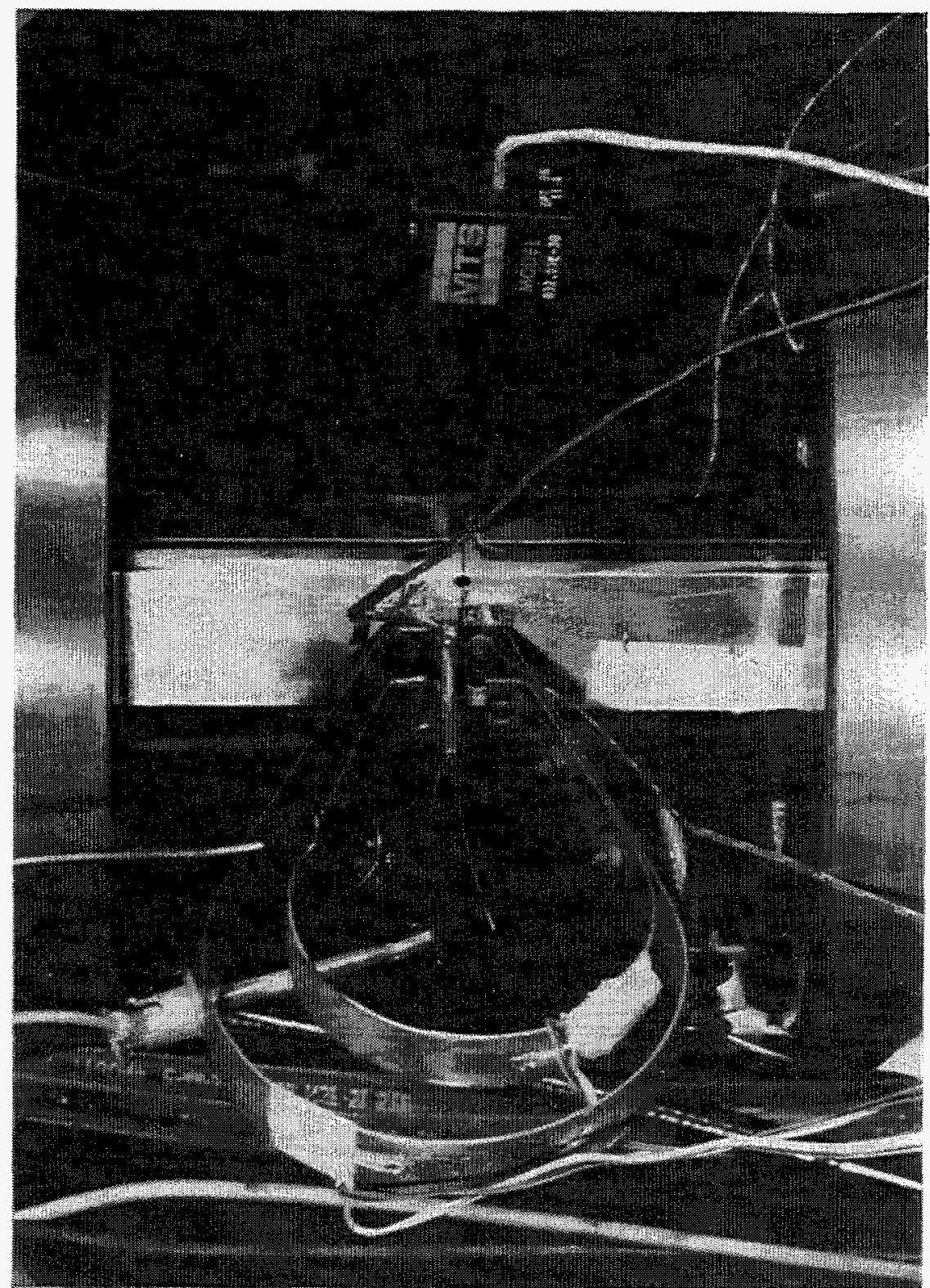

 
In order to conduct experiments that required cyclic loading, a computer was used for real-time control of the experiment. Since these tests were conducted in displacement control at a constant loading rate, and cyclic loading is a function of load, real-time control was necessary to regulate the loading in displacement control and to evaluate the load during unloading to achieve a desired stress ratio. A BASIC program, identical to the control program used in the IPIRG-1 program, was used to achieve this real-time control. The BASIC program loads the specimen in tension to a desired displacement, records the peak load, and then loads the specimen in compression to a fraction of the measured peak load based on the specified stress ratio. The program increments the displacement by a specified amount and repeats the previous steps. The process continues until the desired number of cycles are obtained.

The data recorded during these tests included load, ram displacement, load-line displacement, inside and outside clip-gage displacement, and direct-current electric potential. All data were taken with the LABTECH ${ }^{\circledR}$ NOTEBOOK software in conjunction with a Metrabyte DAS-20 card. A standard X-Y-Y plotter was used as a backup.

After sufficient crack growth, $(\triangle E P$ of about $400 \mu \mathrm{V})$, the specimens were taken out of the test frame. They were then heat tinted at $540 \mathrm{C}(1,000 \mathrm{~F})$ to darken the crack surfaces and fractured completely by placing them back into the servo-hydraulic system and pulling them to failure.

\subsubsection{SEN(T) Experimental Results}

Figure 3.7 shows the load-displacement plots for the five SEN(T) specimens. Note that these plots represent the data corresponding to the upper envelope of the load-displacement record. Note also that one of the monotonically loaded specimens (SENT-6) had a significantly deeper crack than the other specimens, which led to smaller loads and displacements than for the other monotonically loaded specimen (SENT-2).

It is clear from the curves that cyclic loads reduced the load and displacement capacity of the material as the stress ratio was made more negative. As the stress ratio was decreased to -1 , the maximum load was decreased by 8 percent. Also, the load-line displacement at maximum load was decreased by about 60 percent as the stress ratio was decreased to -1. As shown in Figure 3.7, the a/w values between the SEN(T) specimens varied, which could have caused the different load-carrying capacities. To normalize the crack length effect, the J-integral was calculated for each specimen. These results are discussed in the next section.

\subsubsection{J-R Curves for the SEN(T) Specimens}

The J-R curves for the SEN(T) specimens tested in this study were calculated using two methods, i.e., the Ahmad J-estimation scheme (Ref. 3.10) based on known stress intensity solutions for this geometry as well as derived stress distributions along the fixed boundary, and the finite element method. Note that finite element analyses were conducted only on Specimens SENT-2, -4 and -6. Appendix A contains the details of both of these analyses. 


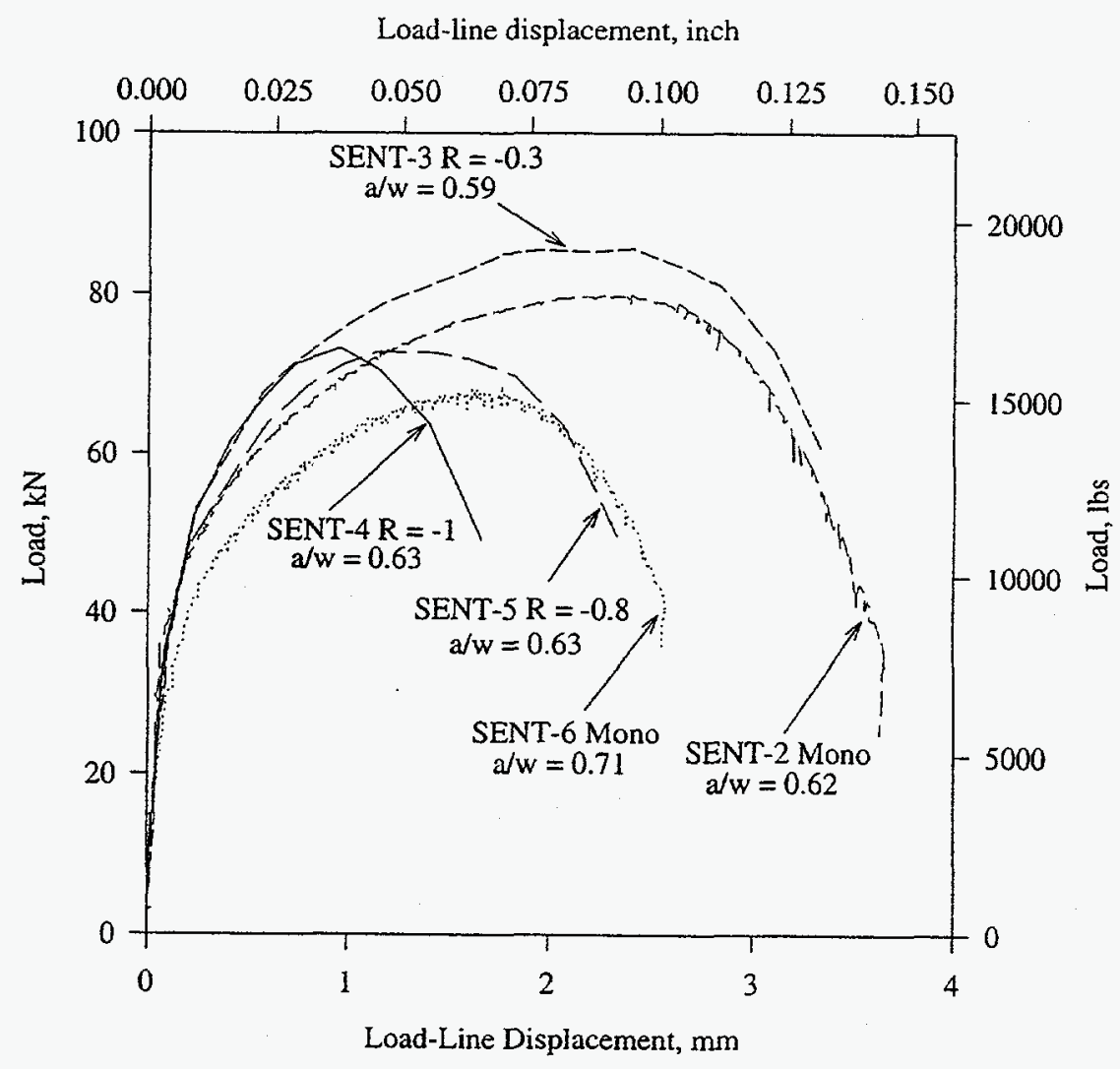

Figure 3.7 Load-displacement record for SEN(T) specimens

Figure 3.8 shows a comparison of the SEN(T) J-R curves for both the finite element method and the Ahmad J-estimation scheme. As described in Appendix A, the finite element analysis provided good estimations of the applied loads for all three specimens analyzed; however, there is a large discrepancy between the J-R curves calculated from the two analysis methods. In Reference 3.10, which describes the derivation of the J-estimation scheme by Ahmad, two finite element analyses were conducted to verify the estimation scheme. However, the authors used a low toughness ferritic steel $\left(n=3.7, J_{i}=149 \mathrm{kN} / \mathrm{m}\right)$ in these analyses. It is possible that the assumptions in the estimation scheme are not valid for the deformations in the higher toughness stainless steel $\left(n=4.895, J_{i}=622.6 \mathrm{kN} / \mathrm{m}\right)$.

As shown in Figure 3.8, the Ahmad scheme showed a large decrease in toughness at a stress ratio of -1 . However, the finite element method only showed a small decrease in resistance at $R=-1$. In fact, the J-R curve for the SENT-4 (QS, R = -1) specimen was nearly equal to the J-R curve for the SENT-6 (QS, mono) specimen, indicating that for this geometry, the effects of increasing the crack depth by 15 percent had the same effect on the resistance as cycling the specimen at $R=-1$. 


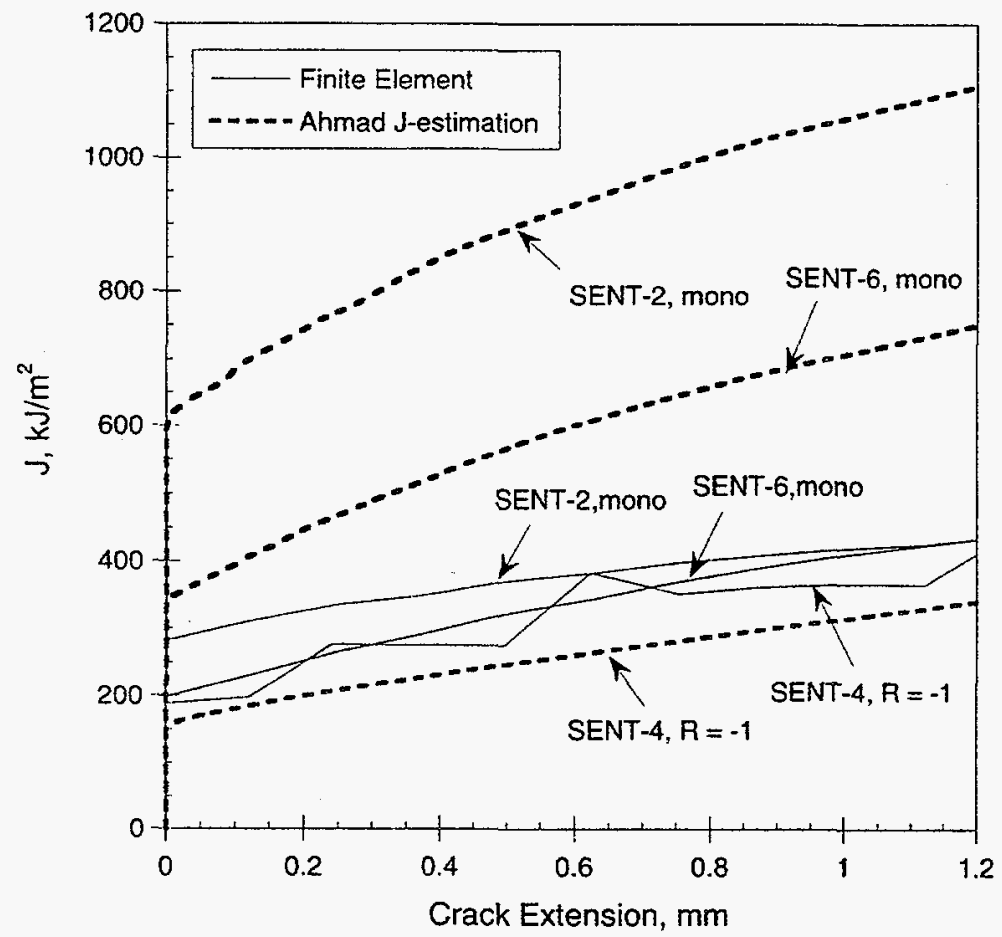

Figure 3.8 Comparison of SEN(T) J-R curves calculated using the Ahmad J-estimation scheme and the finite element method

The values of $J$ at crack initiation are plotted versus crack depth in Figure 3.9. From this figure, the effects of crack depth and cyclic effects become clear. As the crack depth is increased, the apparent toughness at crack initiation is decreased. Also, if it is assumed that a linear relationship is present between the crack depth and $\mathrm{J}_{\mathrm{i}}$, then the cyclic effects can be accounted for by a shift in this linear relationship. Note that the finite element calculated $J_{i}$ values for the monotonic SEN(T) specimens are not much higher than the $J_{i}$ value for Experiment 1.3-3, indicating that the effect of cyclic loads at $R=-0.2$ is small.

\subsection{Compact Tension Specimen Experiments}

In addition to the SEN(T) specimens, a series of compact tension specimen experiments was conducted. The purpose of these experiments was to study the dynamic, cyclic effect on toughness using a standard fracture toughness specimen. The $\mathrm{C}(\mathrm{T})$ specimens tested were machined from both heats of Pipe DP2-A8, and were orientated in the $\mathrm{L}-\mathrm{C}$ direction, i.e., the crack was growing in the circumferential direction and the loading was parallel to the pipes axis.

The specimens were fatigue precracked according to the specification in ASTM E1152-87, Standard Test Method for Determining J-R Curves, to produce an initial crack length of $0.52 \mathrm{w}$ to $0.57 \mathrm{w}$, where $\mathrm{w}$ is the specimen width. The $\mathrm{C}(\mathrm{T})$ specimens were sidegrooved to a depth of 10 percent per side in order to match previous material characterization tests. 


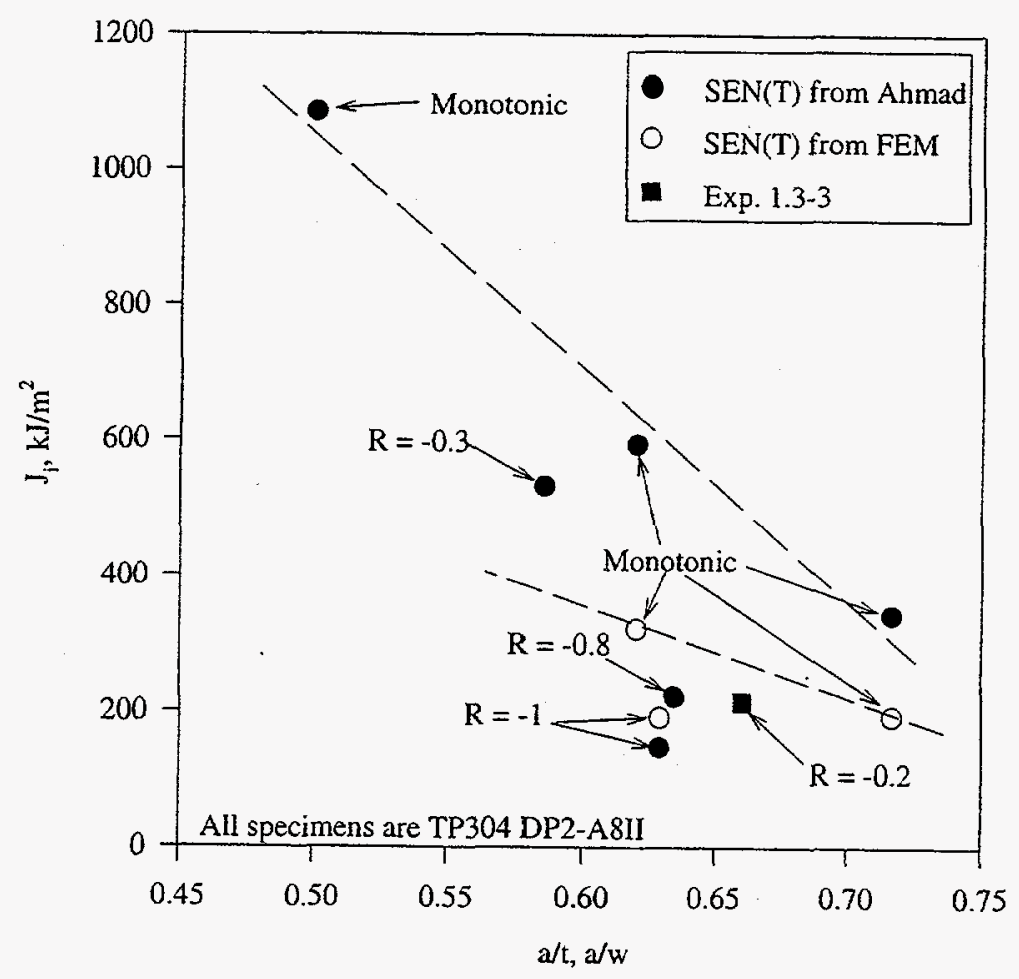

Figure $3.9 \mathbf{J}_{\mathrm{i}}$ versus crack depth for a variety of specimens

\subsubsection{Test Facility and Specimen Preparation}

The rate chosen for the quasi-static, cyclic tests is the same as for a quasi-static, monotonic test where the time to crack initiation is about 10 minutes. For the dynamic, cyclic tests, the rate was similar to a typical pipe-system test, approximately $4 \mathrm{~Hz}$. All specimens were tested in a $111 \mathrm{kN}(25,000 \mathrm{lb})$ servohydraulic test system.

Direct-current electric potential (d-c EP) was used to monitor crack growth during these tests. This method of crack initiation detection and crack growth measurement has been used successfully in both the IPIRG-1 and Degraded Piping Programs (Refs. 3.1 and 3.8). The load cell in the servo-hydraulic test machine was electrically isolated to prevent a current path through the load train. The potential leads were stainless steel wires in order to reduce thermally induced voltages that can arise from dissimilar materials in contact. As shown in Figure 3.10, the potential leads were placed at locations " $C$ " and " $D$ " in order to detect an average crack front in those specimens where the crack front might not be straight. For the quasi-static tests, the direct-current magnitude was adjusted to give a potential of about $400 \mu \mathrm{V}$ at the start of the tests. The tests continued until a $400 \mu \mathrm{V}$ shift in the electric potential was observed.

An onset strain-gaged high temperature clip gage was used to measure load-line displacements. The clip gage were attached to the specimens by seating them on razor blades which were welded directly to the specimen load-line. (This clip gage was calibrated with a linear range of up to $20 \mathrm{~mm}$ [0.8 inch].) 

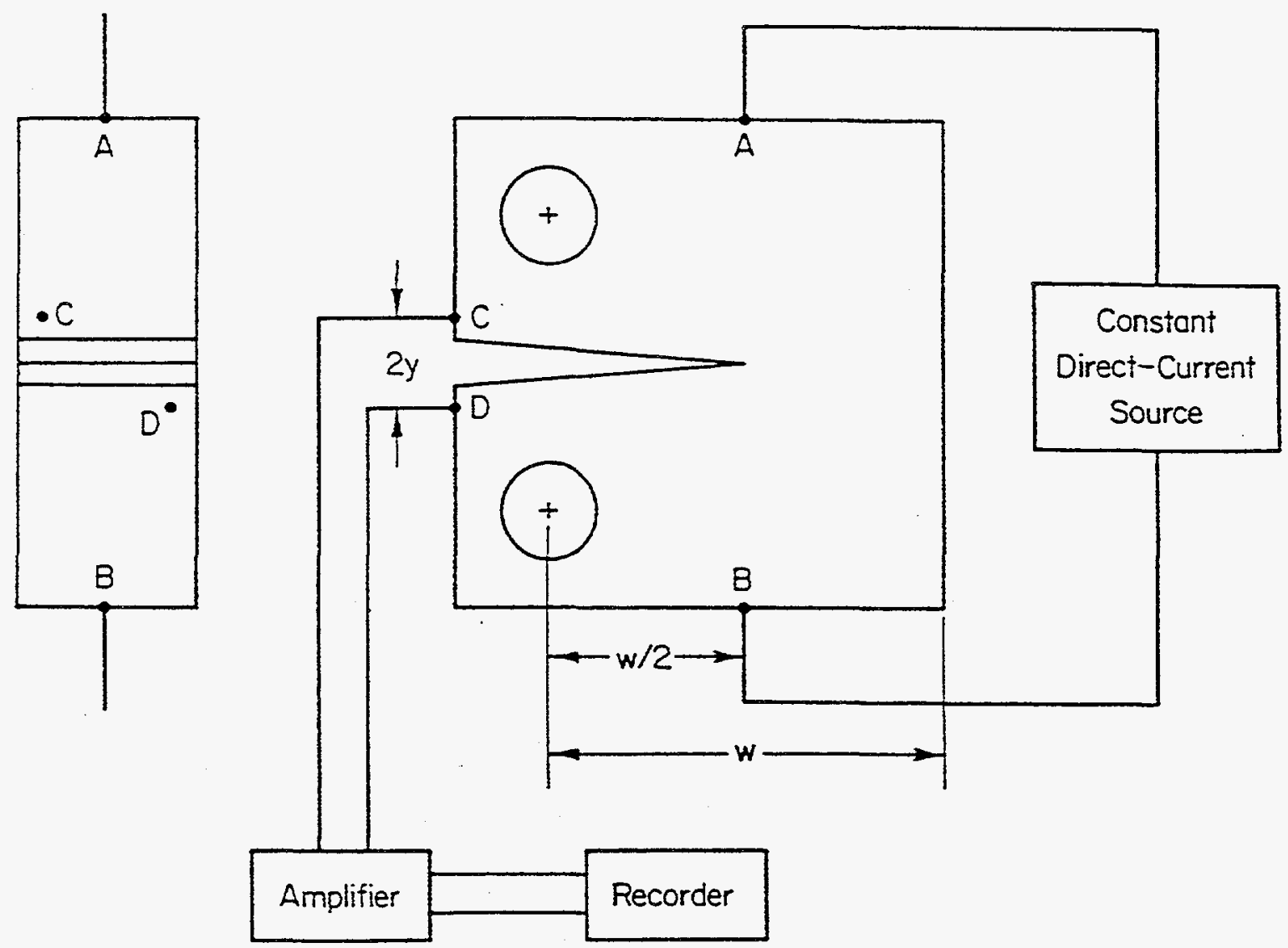

Figure 3.10 Schematic illustration of direct-current electric potential method employed at Battelle to monitor crack growth in $\mathrm{C}(\mathrm{T})$ tests

The data recorded during these tests included load, ram displacement, load-line displacement, and directcurrent electric potential. All data were taken with LabTech Notebook software in conjunction with a Metrabyte DAS-20 card. A standard X-Y-Y plotter and a linear strip chart recorder were used as backup.

Table 3.7 shows the specimen dimensions and Table 3.8 shows the test matrix for the cyclic-loaded C(T) specimens. 
Table 3.7 C(T) specimen dimensions

\begin{tabular}{cllll}
\hline Specimen ID & $\mathbf{w}, \mathbf{m m}(\mathbf{i n c h})$ & $\mathbf{B}, \mathbf{m m}(\mathbf{i n c h})$ & $\mathbf{B}_{\mathrm{N}}, \mathbf{m m}(\mathbf{i n c h})$ & $\mathbf{a}_{\mathrm{i},} \mathbf{m m}(\mathbf{i n c h})$ \\
\hline A8I-13 & $50.59(1.992)$ & $19.86(0.782)$ & $15.80(0.622)$ & $28.08(1.105)$ \\
A8I-14 & $50.81(2.000)$ & $19.86(0.782)$ & $15.70(0.618)$ & $27.70(1.090)$ \\
A8II-15 & $50.81(2.000)$ & $19.62(0.785)$ & $15.95(0.628)$ & $27.35(1.077)$ \\
A8II-16 & $50.59(1.992)$ & $19.62(0.785)$ & $16.15(0.636)$ & $27.89(1.098)$ \\
A8II-17 & $50.81(2.000)$ & $19.96(0.786)$ & $16.00(0.630)$ & $27.43(1.080)$ \\
A8II-18 & $50.81(2.000)$ & $19.86(0.782)$ & $15.77(0.621)$ & $28.55(1.124)$ \\
A8II-20 & $50.81(2.000)$ & $19.86(0.782)$ & $15.90(0.626)$ & $28.63(1.127)$ \\
A8II-21 & $50.81(2.000)$ & $19.86(0.782)$ & $16.00(0.630)$ & $28.24(1.112)$ \\
A8I-22 & $50.81(2.000)$ & $19.81(0.780)$ & $15.72(0.619)$ & $28.35(1.116)$ \\
A8I-23 & $50.81(2.000)$ & $19.89(0.783)$ & $15.82(0.623)$ & $27.81(1.095)$ \\
\hline
\end{tabular}

Table 3.8 Cyclic-load C(T) test matrix

\begin{tabular}{cccc}
\hline $\begin{array}{c}\text { Specimen } \\
\text { ID }\end{array}$ & $\begin{array}{c}\text { Loading } \\
\text { Rate }\end{array}$ & Stress Ratio, $\mathbf{R}$ & $\delta_{\text {cyc }} / \delta_{i}^{(\mathbf{a})}$ \\
\hline A8I-13 & QS & -0.3 & 0.1 \\
A8I-14 & QS & -1 & 0.1 \\
A8II-15 & Dyn & -0.3 & 0.1 \\
A8II-16 & Dyn & -0.3 & 0.1 \\
A8II-17 & QS & 1 & N/A \\
A8II-18 & QS & -1 & 0.1 \\
A8II-20 & Dyn & 1 & N/A \\
A8II-21 & QS & -0.3 & 0.1 \\
A8I-22 & Dyn & -0.3 & 0.1 \\
A8I-23 & Dyn & -0.3 & 0.1 \\
\hline
\end{tabular}

(a) $\delta_{i}$ was taken from Specimen A8I-12a, see Table 2.6.

Two of the specimens, A8I-13 and A8I-14, were fully prepared untested specimens remaining from earlier characterization (IPIRG-1) of this material. The remaining specimens were machined as part of this investigation. The test procedure for cyclically loading these compact tension specimens was developed in the IPIRG-2 program and can be found in the IPIRG-2 Task 3 final report (Ref. 3.9). 


\subsubsection{J-R Curves From C(T) Specimens}

For $\mathrm{C}(\mathrm{T})$ specimens tested under monotonic loading, estimations of $\mathrm{J}$ have been made and published in ASTM 1152, Standard Test Method for Determining J-R curves. However, classical J based on deformation theory is undefined when unloadings occur. Therefore, an engineering approximation of $J$ was required to assess the cyclic effects on fracture toughness. In the IPIRG-1 program (Ref. 3.11), pipe $\mathrm{J}$-R curves were calculated from the load-displacement record using the $\eta$-factor approach. When it came to cyclic pipe tests, the upper envelope of the load-displacement curve was used in the analysis. Even though the formal definition of $J$ is violated when unloadings occur, calculating $J$ from the upper envelope of the load-displacement record can provide a useful tool in the determination of cyclic effects on fracture toughness. Crack initiation and growth in the cyclic-load $C(T)$ tests was determined from the directcurrent electric potential data taken during the experiments. The electric potential data corresponding to the upper envelope of the load-displacement curve was used in all of the crack growth analyses. This approach for calculating cyclic J-R curves has been used and verified for a series of base metal and weld metal cyclic C(T) experiments in Task 3 of the IPIRG-2 program (Ref. 3.9)

Figure 3.11 shows the calculated J-R curves for the specimens machined from Pipe DP2-A8I, while Figure 3.12 shows the J-R curves for the specimens machined from DP2-A8II. Table 3.9 shows the fracture toughness summary for all of the $\mathrm{C}(\mathrm{T})$ experiments. Both Figures 3.11 and 3.12 also show the data for the quasi-static, monotonic specimens machined from the other lot of DP2-A8 for comparison purposes.

From Figure 3.11, the quasi-static monotonic resistance (A8I-12a) from lot A8I is considerably higher (both at crack initiation and during crack growth) than the quasi-static resistance (A8II-17) from lot A8II. An inspection of the fracture surface also indicates that these specimens had much different toughness, see Figure 3.13. This figure shows that Specimen A8I-12a had much more through-thickness deformation than Specimen A8II-17, indicating that Specimen A8I-12a had a higher toughness.

Also from Figure 3.11, the quasi-static, $R=-0.3$ specimen (A8I-13) showed a slight increase in $\mathrm{J}$ at crack initiation, but no significant difference in crack growth resistance up to about $4 \mathrm{~mm}(0.16 \mathrm{inch})$ of crack extension as compared with the quasi-static, monotonic (A8I-12a) specimen. After $4 \mathrm{~mm}$ (0.16 inch) of crack extension, A8I-13 showed a decrease in resistance as compared with Specimen A8I-12a. The quasistatic, $R=-1$ specimen (A8I-14) showed a significant decrease in both crack initiation and crack growth resistance when compared with the quasi-static, monotonic resistance. At $10 \mathrm{~mm}(0.39 \mathrm{inch})$ of crack growth, the resistance of the quasi-static, $R=-1$ specimen was 38 percent of the quasi-static, monotonic (A8I-12a) resistance.

Under dynamic, monotonic loading, Pipe DP2-A8I showed an increase in resistance as compared to quasistatic, monotonic loading. At $4 \mathrm{~mm}(0.16 \mathrm{inch})$ of crack extension, the dynamic, monotonic resistance was 18 percent higher than the quasi-static, monotonic resistance. This behavior is typical of stainless steel nuclear pipe material. The dynamic, $R=-0.3$ specimens (A8I-22 and A8I-23) showed no difference in toughness at crack initiation but did show a slight decrease in toughness after some crack extension as compared with the dynamic, monotonic experiment (A8I-9a). These trends indicate that there is no interaction between the dynamic and cyclic effects on toughness for this material. 


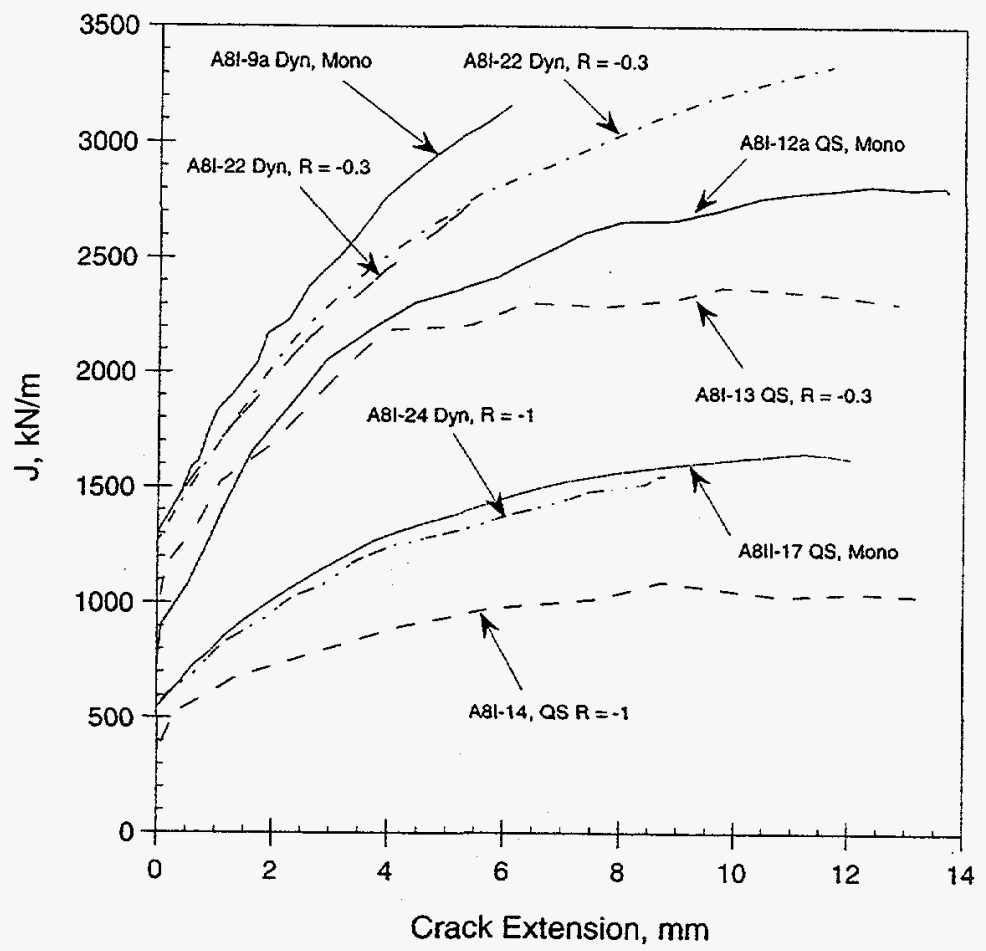

Figure 3.11 J-R curves from C(T) specimens machined from Pipe DP2-A8I

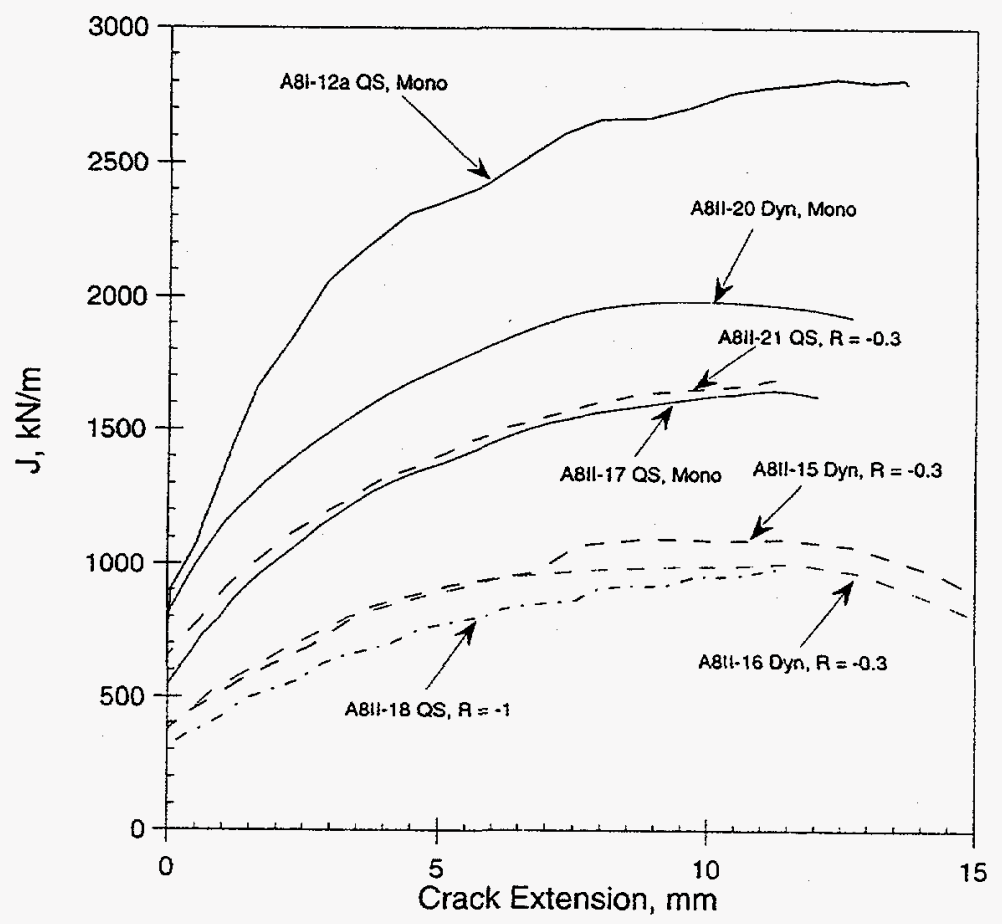

Figure 3.12 J-R curves from $C(T)$ specimens machined from Pipe DP2-A8I 
Section 3

RESOLUTION OF THE TOUGHNESS DISCREPANCY BETWEEN C(T) SPECIMEN AND SURFACE-CRACKED PIPE SPECIMEN
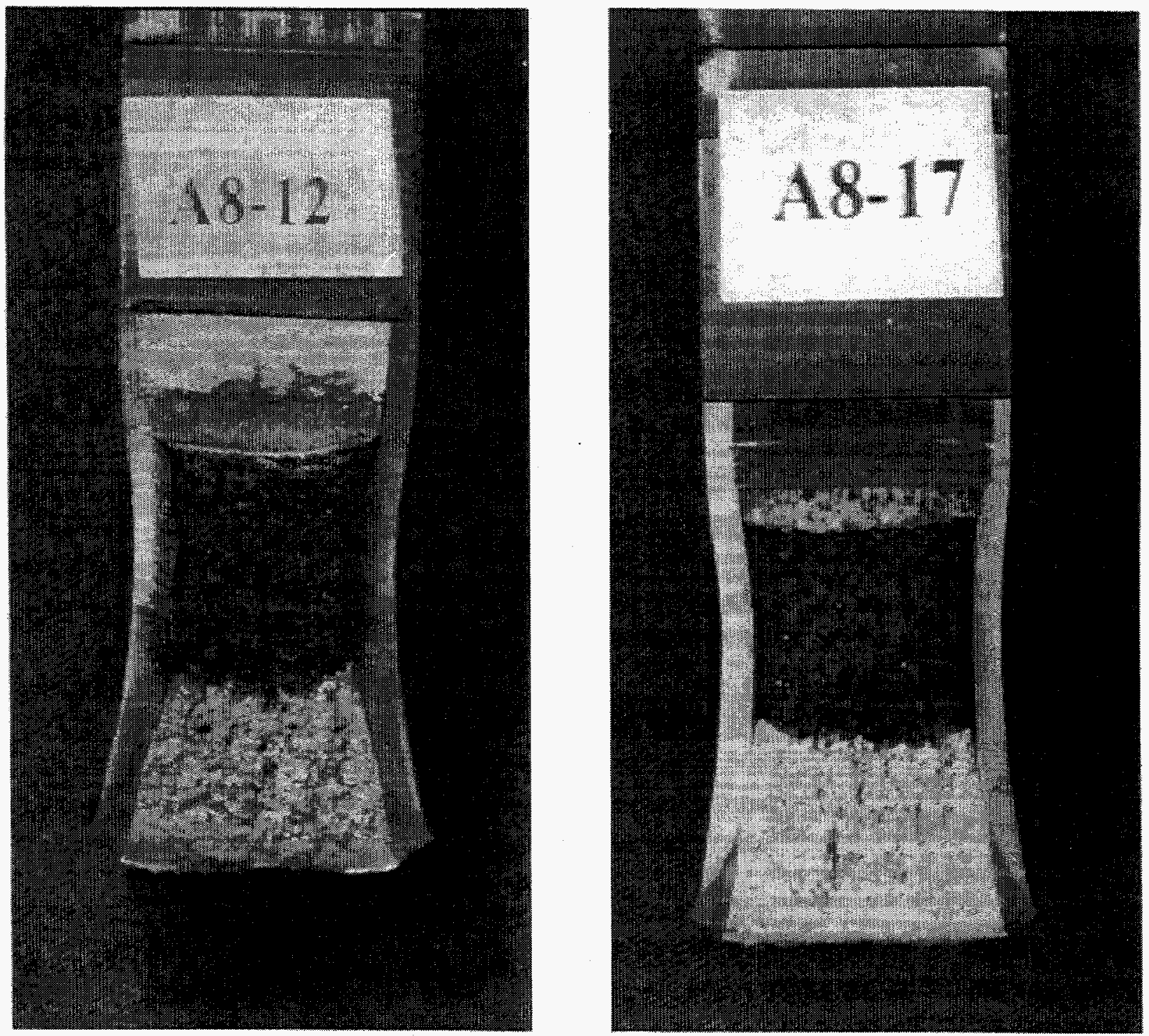

Figure 3.13 Fracture surfaces of A8I-12a and A8II-17 
Table 3.9 Fracture toughness summary

\begin{tabular}{|c|c|c|c|c|c|}
\hline \multirow{2}{*}{$\begin{array}{l}\text { Specimen } \\
\text { Identification }\end{array}$} & \multirow[b]{2}{*}{ Load History } & \multicolumn{2}{|c|}{$\mathrm{J}$ at Initiation } & \multicolumn{2}{|c|}{$\mathbf{d J} / \mathbf{d a}^{(\mathbf{a})}$} \\
\hline & & $\mathrm{kJ} / \mathrm{m}^{2}$ & lb/in & $\mathbf{M J} / \mathrm{m}^{3}$ & lb/in ${ }^{2}$ \\
\hline A8I-12a & QS, Mono & 854 & 4,876 & 481 & 69,720 \\
\hline A8I-9a & Dyn, Mono & 1,302 & 7,430 & 500 & 72,470 \\
\hline A8I-13 & $\mathrm{QS}, \mathrm{R}=-0.3$ & 952 & 5,435 & 287 & 41,600 \\
\hline A8I-14 & $\mathrm{QS}, \mathrm{R}=-1$ & 356 & 2,032 & 214 & 31,000 \\
\hline A8II-15 & Dyn, $R=-0.3$ & 395 & 2,260 & 123 & 17,840 \\
\hline A8II-16 & Dyn, $R=-0.3$ & 376 & 2,147 & 138 & 20,010 \\
\hline A8II-17 & QS, Mono & 546 & 3,118 & 255 & 37,000 \\
\hline A8II-18 & $\mathrm{QS}, \mathrm{R}=-1$ & 313 & 1,786 & 116 & 16,800 \\
\hline A8II-20 & Dyn, Mono & 815 & 4,655 & 310 & 45,000 \\
\hline A8II-21 & $\mathrm{QS}, \mathrm{R}=-0.3$ & 652 & 3,722 & 240 & 34,800 \\
\hline A8I-22 & Dyn, $R=-0.3$ & 1,297 & 7,404 & 340 & 49,300 \\
\hline A8I-23 & Dyn, $R=-0.3$ & 1,269 & 7,248 & 401 & 58,200 \\
\hline
\end{tabular}

(a) Calculated between crack extensions of $0.15 \mathrm{~mm}(0.006 \mathrm{inch})$ and $1.5 \mathrm{~mm}(0.06 \mathrm{inch})$.

From Figure 3.12, the dynamic, monotonic resistance (A8II-20) for Pipe DP2-A8II was significantly higher than the quasi-static, monotonic resistance (A8II-17). This trend was similar to the trends for Pipe DP2-A8I. However, the J-R curve for the dynamic, monotonic specimen machined from Pipe DP2-A8II was still significantly lower than the J-R curve for the quasi-static monotonic specimen machined from Pipe DP2-A8I.

The quasi-static $R=-0.3$ specimen (A8II-21) had a slightly higher $\mathrm{J}_{\mathrm{i}}$ value, but no significant difference in the J-values during crack growth, as compared with the quasi-static, monotonic specimen (A8II-17). Both of the dynamic, $R=-0.3$ specimens (A8II-15 and A8II-16), showed a significant decrease in toughness as compared with the quasi-static, monotonic (A8II-17) resistance. In Task 3 of the IPIRG-2 program (Ref. 3.9), data from quasi-static, cyclic and dynamic, cyclic $C(T)$ specimen tested at $R=-1$ suggested that there was no interaction between the dynamic and cyclic effects on toughness. In fact, a good estimation of experimental dynamic, cyclic $(R=-1)$ toughness can be made by multiplying the percent change in toughness due to dynamic, monotonic and quasi-static, cyclic $(R=-1)$ loading to the baseline quasi-static, monotonic resistance. However, this trend does not seem to be true for specimens tested at dynamic, $R=-0.3$ loading rates for material DP2-A8II. Since the dynamic, monotonic resistance showed an increase in toughness and the quasi-static $R=-0.3$ showed no change in toughness (after some crack growth) as compared with the quasi-static, monotonic resistance, the dynamic, $R=-0.3$ resistance would be slightly higher than the quasi-static, monotonic resistance if no interaction between the dynamic and cyclic effects existed. However, as shown in Figure 3.11, the dynamic, $R=-0.3 \mathrm{~J}-\mathrm{R}$ curves are considerably lower than the quasi-static, monotonic J-R curve. 
The quasi-static, $R=-1$ specimen (A8II-18) had a significantly lower value of $J$ at crack initiation as compared with the quasi-static, monotonic specimen (A8II-17). At a crack extension of $10 \mathrm{~mm}$ (0.39 inch) the J-value was 53 percent of the J-value for the quasi-static, monotonic specimen. Curiously, the resistance for the quasi-static $R=-1$ specimen was very similar to the resistance for the dynamic, $R=-0.3$ specimen. For this lot of material, even though there seemed to be some interaction between the cyclic and dynamic effects on toughness, the J-R curve from the quasi-static, $R=-1$ specimen seems to provide a reasonable lower bound on toughness. Note that even though no dynamic, $R=-1$ data exists, the quasistatic $R=-1 \mathrm{~J}-\mathrm{R}$ curve can be used as a lower bound toughness value since the typical seismic history has a more positive effective stress ratio.

Since the composition differences between the A8I and A8II specimens appear to influence the measured toughness characteristics, it is important to determine if the stress-strain behavior is also influenced. Table 3.4 also shows the chemical composition for tensile specimens A8I-39, made during the Degraded Piping Program, and A8II-105, made during the IPIRG-1 Program. Like C(T) specimens A8II-17 and AI-12a, the chemical compositions are distinctly different. However, when the tensile properties are compared, Figure 3.14 , the differences are minimal.

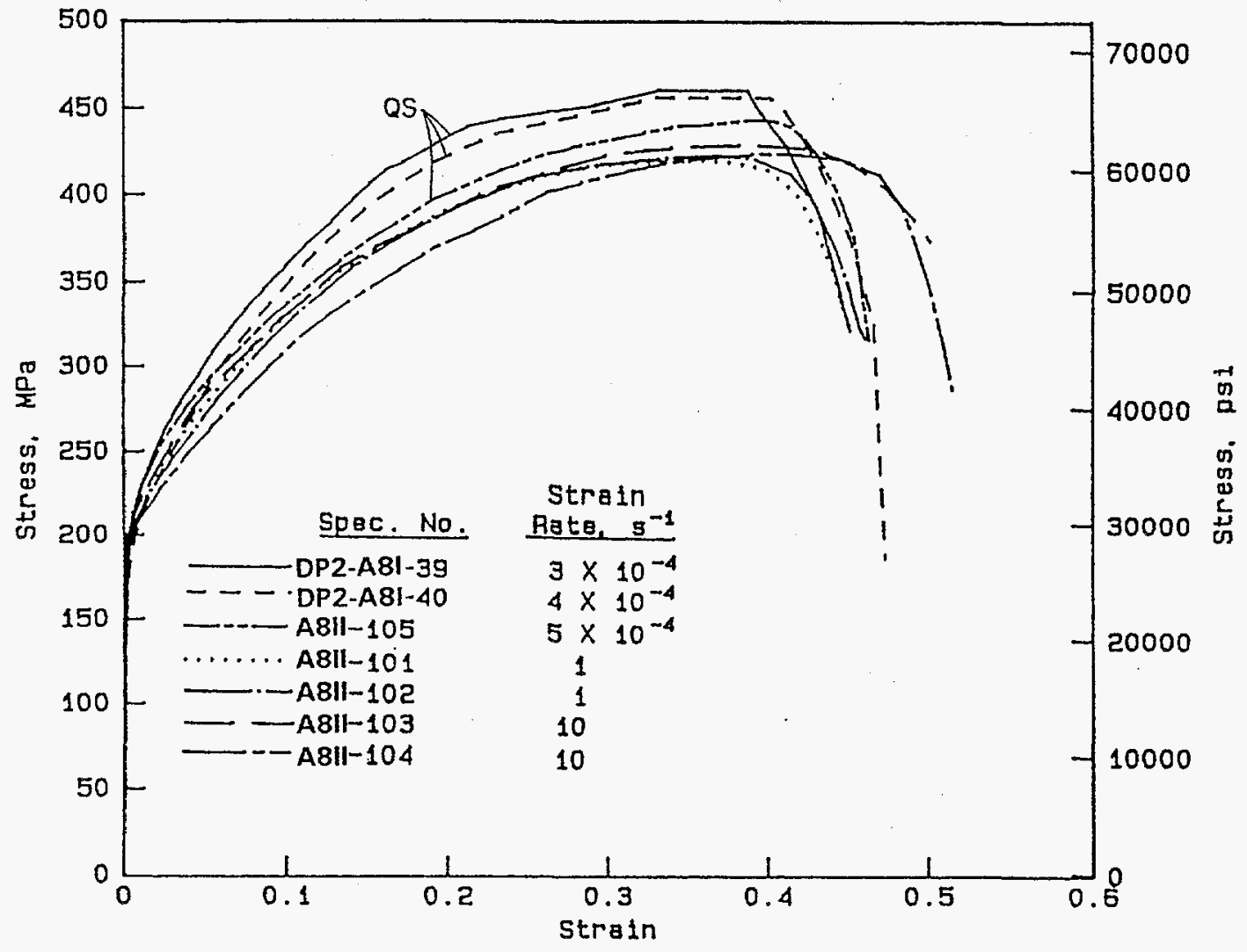

Figure 3.14 Engineering stress-strain curves at 288 C (550 F) for A358 Type 304 stainless steel pipe (DP2-A8) tested at several different strain rates 


\subsection{IPIRG-1 Experiment 1.3-3 - Revisited}

In knowing that there exists two distinctly different material behaviors within the lot of stainless steel pipe labeled DP2-A8, the results from Experiment 1.3-3 need to be reanalyzed. Both the J-R curve and the maximum stress predictions are revisited.

\subsubsection{J-R Curve From Experiment 1.3-3}

As explained in Section 3.1.1, the J-R curve calculated in Reference 3.2 for Experiment 1.3-3 was much lower than the J-R curve from the quasi-static, monotonic $C(T)$ specimen (A8I-12a). However, since these two specimens come from different heats of Pipe DP2-A8 (See Table 3.4), this comparison is not valid. Figure 3.15 shows a comparison of J-R curves from the various specimens taken from DP2-A8II. Specimen A8I-12a is also shown in this figure for comparison purposes. This figure shows that the SEN(T) specimens have J-R curves that are very similar to the J-R curve from Experiment 1.3-3,

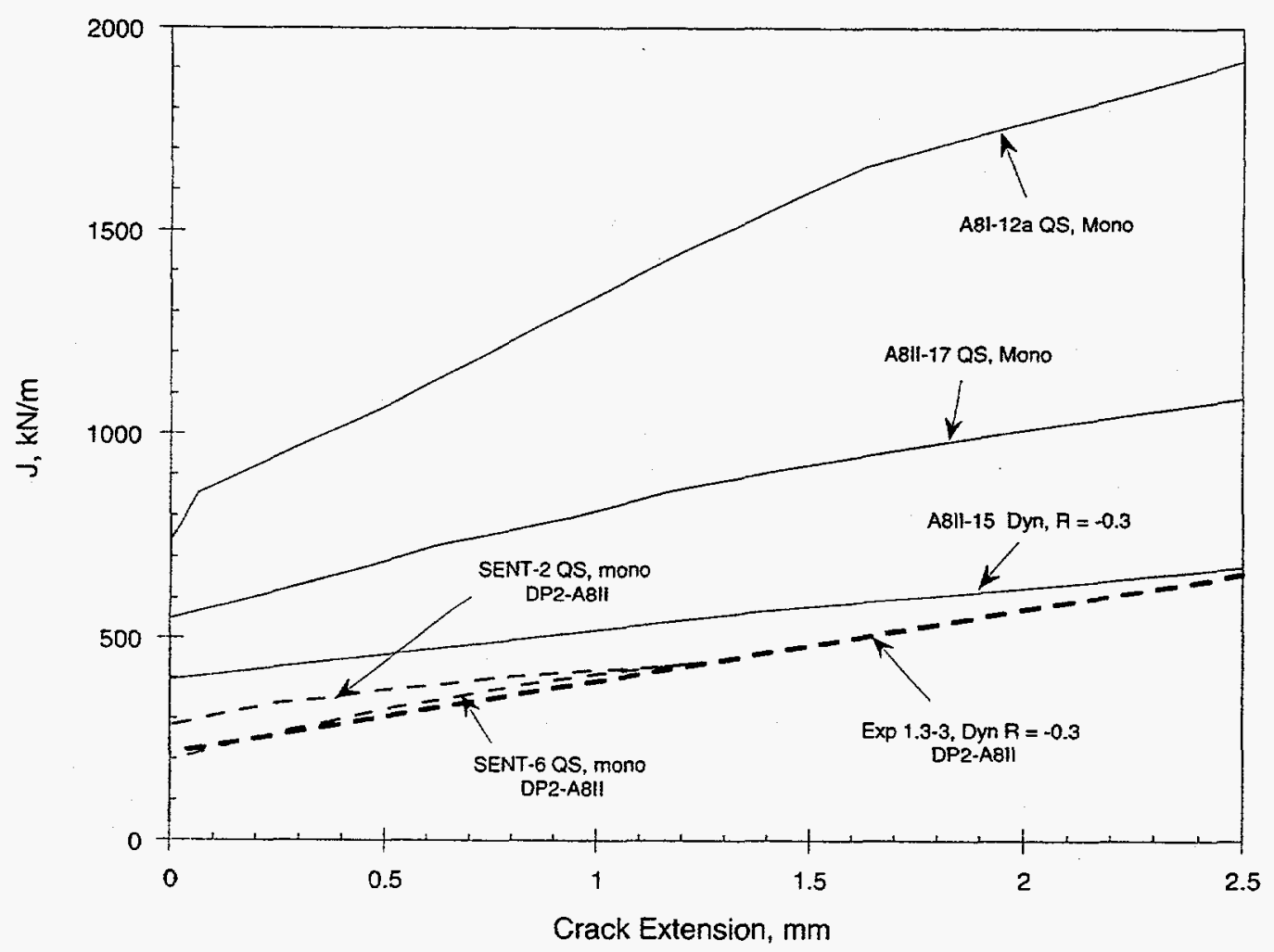

Figure 3.15 Several J-R curves for comparison with Experiment 1.3-3 
indicating that the SEN(T) specimen has a closer representation of the constraint conditions in a surfacecracked pipe than the $C(T)$ specimen. Note that no SEN(T) specimens were conducted with a dynamic, cyclic load history. Also, the SEN(T) J-R curves shown are from the plane-stress finite element analysis and not the Ahmad J-estimation scheme analysis. Even though no dynamic, cyclic SEN(T) specimens were conducted, the dynamic, cyclic $(R=-0.3) C(T)$ results show a substantial decrease in toughness as compared to the quasi-static, monotonic $\mathrm{C}(\mathrm{T})$ results.

Therefore, since Experiment $1.3-3$ was a dynamic, $R=-0.2$ experiment, the $\mathrm{J}-\mathrm{R}$ curve calculated from this experiment would be expected to be below the quasi-static, monotonic J-R curves (SENT-2 and SENT-6) However, the crack depth for Specimen SENT-6 $(a / t=0.72)$ is somewhat deeper than the crack depth for Pipe Experiment 1.3-3 $(\mathrm{a} / \mathrm{t}=0.66)$. Since an $\mathrm{SEN}(\mathrm{T})$ specimen conducted with an $\mathrm{a} / \mathrm{t}=\mathbf{0 . 6 6}$ and with dynamic, $R=-0.3$ loading rates was not conducted, a precise $J-R$ curve comparison between the $S E N(T)$ and $\mathrm{SC}$ pipe specimens is difficult to make.

Taking into account the effects of constraint, dynamic-cyclic loading, and the material property variations between heats of DP2-A8, the J-R curve calculated in Reference 3.2 for Experiment 1.3-3 is reasonable for its geometry and loading history. From the evidence presented, it can be assumed that an SEN(T) specimen tested under dynamic, $R=-0.3$ loading conditions would produce a $J-R$ curve similar to the ane calculated for Experiment 1.3-3.

\subsubsection{Predictions of Maximum Experimental Stress}

Since it has been determined that there exists two distinctly different chemical compositions and toughness properties for Pipe DP2-A8, the correct material properties should be used in predicting the response of Experiment 1.3-3. When the dynamic, monotonic C(T) (A8I-9a) J-R curve was used to analyze IPIRG-1 Experiment 1.3-3, the fracture ratios were much lower than the average fracture ratios from NUREG/CR6298 (see Section 3.1.2). Unlike the simulated-seismic history of IPIRG-2 Pipe Experiment 1-1, the single-frequency load history of Pipe Experiment 1.3-3 had much more plasticity in the cycles prior to maximum moment. Therefore, at the time that these analyses were conducted, it was concluded that cyclic effects were causing a reduction in the fracture ratio. In light of the fracture toughness differences between Pipes A8I and A8II, however, it is more appropriate to analyze Experiment 1.3-3 using the new pipe A8II properties.

Experiment 1.3-3 was a dynamic pipe-system experiment and it had a significant number of plastic loaded cycles prior to maximum moment. Taking into account the dynamic, cyclic effects discussed in the preceding section, the optimum J-R curve to use should be a dynamic, cyclic one. Analyzing Experiment 1.3-3 $(R=-0.2)$ using specimen A8II-15 (dynamic, $R=-0.3, C_{3}=153.79 \mathrm{~kJ} / \mathrm{m}^{2}, \mathrm{~m}=0.721$ ), the fracture ratios fall very close to the NUREG/CR-6298 averages (Ref. 3.7), see Table 3.10.

These results indicate that in order to make accurate maximum stress predictions for this pipe material, the $\mathrm{J}-\mathrm{R}$ curve used in the analysis must come from a specimen whose loading history closely matches that of the pipe-system experiment. 
Table 3.10 J-estimation scheme analyses of IPIRG pipe system experiments that used DP2-A8 specimens

\begin{tabular}{lllllcccc}
\hline & & & & \multicolumn{4}{c}{ Experiment/Predicted Maximum Stresses } \\
\cline { 6 - 8 } Experiment & $\begin{array}{l}\text { Pipe Test } \\
\text { Conditions }\end{array}$ & $\begin{array}{l}\text { C(T) } \\
\text { Specimen }\end{array}$ & $\begin{array}{l}\text { C(T) Test } \\
\text { Condition }\end{array}$ & SC.TNP1 & SC.TNP2 & SC.ENG1 & SC.ENG2 \\
\hline $1.3-3$ & $\begin{array}{l}\text { Single } \\
\text { frequency }\end{array}$ & A8I-9a & Dyn, mono & 0.816 & 1.066 & 1.055 & 1.225 \\
$1.3-3$ & $\begin{array}{l}\text { Single } \\
\text { frequency }\end{array}$ & A8II-15 & Dyn, R=0.3 & 1.039 & 1.397 & 1.383 & 1.620 \\
$1-1$ & $\begin{array}{l}\text { Sim. } \\
\text { Seismic }\end{array}$ & A81-9 & Dyn, mono & 0.999 & 1.291 & 1.222 & 1.403 \\
$\begin{array}{l}\text { Average of 16 pipe } \\
\text { tests from } \\
\text { NUREG/CR-6298 }\end{array}$ & -- & - & -- & 1.100 & 1.410 & 1.390 & 1.650 \\
\hline
\end{tabular}

\subsection{References}

3.1 Scott, P., and others, "The IPIRG-1 Pipe System Fracture Tests: Experimental Results," PVP Vol. 280, pp 135-151, June 1994.

3.2 Olson, R., Scott, P., Marschall, C., and Wilkowski, G., "Comparison of Fracture Toughness Values from an IPIRG-1 Large-Scale Pipe System Test and C(T) Specimens on Wrought TP304 Stainless Steel," ASME PVP, Vol. 280, pp 241-254, June 1994.

3.3 Kanninen, M.F., and others, "Mechanical Fracture Predictions for Sensitized Stainless Steel Piping with Circumferential Cracks," Final Report, EPRI NP-192, September 1976.

3.4 Wilkowski, G.M., and Scott, P.M., "A Statistical Based Circumferentially Cracked Pipe Fracture Mechanics Analysis for Design or Code Implementation," Nuclear Engineering and Design, Vol. 111, pp 173-187, 1989.

3.5 Scott, P., and Ahmad, J., "Experimental and Analytical Assessment of Circumferentially SurfaceCracked Pipes Under Bonding," NUREG/CR-4872, April 1987.

3.6 Krishnaswamy, P., and others, "Fracture Behavior of Short Circumferentially Surface-Cracked Pipe," NUREG/CR-6298, November 1995.

3.7 Scott, P., and others, "IPIRG-2 Task 1 - Pipe System Experiments with Circumferential Cracks in Straight Pipe Locations," NUREG/CR-6389, January 1997. 
3.8 Wilkowski, G., Ahmad, J., Barnes, C., Broek, D., Kramer, G., Landow, M., Marschall, C., Maxey, W., Nakagaki, M., Scott, P., Papaspyropoulous, V., Pasupathi, V., and Popelar, C., "Degraded Piping Program - Phase II Semiannual Report March 1984-September 1984," NUREG/CR-4082, BMI 2120, Vol. 1, January 1985.

3.9 Rudland, D., Brust, F., and Wilkowski, G., "The Effect of Cyclic and Dynamic Loading on the Fracture Resistance of Nuclear Piping Steels," NUREG/CR-6440, BMI-2190, December 1996.

3.10 Ahmad, J., Papaspyropoulos, V., and Hopper, A.T., "Elastic-Plastic Analysis of Edge-Notched Panels Subjected to Fixed Grip Loading," Engineering Fracture Mechanics, Vol. 38, No. 4/5, pp 283-294, 1991.

3.11 Scott, P., Kramer, G., Vieth, P., Francini, R., and Wilkowski, G., "The Effect of Dynamic and Cyclic Loading During Ductile Tearing on Circumferentially Cracked Pipe -- Experimental Results," ASME PVP, Vol. 280, pp 207-220, June 1994. 


\subsection{DISCUSSION OF RESULTS}

This section discusses the technical results presented in this report. First, the results from the material characterization study, which addresses the different chemical compositions, and fracture toughness tests from the two heats of DP2-A8, are discussed. Second, the results from the SEN(T) experiments which addresses the effect of constraint on the results from Experiment 1.3-3 are discussed. Finally, the results from the $C(T)$ experiments, which addresses the dynamic, cyclic effects on toughness are discussed. At the end of each section, the technical implications of the results as they pertain to past pipe experiments, and ASME Code procedures are discussed.

\subsection{Material Property Results}

In this investigation, a series of chemical analyses was performed to help explain the differences in fracture toughness values observed between a standard $C(T)$ specimen and a $S C$ pipe specimen, both machined from Pipe DP2-A8. It was found that Pipe DP2-A8 had two distinct chemical compositions that consistently group together based on manganese, sulphur, silicon, nickel, and chromium content. Table 4.1 shows the average chemical composition of each heat of DP2-A8 as well as the ASTM specification maximums.

Table 4.1 Average chemical compositions for Pipe DP2-A8

\begin{tabular}{cccc}
\hline & DP2-A8I & DP2-A8I & $\begin{array}{c}\text { ASTM } \\
\text { Spec. (max) }\end{array}$ \\
\hline $\mathrm{C}$ & 0.055 & 0.043 & 0.08 \\
$\mathrm{Mn}$ & 1.37 & 1.78 & 2.00 \\
$\mathrm{P}$ & 0.022 & 0.022 & 0.045 \\
$\mathrm{~S}$ & 0.002 & 0.019 & 0.030 \\
$\mathrm{Si}$ & 0.62 & 0.34 & 0.75 \\
$\mathrm{Ni}$ & 8.00 & 8.92 & $8-12$ \\
$\mathrm{Cr}$ & 17.99 & 18.57 & $18-20$ \\
$\mathrm{Mo}$ & 0.18 & 0.28 & - \\
$\mathrm{Ti}$ & $<0.01$ & $<0.01$ & - \\
$\mathrm{Cb}$ & $<0.05$ & $<0.05$ & - \\
$\mathrm{Cu}$ & 0.09 & 0.31 & - \\
\hline
\end{tabular}


The two heats of DP2-A8 had distinctly different fracture toughness, but similar stress-strain behaviors. Table 4.2 shows a summary of tensile and fracture toughness properties for each heat of DP2-A8. All the data shown in Table 4.2 are taken from quasi-static, monotonic experiments.

Table 4.2 Tensile and fracture toughness summary for Pipe DP2-A8

\begin{tabular}{|c|c|c|c|c|c|c|c|c|c|c|}
\hline \multirow[b]{2}{*}{ Heat } & \multicolumn{5}{|c|}{ Stress-strain Data } & \multirow[b]{2}{*}{$\begin{array}{l}\text { Specimen } \\
\text { ID }\end{array}$} & \multicolumn{3}{|c|}{ J-R Curve Data ${ }^{(a)}$} & \multirow[b]{2}{*}{$\begin{array}{l}\text { Specimen } \\
\text { ID }\end{array}$} \\
\hline & $\begin{array}{c}\sigma_{y}, \\
\mathrm{MPa}\end{array}$ & $\begin{array}{c}\sigma_{\mathrm{w}} \\
\mathrm{MPa}\end{array}$ & $\epsilon_{0}$ & $\alpha$ & $\mathrm{n}$ & & $\begin{array}{c}\mathbf{J}_{\mathrm{i}}, \\
\mathrm{kJ} / \mathrm{m}^{2}\end{array}$ & $\begin{array}{c}\mathrm{C}_{3} \\
\mathrm{~kJ} / \mathrm{m}^{2}\end{array}$ & $\mathrm{~m}$ & \\
\hline DP2-A8I & 171 & 456 & 0.00936 & 5.34 & 4.17 & A8I-40 & 854 & 452 & 0.769 & A8I-12a \\
\hline DP2-A8II & 200 & 443 & 0.00967 & 6.48 & 5.10 & A811-105 & 546 & 300 & 0.615 & A8II-17 \\
\hline
\end{tabular}

(a) Where $\mathrm{J}=\mathrm{J}_{\mathrm{i}}+\mathrm{C}_{3}(\Delta \mathrm{a} / \mathrm{r})^{\mathrm{m}}$, where $\mathrm{r}=1 \mathrm{~mm}$.

Table 4.2 shows only a small change in tensile properties between DP2-A8I and DP2-A8II. The ultimate strength for Pipe DP2-A8I was 3 percent higher and the yield strength was 14 percent lower then the strengths for Pipe DP2-A8II. The largest difference in the material properties was in the toughness. The J value at crack initiation $\left(\mathrm{J}_{\mathrm{i}}\right.$ ) for Pipe DP2-A8II was 36 percent less than the $\mathrm{J}_{\mathrm{i}}$ value for Pipe DP2-A8I. Also, the $\mathrm{dJ} / \mathrm{da}$ value for Pipe DP2-A8II was 45 percent lower than the $\mathrm{dJ} / \mathrm{da}$ value for Pipe DP2-A8I. Clearly, the toughness of the two heats of DP2-A8 are very different, which will have implications to both past pipe test analyses and future ASME Section XI and Leak-Before-Break calculations, as discussed next.

\subsubsection{Implications to Past Pipe Test Data}

Pipe DP2-A8 has been used in Battelle pipe tests since the early 1980 's. The results from this investigation not only affect the numerous data record books written for tests using Pipe DP2-A8, but also the circumferentially-cracked pipe database (CIRCUMCK), and the material property database (PIFRAC). The pipe experiments and the material characterization specimens are grouped by heat number in Table 4.3. A complete listing of DP2-A8 specimens can be found in Appendix B.

To assess the impact of A8I versus A8II materials, a series of sensitivity analyses was performed which was aimed at determining the difference in moment predictions when using the different DP2-A8 material properties in the same analyses. In this evaluation, both through-wall-cracked and surface-cracked pipe were investigated. The through-wall crack investigated was 20 percent of the circumference in length for an unpressurized pipe with an $R_{m} / t=5$. This crack length tends to give a maximum difference between limit load and an elastic-plastic fracture mechanics (EPFM) result, i.e., the EPFM/limit load ratio is minimized. The surface-crack investigated was 50 percent of the circumference in length with an a/t $=0.5$, for an unpressurized pipe with an $R_{m} / t=5$. Past work (Ref. 4.1) has shown that normalizing the EPFM to limit-load values for surface cracks gives essentially the same result for any surface crack geometry. Hence, the normalized results in Figure 4.1 are probably valid for any surface crack depth and length combination. Both sets of material properties shown in Table 4.2 was used in the analyses, i.e., the quasistatic J-R curves for the low and higher toughness stainless steels (no cyclic or dynamic effects are 
Table 4.3 Specimen listing by heat of Pipe DP2-A8

\begin{tabular}{|c|c|c|c|}
\hline \multicolumn{2}{|l|}{ DP2-A8I } & \multicolumn{2}{|l|}{ DP2-A8II } \\
\hline Specimen ID & $\begin{array}{c}\text { Specimen } \\
\text { Type }\end{array}$ & Specimen ID & $\begin{array}{l}\text { Specimen } \\
\text { Type }\end{array}$ \\
\hline Experiment 1-1 & $\mathrm{SC}$ pipe & Experiment 1.3-3 & SC pipe \\
\hline A $8-35,-36,-37,-38,-39,-40$ & Tensile & A8-101, $-102,-103,-104,-105$ & Tensile \\
\hline $\begin{array}{l}\text { A8-9a, }-10 a,-11 a,-12 a,-13,-14 \\
-22,-23\end{array}$ & $\mathrm{C}(\mathrm{T})$ & SENT-2, $-3,-4,-5,-6$ & $\operatorname{SEN}(T)$ \\
\hline A $8-41,-42,-43,-44,-47,-48,-49$, & $\mathrm{C}(\mathrm{T})$ & A8-15, $-16,-17-18,-20,-21$, & $\mathrm{C}(\mathrm{T})$ \\
\hline$A 8-52,-54,-55,-56,-57$ & $\mathrm{C}(\mathrm{T})$ & & \\
\hline A $8-71,-72$ & $\mathrm{C}(\mathrm{T})$ & & \\
\hline
\end{tabular}

considered in this comparison). The LBB.ENG2 (Ref. 4.2) J-estimation scheme method was used to analyze the through-wall-cracked pipe, while the SC.TNP1 (Ref. 4.3) J-estimation scheme method was used to analyze the surface-cracked pipe. These two.J-estimation schemes were found to be the most accurate of all methods when compared with experimental results (Refs. 4.2 and 4.3).

The results of these analyses are shown in Figure 4.1. $\mathrm{M}_{\text {EPFM (at max load) }}$ is the maximum moment calculated from either the LBB.ENG2 (TWC) or SC.TNP1 (SC) analyses. $M_{\mathrm{NSC}}$ is the limit-load solution using the original Net-Section-Collapse solution (Ref. 4.4). (The inverse of $\mathrm{M}_{\mathrm{EPFM}} / \mathrm{M}_{\mathrm{NSC}}$ is essentially the Z-factor used in ASME Section XI pipe flaw analyses.)

The results of these calculations show that there is a slight diameter dependancy on the ratio of the EPFM to limit-load failure stresses. In general, the surface-cracked pipe curves are above the through-wallcracked pipe curves. This is a general trend seen previously in experimental data as well (Ref. 4.3).

For the high toughness stainless steel pipe (DP2-A8I), the surface-crack curve is above or within 10 percent of the limit-load solution (i.e., EPFM/NSC $=1.0$ ) for pipe diameters of practical size. Since experimental results may scatter about 10 percent, a difference of 10 percent from limit-load is not considered significant. Hence, the current assumption of limit-load analyses being applicable to stainless steel pipes is valid in this case. For the lower toughness stainless steel pipe (DP2-A8II), the surface-crack curve went significantly below the ratio of 0.9 (more than 10 percent difference from the limit-load solution) for pipe diameters of practical interest.

For the through-wall-cracked pipe case, the low toughness curve (DP2-A8II) is significantly below limit load for all pipe diameters, and the high toughness curve (DP2-A8I) is below limit load for larger diameter pipe. 
Pipe Diameter, inch

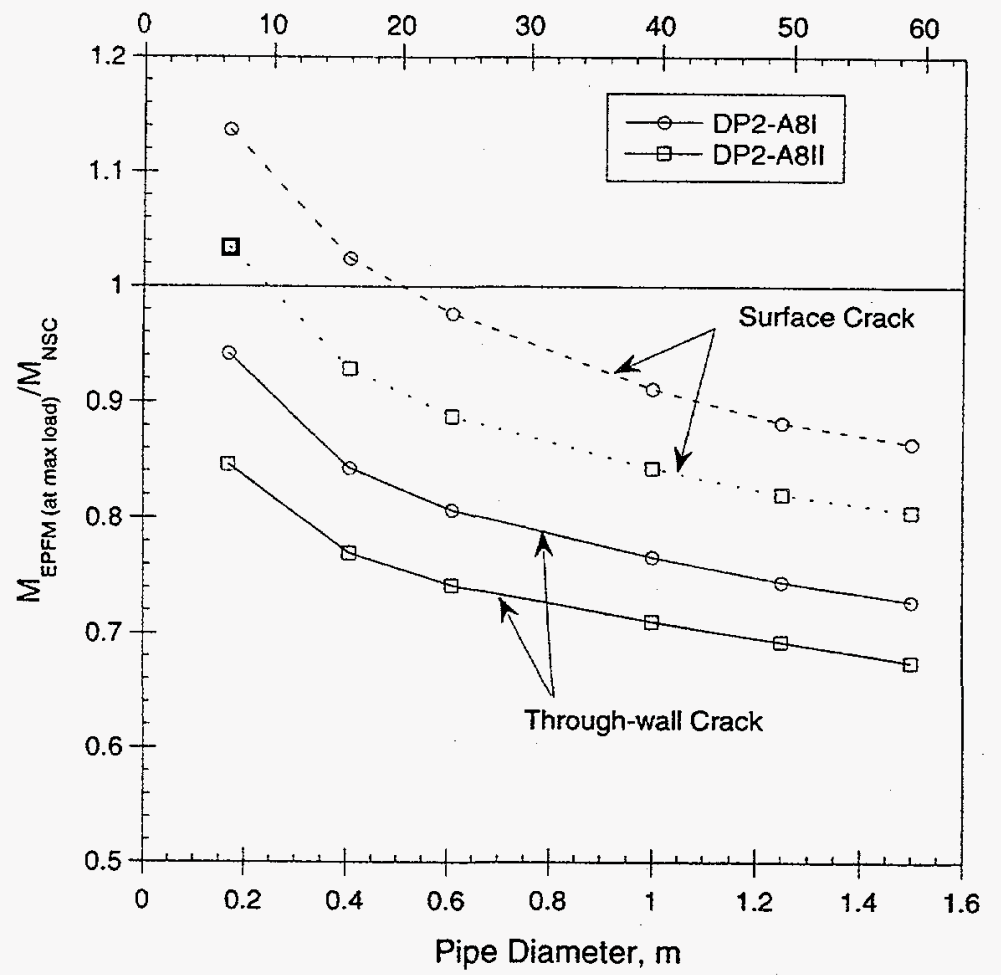

Figure 4.1 Sensitivity analyses using DP2-A8I and DP2-A8I material properties

\subsubsection{Implications to ASME Section XI and LBB}

The significance of these results is that they imply that some stainless steel base metals may have maximum loads that are below the limit-load solution for both the surface-crack and through-wall cracked pipe cases. The results in this report imply that the ASME Section XI Appendix C approach for stainless steel base metals should be reconsidered, and perhaps a Z-factor is needed for some stainless steel base metals. Note: the effect of dynamic and cyclic load effects were not considered in this evaluation. Dynamic loading can increase the toughness of austenitic materials (depending on the yield to ultimate strength ratio), but the cyclic loading (depending on many parameters) can decrease the toughness.

Similarly, NRC Draft Standard Review Plan 3.6.3 for LBB also assumes that stainless steel base metal would fail at limit-load conditions, which Figure 4.1 shows is not necessarily true even for the high toughness pipe (DP2-A8I) if the diameter is greater than $600 \mathrm{~mm}$ (24 inches).

From discussions with experienced metallurgists, the problem here lies in the fact that the steel industry is quite capable of making higher toughness stainless steel, but the ASTM standards on chemical composition requirements have not kept up with the capabilities of the industry. Such standards are consensus standards, and with steel fabricators on the committees, they may be difficult to change. Hence, if there is the occasional heat of stainless steel with chemical compositions close to the current ASTM limits, that heat will not be rejected even though the sulphur content may be 15 times larger than the typical heat sulphur level. An alternative is for the fabricator of a new plant to make a supplemental requirement on the chemical composition of the steel being purchased. Prior to making any code or 
regulatory requirement changes, a further study of the variability of chemical compositions of stainless steel and correlations with toughness (using existing data if possible) is advisable. It is also possible to take an existing heat of stainless steel and systematically vary the sulphur and other impurities, conduct the appropriate toughness tests on these laboratory heats, and determine the optimum composition limits.

\subsection{Constraint Effects on Toughness}

A series of single-edge-notched tensile specimens were conducted to determine the whether this geometry could be used to predict the surface-cracked pipe response. Both monotonic and cyclic experiments were conducted, but only quasi-static loading rates were used. All SEN(T) specimens were machined from Pipe DP2-A8II. The experimental results showed that at a stress ratio of -1 the specimen experienced less plasticity than a similar specimen tested with monotonic loading. However, there was a minimal difference between the specimen tested at $R=-0.3$ and the one tested with monotonic loading, indicating that at $R=-0.3$, the effects of cyclic loads on the load-carrying capacity were minimal.

An estimate of the J-integral for this specimen geometry was made using two methods, i.e., the finite element method and the Ahmad J-estimation scheme method (Ref. 3.10). Even though the finite element method made good predictions of the experimental loads, the $J$ values calculated were a factor of approximately 2 lower than the J values calculated from the Ahmad scheme for the monotonic experiments. In Reference 3.10, the authors performed two finite element analyses to verify their estimation scheme. They used two carbon steel SEN(T) specimens with a crack depths of 50 percent of the wall thickness. As stated in Reference 3.10, each of the experiments used in the comparison of J values exhibited gross section yielding before crack initiation. It is possible that the difference in constraint between an SEN(T) specimen with an $\mathrm{a} / \mathrm{t}=0.5$ and one with an $\mathrm{a} / \mathrm{t}=0.7$ could cause errors in the estimates of J. The authors of Reference 3.10 did not include high toughness materials or deep flawed specimens in their comparisons. Therefore, the results in this study indicate that the Ahmad J-estimation scheme may need to be revised for deeply flawed SEN(T) specimens made from higher toughness materials.

If the $J$ values calculated for the SEN(T) specimens from the finite element analyses are compared with the $\mathrm{J}$ values calculated for Experiment 1.3-3, an observation on the constraint of radially growing flaws can be made. For this geometry, the calculated J values are dependent on the depth of the surface flaw. The results show that the deeper the flaw, the lower the $J$ values at crack initiation. Curiously, the $J_{i}$ value for Experiment 1.3-3 (dynamic, cyclic with $a / t=0.66$ ) was similar to the $J_{i}$ value for Specimen SENT-6 (quasi-static, monotonic with $a / t=0.72$ ). Even during crack growth, the J-R curve for Experiment 1.3-3 was similar to the J-R curve for Specimen SENT-6. This fact indicates that the dynamic, cyclic loading may be affecting the toughness in Experiment 1.3-3. This topic is discussed in Section 4.3.

\subsubsection{Technical Implications}

In this investigation, the SEN(T) specimen gave a better prediction of the J-value in a surface-cracked pipe than the standard C(T) specimen. The difference is that the SEN(T) specimen has approximately the same crack tip constraint as a surface-cracked pipe, which is less severe than the constraint from a $C(T)$ test. Therefore, a $\mathrm{C}(\mathrm{T})$ specimen will produce an overestimate of the fracture response in a surface-cracked pipe. 
However, at this point, the reliability of the J-estimation scheme developed by Ahmad for use with fixed gripped SEN(T) specimens has not been proven for all materials and crack geometries. Therefore, the usefulness of using the SEN(T) geometry is limited since the expense of running a detailed finite element analysis for each SEN(T) experiment conducted would be unreasonable. Modifications to the current Ahmad J-estimation scheme would have to be made before the SEN(T) specimen could be used in predicting pipe response with any reliability.

\subsection{Dynamic and Cyclic Effects on Toughness}

The effects of loading history on Pipe DP2-A8 was investigated by performing a series of compact tension experiments. Table 4.4 shows the variety of loading histories used on compact tension specimens machined from Pipe DP2-A8.

Table 4.4 Compact tension specimen loading histories

\begin{tabular}{lll}
\hline & \multicolumn{2}{c}{ Specimen Numbers } \\
\cline { 2 - 3 } Load History & Pipe DP2-A8I & Pipe DP2-A8II \\
\hline $\begin{array}{l}\text { Quasi-static, } \\
\text { Monotonic }\end{array}$ & A8I-12a ${ }^{\text {(a) }}$ & A8II-17 \\
Dynamic, Monotonic & A8I-9a ${ }^{(a)}$ & A8II-20 \\
Quasi-static, $R=-0.3$ & A8I-13 & A8II-21 \\
Quasi-static, $R=-1$ & A8I-14 & A8II-18 \\
Dynamic, $R=-0.3$ & A8I-22, A8I-23 & A8II-15, A8II-16 \\
\hline
\end{tabular}

(a) Tested in IPIRG-1.

\subsubsection{Pipe DP2-A8I}

The results from the experiments conducted from Pipe DP2-A8I indicate that the toughness (at both crack initiation and during crack growth) due to dynamic, monotonic loading is higher than the toughness due to quasi-static, monotonic loading. In fact, at $5 \mathrm{~mm}(0.20 \mathrm{inch})$ of crack growth, the dynamic resistance was 33 percent higher than the quasi-static resistance. This trend is typical of austenitic steels tested at these temperatures. In Task 3 of the IPIRG-2 program (Ref. 4.5), the effect of dynamic loading on the toughness was shown to be linearly related to the materials yield-to-ultimate ratio. For the stainless steel materials tested in that investigation, dynamic loading always increased in toughness as compared with quasi-static loading.

Results on this pipe material also indicate that cycling the specimens at $R=-0.3$ at quasi-static loading rates does not change the resistance substantially up to $5 \mathrm{~mm}(0.02 \mathrm{inch})$ of crack extension as compared 
with quasi-static, monotonic loading. However, after $5 \mathrm{~mm}(0.02 \mathrm{inch})$ of crack extension, the resistance for the $\mathrm{R}=-0.3$ loading was slightly lower than the quasi-static, monotonic loading. This result is similar to the results in Task 3 of the IPIRG-2 program (Ref. 4.5). The stainless steel tested in that program (DP2-A23, 6-inch nominal diameter, TP304) showed a minimal decrease in resistance at $R=-0.3$ as compared with monotonic loading. However, the lower toughness carbon steel (DP2-F30) tested in that investigation showed some toughness degradation at a stress ratio of -0.3 . It was concluded that the amount of toughness degradation is related to the materials quasi-static, monotonic resistance. Since the quasi-static, monotonic toughness the DP2-A8I material is 25 percent lower than the DP2-A23 and nine times higher than the DP2-F30 toughness, it can be assumed that the cyclic behavior would be similar to the behavior of the DP2-A23. Results from Reference 4.5 also indicated that there was no interaction between the cyclic and dynamic effects on toughness. In fact, it was shown that the effects were multiplicative, i.e., an estimate of the dynamic, cyclic toughness could be made by multiplying the percent change in toughness due to cyclic and dynamic effects by the quasi-static, monotonic resistance. This trend seems to be valid for material DP2-A8I. The dynamic, $R=-0.3$ specimen showed only a slight decrease in resistance as compared with the dynamic, monotonic specimen. This behavior was similar to the quasi-static, $R=-0.3$ specimen which showed a slight decrease in toughness (after some crack growth) as compared with the quasi-static, monotonic resistance.

At quasi-static $R=-1$ loading rates, the resistance at both crack initiation and during crack growth was substantially lower than the quasi-static, monotonic resistance. At $5 \mathrm{~mm}(0.20$ inches) of crack extension, the cyclic resistance was 33 percent of the monotonic resistance. Again these trends are similar to the trends observed in the materials tested in Task 3 of the IPIRG-2 program (Ref. 4.5).

\subsubsection{Pipe DP2-A8II}

Results from the specimens machined from Pipe DP2-A8II indicate that the quasi-static, monotonic resistance (at $5 \mathrm{~mm}$ ( 0.20 inches) of crack extension) is approximately 55 percent of the quasi-static, monotonic resistance for Pipe DP2-A8I. As was the case for the DP2-A8I material, dynamic loading increased the resistance at both crack initiation and crack growth as compared with quasi-static loading. For this material, dynamic loading increased the resistance (at $5 \mathrm{~mm}$ [ 0.20 inches]) of crack extension) by 40 percent as compared with quasi-static loading. Note that this increase in resistance is similar to that observed in the DP2-A8I material.

Loading the specimen with quasi-static rates at $\mathrm{R}=-\mathbf{0 . 3}$ did not significantly change the resistance as compared with the quasi-static, monotonically loaded specimen. The J values at crack initiation and during crack growth were slightly higher than the $J$ values during quasi-static, monotonic loading. However, at quasi-static, $\mathrm{R}=-1$ loading, the resistance was much lower than the quasi-static, monotonic loading, which again is similar to that observed in the DP2-A8I material.

Results from the dynamic, cyclic $(R=-0.3)$ experiments conducted on this material indicate that the resistance at both crack initiation and during crack growth was decreased as compared with both the quasistatic, and dynamic monotonic resistances. Reference 4.5 demonstrates that for specimens tested at $R=-1$, there was no interaction between the dynamic and cyclic effects on fracture. The resistance of the dynamic, cyclic $(R=-1)$ toughness at a certain amount of crack extension was estimated (with good accuracy) by multiplying the percent change in the quasi-static, monotonic resistance due to quasi-static, cyclic and dynamic, monotonic loading by the quasi-static, monotonic resistance. However, this trend does 
not seem to be valid for $A 8 I I$ specimens tested at $R=-0.3$. The amount of interaction between cyclic and dynamic effects on toughness may be related to the materials quasi-static monotonic toughness. As described in Reference 4.5, the lower toughness A106 Grade B carbon steel was more affected by intermediate stress ratio loading than the higher toughness TP304 stainless steel tested. It is possible that this lower toughness stainless steel, DP2-A8II, may show an interaction that may not be present in the higher toughness stainless steel, DP2-A81. However, a detailed study of this interaction is beyond the scope of this investigation.

\subsubsection{Predictions of Maximum Experimental Stress}

Maximum experimental stress predictions were made for IPIRG-1 Experiment 1.3-3 and IPIRG-2 Experiment 1-1. The simulated-seismic forcing function used in Experiment 1-1 produced a response of mainly elastic cycles and one large plastic cycle up to maximum moment, which could be analyzed as a dynamic, monotonic experiment. Therefore, this experiment was analyzed using the results from a dynamic, monotonic $C(T)$ specimen that was made from the same heat of material as the pipe experiment (DP2-A8I). The fracture ratios calculated from these analyses compared very closely with the average fracture ratio values from a series of pipe tests conducted in the Short Cracks in Piping and Piping Weld program (Ref. 4.1).

However, since Experiment 1.3-3 was a dynamic, cyclic experiment with many plastic cycles at a stress ratio of -0.2 , the dynamic cyclic $(R=-0.3)$ toughness from the $C(T)$ experiment was used in predicting the response of Experiment 1.3-3. The fracture ratios calculated from these analyses compared very closely with the average fracture ratio found in Reference 4.1 .

\subsubsection{Technical Implications}

In order to make accurate moment predictions, it is necessary to use the most appropriate material properties in the analyses. As shown in this investigation, there may be an interaction between the dynamic and cyclic effects on toughness in some cases; therefore, in the case of the simulated-seismic history used in the IPIRG-2 program, which acts as a dynamic, monotonic experiment, the dynamic, monotonic properties are appropriate. However, in an experiment where cyclic effects may be a factor, the appropriate dynamic, cyclic properties have to be used. Only when it has been proven that no interaction exists can the quasi-static, cyclic and dynamic, monotonic resistances be used to make an estimate of the dynamic, monotonic resistance.

\subsection{References}

4.1 Krishnaswamy, P., and others, "Fracture Behavior of Short Circumferentially Surface-Cracked Pipe," NUREG/CR-6298, November 1995.

4.2 Brust, F. W., and others, "Approximate Methods for Fracture Analysis of Through-Wall-Cracked Pipes," NUREG/CR-4853, February 1987. 
4.3 Brust, F., Scott, P., Rahman, S., Ghadiali, N., Kilinski, T., Francini, R., Marschall, C., Muira, N., Krishnaswamy, P., and Wilkowski, G., "Assessment of Short Through-Wall Circumferential Cracks in Pipes - Experiments and Analyses,"NUREG/CR-6235, April 1995.

4.4 Kanninen, M. F., and others, "Mechanical Fracture Predictions for Sensitized Stainless Steel Piping with Circumferential Cracks," Final Report, EPRI NP-192, September 1976.

4.5 Rudland, D. L., Brust, F., and Wilkowski, G. M., "The Effects of Cyclic and Dynamic Loading on the Fracture Resistance of Nuclear Piping Steels," NUREG/CR-6440, BMI-2190, December 1996. 



\subsection{CONCLUSIONS}

Experiment 1.3-3 was a single-frequency pipe-system experiment conducted during the IPIRG-1 program. The J-R curve calculated from the experimental results was considerably lower at both crack initiation and during crack growth as compared with the J-R curve calculated from the quasi-static, monotonic $C(T)$ specimen. Also, maximum experimental stress predictions of this experiment using the quasi-static $C(T)$ results were considerably lower than the maximum stress predictions from other comparable pipe experiments. In order to resolve these issues, a series of chemical analyses, single-edge-notched tensile specimen, and compact tension specimen experiments were conducted. The major conclusions from these experiments are listed below.

- There are two distinct lots of material for the 16-inch nominal diameter, Schedule 100 , TP304 stainless steel pipe originally labeled DP2-A8. These materials have different chemical compositions and toughness values. However, there was little difference in the stress-strain response between the two lots.

- The lower toughness stainless steel, which includes the material tested in Experiment 1.3-3 was subsequently labeled DP2-A8II, while the higher toughness material, which includes the material tested in Experiment 1-1 was labeled DP2-A8I.

- Both materials showed an increase [approximately 30 percent at $5 \mathrm{~mm}(0.20$ inches $)$ of crack growth] in toughness under dynamic, monotonic loading as compared with quasi-static, monotonic loading.

- Both materials showed only a small change in resistance at both crack initiation and during crack growth when tested at quasi-static, $R=-0.3$ loading rates as compared with quasistatic, monotonic loading.

- Both materials showed a large decrease in resistance at crack initiation and during crack growth [approximately 33 percent at $5 \mathrm{~mm}$ ( 0.20 inches) of crack growth] when cycled with quasi-static, $R=-1$ loading as compared with quasi-static, monotonic loading.

- There appears to be no interaction between dynamic and cyclic $(R=-0.3)$ effects on toughness for DP2-A8I. However, there is an interaction between these effects for the DP2-A8II material which produced a J-R curve for the dynamic, $R=-0.3$ experiment that was similar to the quasi-static, $R=-1$ experiment.

- The SEN(T) specimen geometry seems to produce a good representation of the constraint in a circumferentially surface-cracked pipe. The J-R curve calculated from the finite element analyses of the SEN(T) specimen closely represented that of the surface-cracked pipe. (The surface-cracked pipe $J$ values came from an $\eta$-factor analysis, whereas a more detailed FEM analysis with constraint parameters is desirable to validate this point.) However, no dynamic, cyclic SEN(T) specimen experiment was conducted for comparison purposes. 
- Maximum stress predictions for Experiment 1.3-3 were close to the average values of the maximum stress predictions presented in NUREG/CR-6298 when the dynamic, $R=-0.3$ toughness data from a $C(T)$ experiment was used in the analysis.

- The key conclusion of this report is that there is a variability of stainless steel base metal toughnesses that is allowed by the current ASTM specifications. This variability has a significant effect on the load-carrying capacity of circumferentially cracked stainless steel pipe with cracks in the base metal. This result has the following implications:

- The ASME Section XI Appendix C criteria for stainless steel base metals should reconsider its criteria, i.e., a Z-factor may be needed for some stainless steels.

- $\quad$ The NRC Draft Standard Review Plan 3.6.3 for LBB assumes that stainless steel base metal pipes will always reach limit-load conditions, which is not the case.

- However, before making any code or regulatory changes, a statistical study of chemical compositions and toughness data is advisable. This effort could help to determine optimum chemical composition limits, which would also be of value for specification for new plant piping procurements.

Although steel-making practices are quite capable of making stainless steel with lower impurities and hence sufficiently high toughness values for limit-load conditions to occur, the ASTM standard has not kept up with the steel-making technology. A supplemental requirement could be put on purchases of new steels to alleviate this problem. 


\section{APPENDIX A}

\section{ANALYSIS OF SEN(T) SPECIMENS}

MACHINED FROM PIPE DP2-A8II 



\section{APPENDIX A: ANALYSIS OF SEN(T) SPECIMENS MACHINED FROM PIPE DP2-A8II}

\section{A.1 Introduction}

The SEN $(T)^{*}$ tests were performed under displacement-controlled, fixed-grip conditions. The philosophy behind using a fixed-grip condition for the experiments is as follows. In an uncracked pipe subjected to bending loads, the usual beam-theory assumptions of plane sections remaining plane is a good approximation for pipe geometries. In a surface-cracked pipe subjected to bending, the assumption of plane sections remaining plane is obviously violated in the vicinity of the crack. However, as the distance from the crack plane increases, the sections increasingly approach a condition of plane deformation. At a distance of about one pipe radius from the crack plane, the condition of plane sections remaining plane after deformation becomes nearly valid (based on numerical solutions). If an SEN(T) specimen was cut from the pipe (see Figure A.1), at a distance " 1 " from the crack plane, the applied deformation is nearly $\left(\delta_{1}+\delta_{2}\right) / 2$. That is, the SEN(T) specimen is acted upon by a fixed displacement of $\left(\delta_{1}+\delta_{2}\right) / 2$.

The idea behind the SEN(T) specimen is to obtain fracture toughness data (J-R curves) from a specimen that approaches the condition which approximates that experienced by a surface-cracked pipe.

Unfortunately, the fixed-grip loading condition complicates the analysis procedure compared with applying a uniform stress. Estimation schemes for uniform stress loading already exist and are considered accurate for calculating J (Ref. A.1). For the SEN(T) specimen subjected to fixed-grip loading, an estimation scheme was developed by Ahmad et al. (Ref. A.2). However, the accuracy of this estimation scheme has not yet been validated for a wide range of materials. One objective of this appendix is to examine the accuracy of the estimation scheme of Reference A.2.

\section{A.1.1 Unique Effects of Fixed Grip Conditions on the SEN(T)}

The complications which arise due to the application of fixed-grip loading on the SEN(T) specimen are illustrated as follows. Consider the deformed shape of the SEN(T) specimen subjected to uniform stress (Figure A.2a) and fixed-grip displacement (Figure A.2b). Figure A.2 represents the results of elastic finite element analyses of the specimen where only one-half of the specimen is modeled due to symmetry considerations. The initial (unloaded) mesh is also shown on this figure. The deformation field of Figure A.2b may be obtained by 'bending' the SEN(T) specimen of Figure A.2a in the direction of crack closure. This 'closing' portion of the loading greatly complicates the J-estimation procedure. In fact, for the elasticplastic case, the stressing throughout the body does not remain proportional throughout the loading history, as the plastic zone spreads, even for a stationary crack. Indeed, it is observed that $\mathrm{J}$ is somewhat path dependent for a stationary crack (elastic-plastic analysis) due to this effect.

All SEN(T) specimens were machined from Pipe DP2-A8II. All analyses in this section were performed using the properties of Pipe DP2-A8II. 

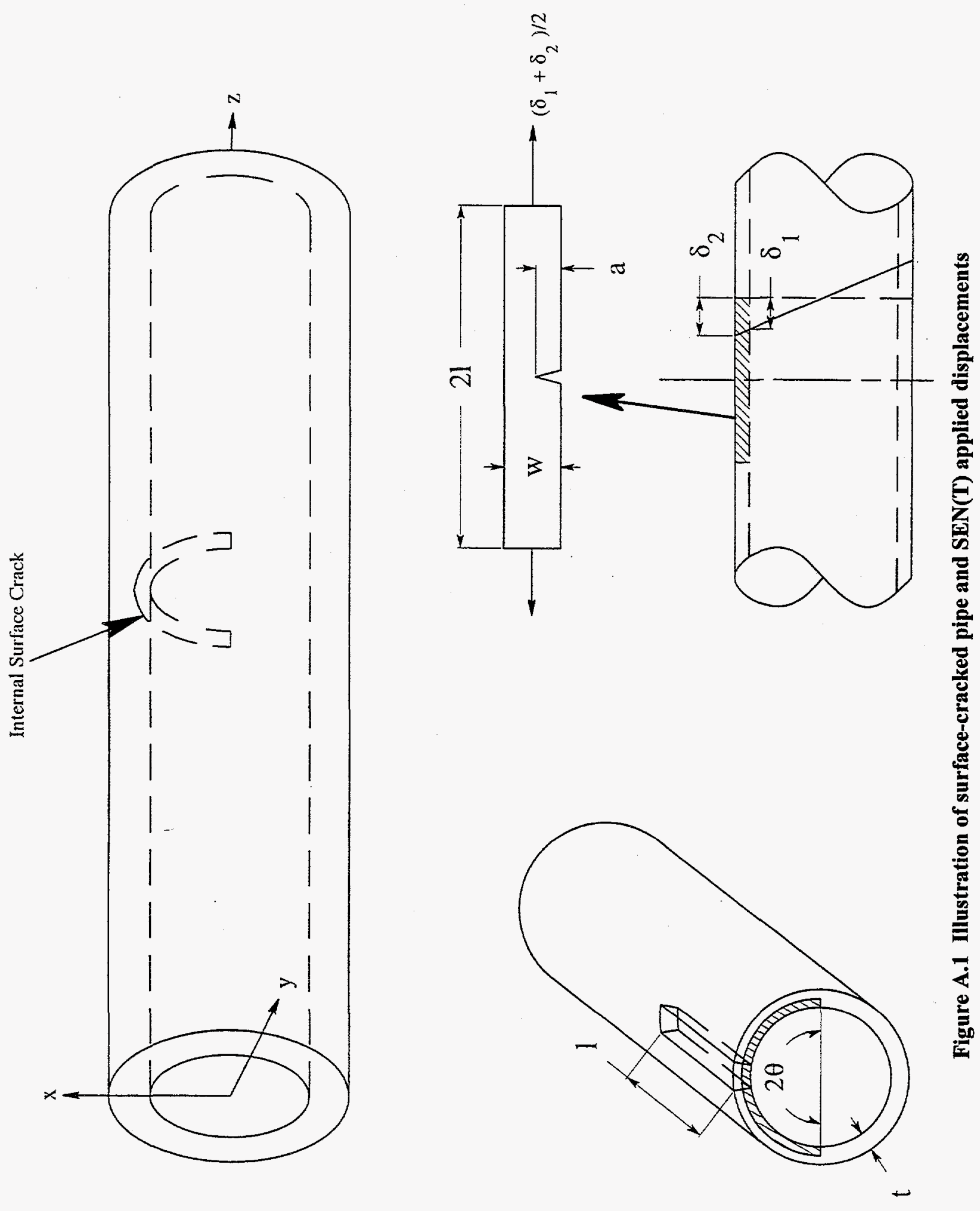

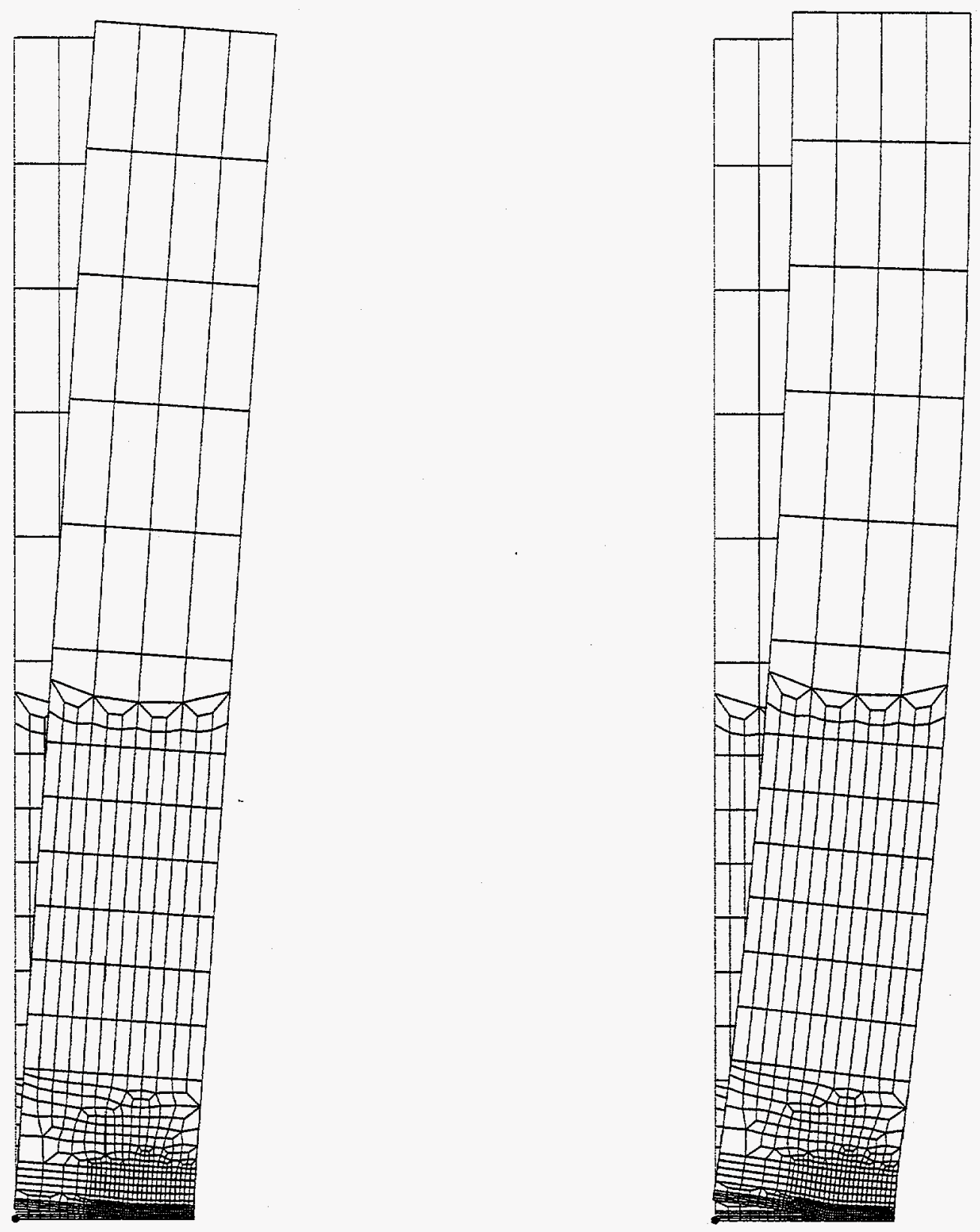

(a) Uniform applied stress

(b) Uniform (fixed grip) applied displacement

Figure A.2 Deformed shape in SEN(T) FEM analysis 


\section{A.2 Experimental Crack Growth Measurement}

Crack initiation and growth were determined from the direct-current electric potential (d-c EP) data taken during the experiments. The electric potential corresponding to the upper envelope of the loaddisplacement curve is used in all crack growth analyses. The procedure for calculating crack initiation and growth was as follows. First, the point of crack initiation was estimated from the departure from linearity of the EP versus load-line-displacement curve. Engineering judgement, together with a statistical analyses of the experimental data points, was employed in final selection of the crack initiation point, making certain that it lay somewhat beyond the elastic portion of the load-displacement curve and before maximum load. In the cyclic-load TWC pipe tests conducted in IPIRG-1, a distinct change in the EP readings could be seen at the point of crack initiation and re-initiation; however, in the small-scale specimen tests, the change in slope of the EP readings between blunting and crack growth was less evident. The procedure for calculating $\mathrm{J}$ from the upper envelope of the load-displacement record contains the assumption that the crack initiated and re-initiated at a displacement equal to the maximum displacement of the previous cycle.

Once the decision was made on the crack initiation point, the electric potential value at this point was called $U_{0}$. Approximately 30 to 50 data sets (load, load-line displacement, and d-c EP) were then selected from the continuous upper envelope test record. In the cases where fewer than 30 data sets were available, all of the data sets were used. Some of the data sets were taken from the test record prior to crack initiation and some were taken from the growing crack part of the test. Due to crack tip blunting, which changes the electrical resistivity of the material, the d-c EP values increase before crack initiation occurs. The change in EP is misleading in that it implies that the crack is growing. Therefore, the values of electric potential prior to crack initiation were set to the initiation value, $U_{0}$. After crack initiation, new values of the crack length were calculated using the Johnson equation (Ref. A.3), Equation A-1.

$$
a=\left(\frac{2 w}{\pi}\right) \cos ^{-1}\left[\frac{\cosh \left(\frac{\pi y}{2 w}\right)}{\left.\cosh \left(\frac{U}{U_{0}}\right) \cosh ^{-1}\left(\frac{\cosh \left(\frac{\pi y}{2 w}\right)}{\cos \left(\frac{\pi a_{i}}{2 w}\right)}\right)\right]}\right]
$$

where $a$ is the crack length, $a_{i}$ is the original crack length, $w$ is the specimen width (see Figure 3.3 ), and $2 y$ is the spacing of the electric potential probes. Earlier EP calibration studies on SEN(T) specimens (Ref. A.3) with various crack lengths, have shown that the Johnson equation is appropriate for this specimen geometry. Battelle has modified Equation A-1 to permit $2 y$ to increase in proportion to the load-line displacement during the test since experience has shown that this modification provides a more accurate estimate of the actual crack extension for more-ductile materials (Ref. A.4). 


\section{A.3 Finite Element Analysis - General Considerations}

Table A.1 illustrates the matrix of analyses that were performed on the SEN(T) specimens. The first three represent analyses of specimens that were tested and reported in Section 3. The last two analyses in Table A.1 do not correspond to an experiment, but were performed to determine the effect of crack depth

Table A.1 Finite element analyses matrix

\begin{tabular}{lcc}
\hline $\begin{array}{l}\text { Specimen } \\
\text { Identification }\end{array}$ & Stress Ratio, $\mathbf{R}$ & $\mathbf{a}_{\mathbf{j}} / \mathbf{w}$ \\
\hline SENT-2 & $1^{\text {(a) }}$ & 0.618 \\
SENT-4 & -1 & 0.635 \\
SENT-6 & 1 & 0.712 \\
PB4 & 1 & 0.820 \\
PB5 & 1 & 0.500 \\
\hline
\end{tabular}

(a) $R=1$ is monotonic loading.

on the fracture resistance. The specimen dimensions are listed in Table 3.5. The tensile test data used are those for Pipe DP2-A8I which are essentially the same as for Pipe DP2-A8II.

A typical finite element mesh used for these analyses is illustrated in Figure A.3. This mesh is that actually used for the SENT-2 analysis. Figure A.3 represents one half of the specimen as the model exercised advantage of symmetry for the analysis. The meshes for all of the other cases were similar to this mesh. Eight-node isoparametric elements with reduced integration were used for all analyses. It is seen that the mesh is quite refined in the vicinity of the crack tip with the crack-growth mesh refinement equal to 0.125 $\mathrm{mm}(0.005 \mathrm{inch})$. Plane stress, plane strain, and generalized plane strain analyses were performed for each case analyzed in Table A.1. The ABAQUS finite element code was used for all analyses.

For the three analyses which had experimental data for comparison with predictions, (Cases SENT-2,-4,-6) the experimentally measured displacement versus crack growth served as input. Figure A.4 illustrates the total load-line displacement versus crack growth experimental record that was used as input to the analysis of the SENT-2 specimen. The displacements at all nodes at the top of the model (Figure A.3) were forced to follow the displacement versus crack growth record of Figure A.4 to simulate the fixed-grip displacement condition of the tests. For crack growth, since eight-noded elements were used, both nodes in the element ahead of the crack tip through which the crack is growing were released simultaneously. The load, J-integral, crack-tip-opening angle (CTOA), etc., were calculated and compared with experimental results. The total load was obtained by summing the reaction forces for all nodes which were applied by the fixed displacement at the top of the specimen (Figure A.3).

\section{A.4 SEN(T) J-estimation Scheme}

Most fracture toughness testing is conducted using either a compact tension, $C(T)$, specimen or a singleedge notched bend, SEN(B), specimen. ASTM E1152, Standard Test Method for Determining J-R Curves 

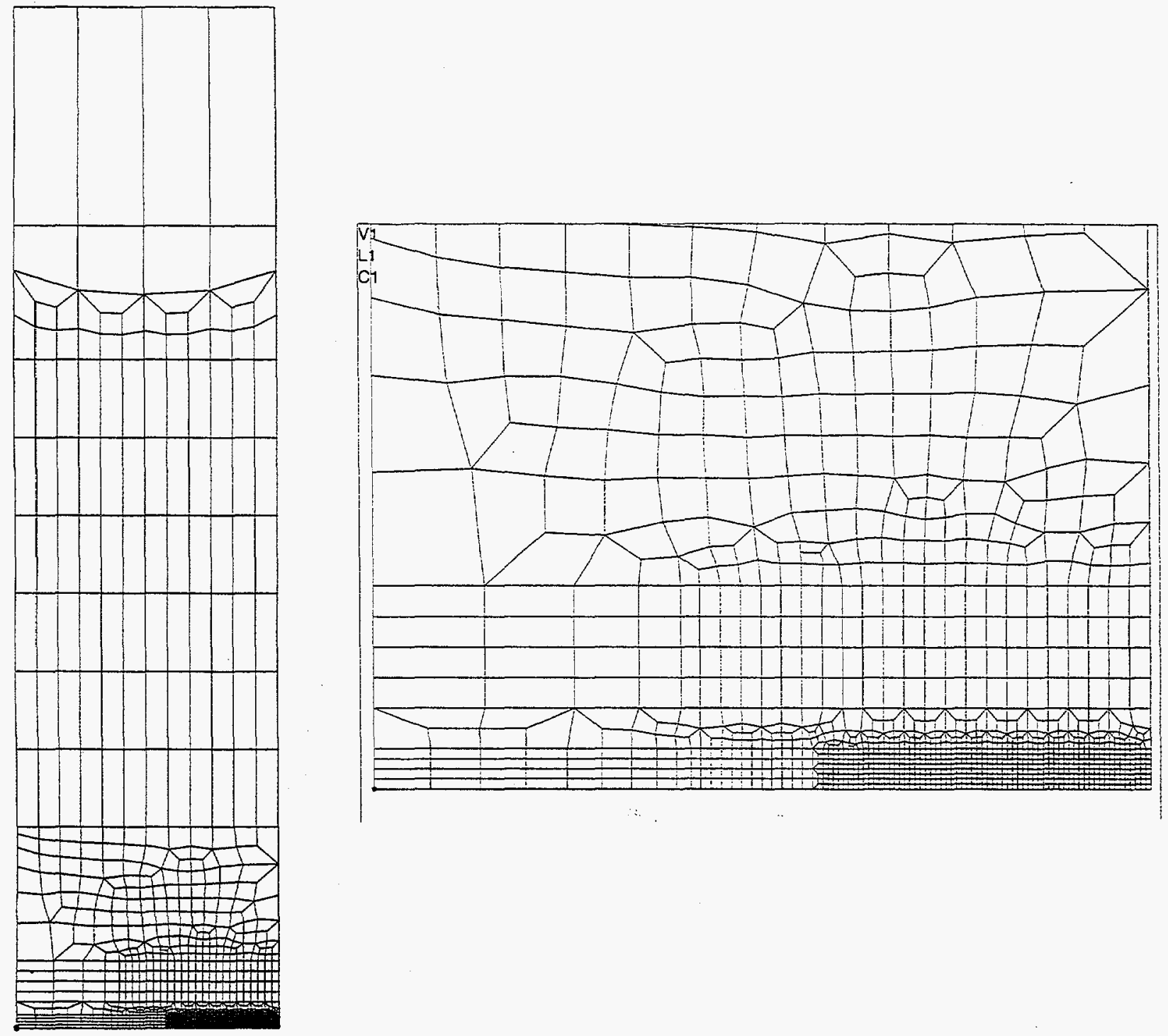

Figure A.3 FEM mesh used for some of the analyses, crack tip mesh refinement is $0.125 \mathrm{~mm}$ (0.005 inch) 


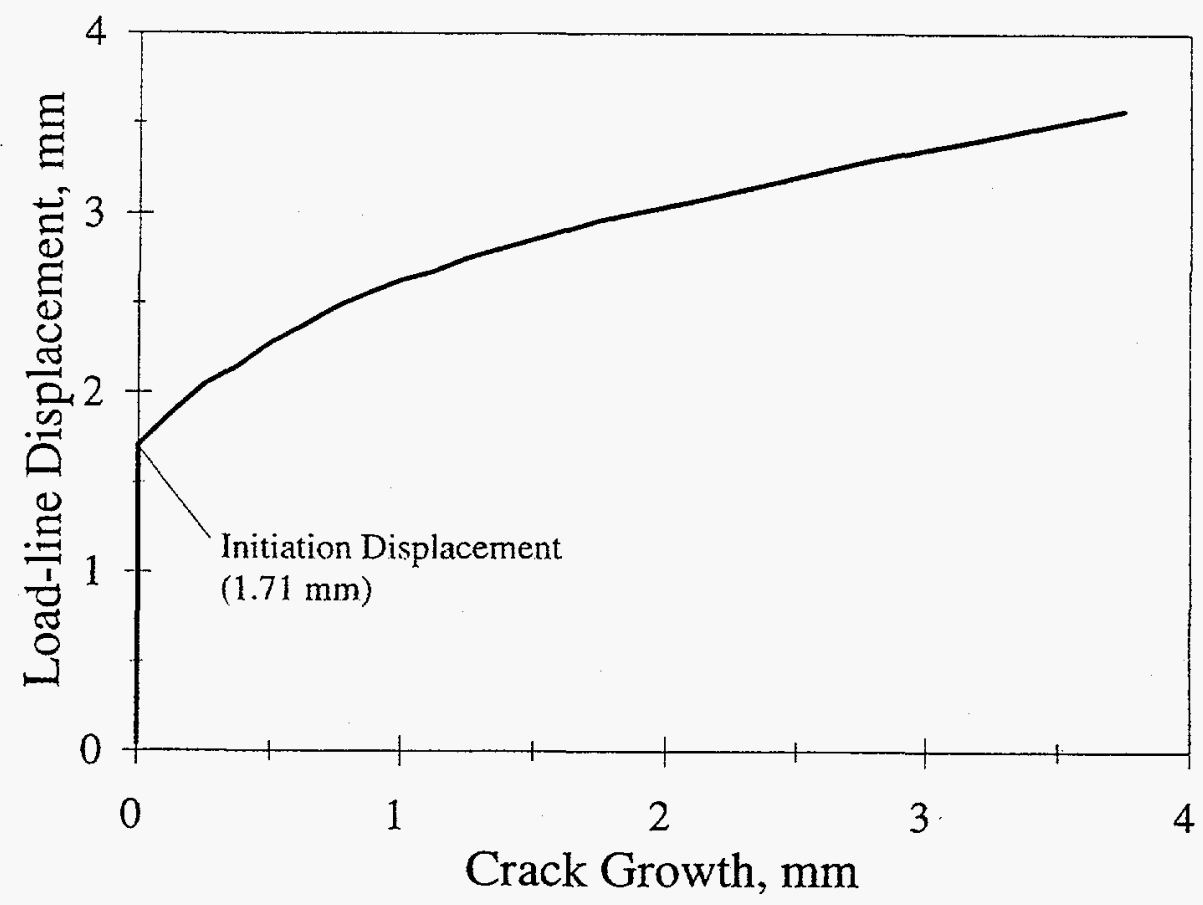

Figure A.4 Total load-line displacement versus crack growth from Experiment SENT-2. Note that, due to symmetry of the model, only one-half of this displacement was applied in the model

uses formulae for determining $\mathrm{J}$ from a specimen's dimensions and load-history record. However, since the single-edge notched tensile specimen is not typically used for fracture characterization, there are no published ASTM formulae for the J determination. Ahmad, and others (Ref. A.2) have derived a J-estimation formula for the single-edge notched tension specimen under fixed gripped loading. This estimation was derived from known stress intensity solutions for this geometry as well as derived stress distributions along the fixed boundary. Finite element analysis was then used to check the accuracy of the analytical approach. Because of the good agreement between analytical and numerical results presented in Reference A.2, this J-estimation scheme was used in this study. However, upon studying the solution, a possible misinterpretation of the analysis procedure was found. In the derivation, several geometry factors were derived that define the stress field at the crack tip. The author used standard geometry factors from Reference A.5. He combined these factors to define the crack tip stresses for any $a / w$. He performed this task by use of the Heaviside functions. For example, one of the geometry correction factors is defined as 


$$
\begin{gathered}
\xi_{1}=\frac{2 \pi}{w} \int_{0}^{a} \frac{a}{w} \times f_{1}^{2} d a \\
f_{1}=u_{-}\left(0.6-\frac{a}{w}\right) \times \sum_{i=0}^{4} n_{i}\left(-\frac{a}{w}\right)^{i}+u_{+}\left(\frac{a}{w}-0.6\right) \times \frac{\left(1+3 \frac{a}{w}\right)}{3.545 \frac{a^{1 / 2}}{w}\left(1-\frac{a}{w}\right)^{3 / 2}}
\end{gathered}
$$

From this derivation, the first portion of Equation A-2 and Equation A-3 should not be evaluated for a/w $>0.6$, i.e., the Heaviside function goes to zero. Therefore, only the second portion of these equations are used in the analysis. This case holds true for all geometry factors in Reference A.2.

In order to provide ease in computation, the Ahmad J-estimation scheme was programmed into an EXCEL spreadsheet. The spreadsheet is automated so that the user inputs the experimental record and material properties to calculate the J-R curve.

Since this estimation scheme calculated $\mathrm{J}$ from an "area under the curve" approach, unloadings complicate the analysis of cyclic tests. Therefore, an "upper envelope" approach was used in the cyclic tests. In previous work on cyclically loaded $1 \mathrm{~T} \mathrm{C(T)} \mathrm{specimens,} \mathrm{Landes} \mathrm{and} \mathrm{McCabe} \mathrm{(Ref.} \mathrm{A.6)} \mathrm{used} \mathrm{an}$ upper envelope of the load-displacement record to calculate J, i.e., an $\eta$-factor approach. Later, Landes and Liaw (Ref. A.7) used the same procedure except that the cyclic crack growth component was calculated by taking into account the amount of crack closure per cycle. In the IPIRG-1 program, pipe J-R curves were calculated from the load-displacement record using the $\eta$-factor approach. When it came to cyclic-load pipe tests, the upper envelope of the load-displacement curve was used in the analysis. Even though the formal definition of $J$ is violated when unloadings occur, calculating $J$ from the upper envelope of the load-displacement record can provide a useful engineering tool in the determination of cyclic-load effects on fracture toughness.

\section{A.5 Analysis Results for Monotonic Loading}

The results for each analysis are presented separately.

\section{A.5.1 SENT-2 Analysis}

The prediction of load versus total load-line displacement from the finite element analyses are compared with experimental data for Specimen SENT-2 in Figure A.5. Recall that the initiation displacement was $1.71 \mathrm{~mm}$ (see Figure A.4). The prediction of the loads from the generalized plane strain analysis compares best with the experimental data. This trend turns out to be the case for all monotonic-loading analyses that 


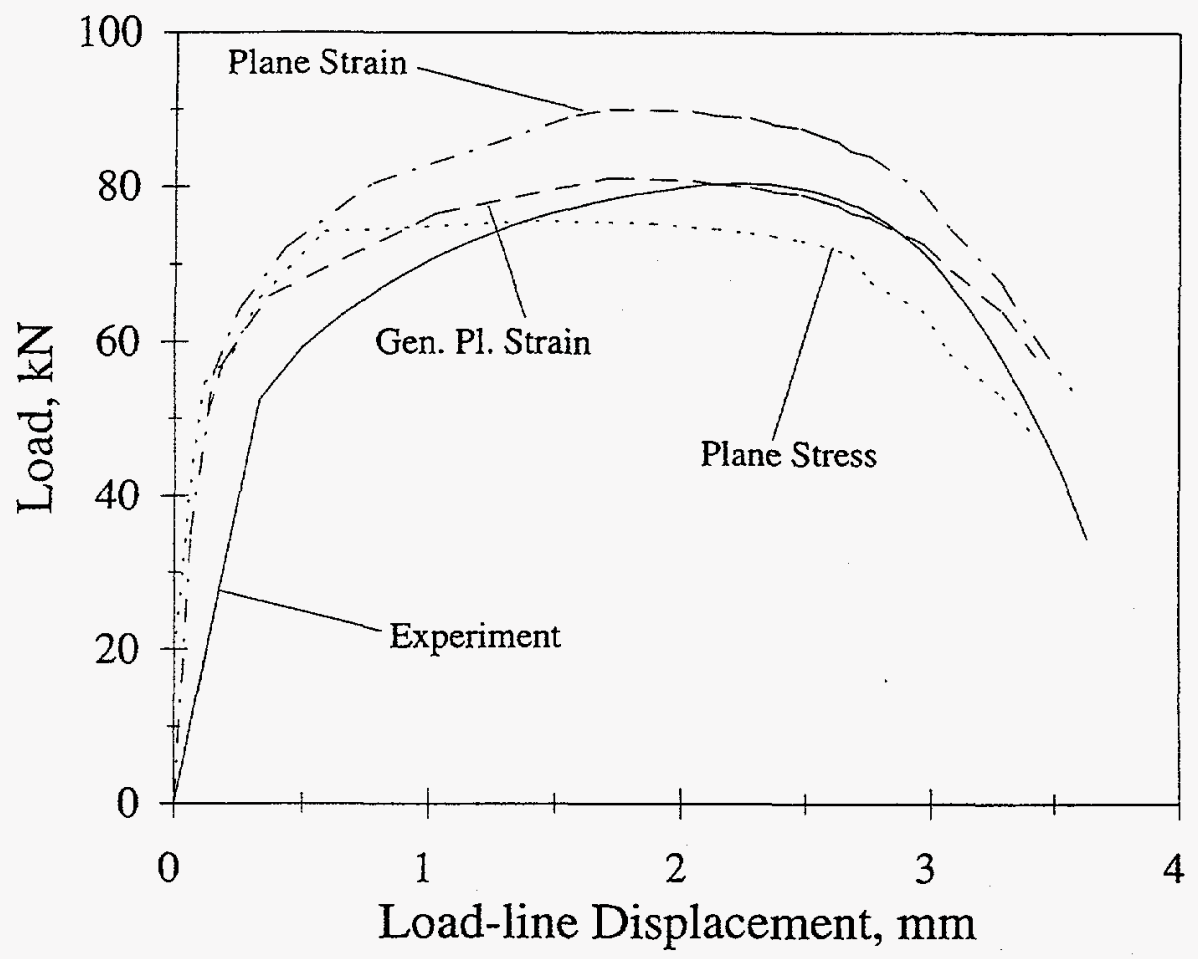

Figure A.5 Load-displacement predictions, SENT-2

The predicted values of $\mathrm{J}$ versus load-line displacement and $\mathrm{J}$ versus load are compared with experimental data in Figures A.6 and A.7, respectively. The predicted results through the entire crack growth history are shown. Of course, the J versus load curves "hook" around since the load decreases past maximum load. It is emphasized that the experimental values of $\mathrm{J}$ are calculated using the procedure described in Reference A.2. Since the load-displacement curves (Figure A.5) are not significantly different between the finite element analysis results and the experimental results, it appears that the Ahmad J-estimation procedure may be somewhat inaccurate for this case. The J-R curve comparison is shown in Figure A.8. It is clear that the procedure for estimating $J$ in Reference A.2 overestimates $J$ for this case. From Figure A.8 it is seen that both the initiation value of $J$ and the slope of the J-R curve differ significantly between the finite element analysis and Ahmad J-estimation scheme. In fact, the values of $\mathrm{J}$ at crack initiation were:

- $\mathrm{J}_{\mathrm{i}}=281 \mathrm{~kJ} / \mathrm{m}^{2}(1,600 \mathrm{lb} / \mathrm{in})$

- $\mathrm{J}_{\mathrm{i}}=321 \mathrm{~kJ} / \mathrm{m}^{2}(1,830 \mathrm{lb} / \mathrm{in})$

- $\mathrm{J}_{\mathrm{i}}=351 \mathrm{~kJ} / \mathrm{m}^{2}(2,000 \mathrm{lb} / \mathrm{in})$

- $\mathrm{J}_{\mathrm{i}}=617 \mathrm{~kJ} / \mathrm{m}^{2}(3,520 \mathrm{lb} / \mathrm{in})$
Plane stress

General plane strain

Plane strain

Ahmad J-estimation

It is clear that the Ahmad J-estimation J values, as calculated using the procedure of Reference A.2, are high by about a factor of two for this stainless steel specimen (SENT-2). The results presented in Figures A.4 through A.9 should be viewed accordingly. 


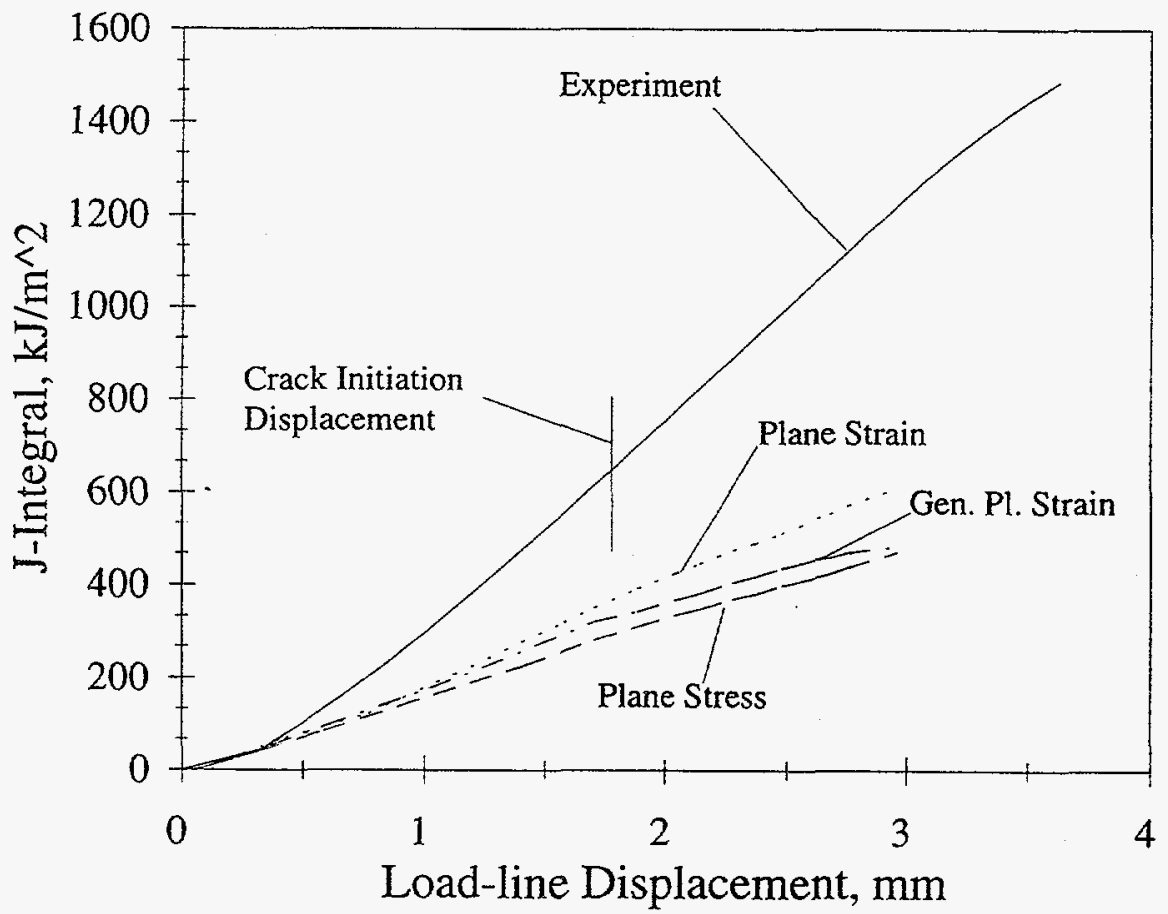

Figure A.6 J versus displacement, SENT-2

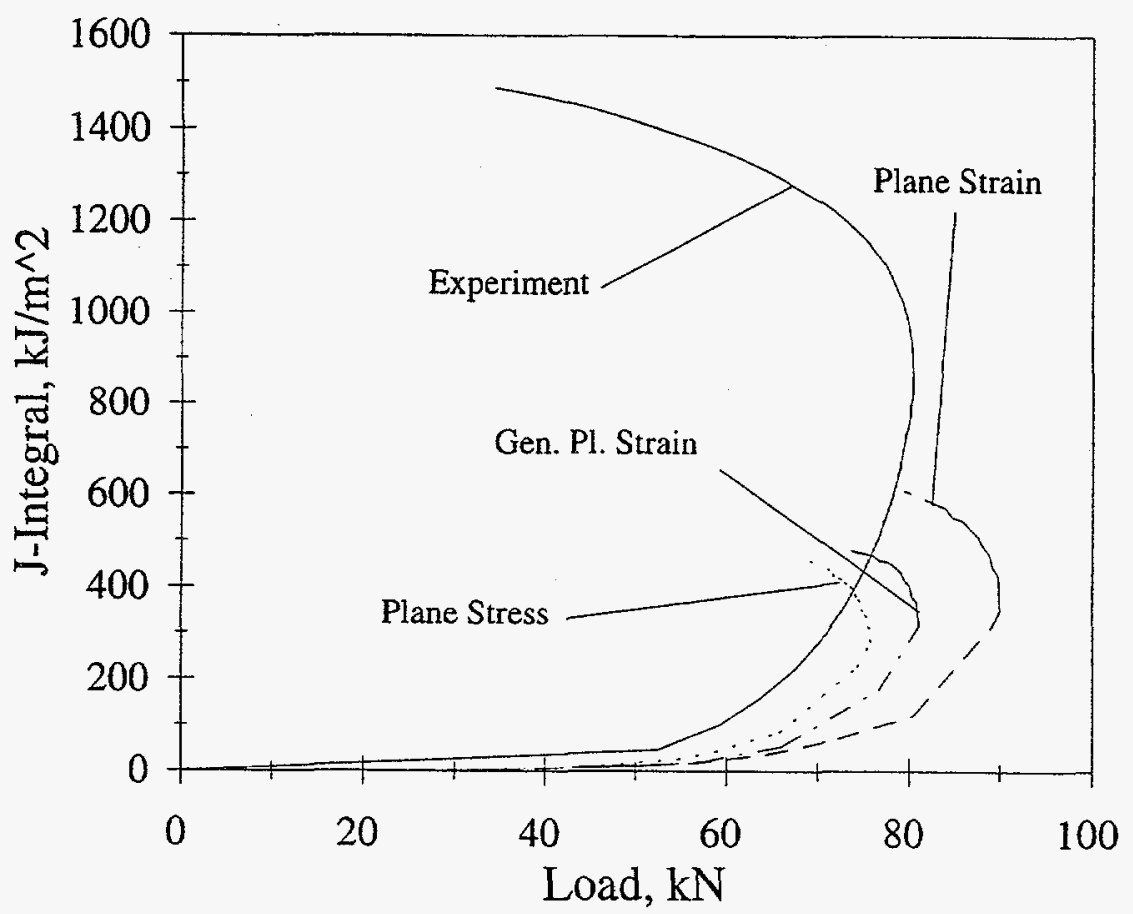

Figure A.7 J versus load, SENT-2 


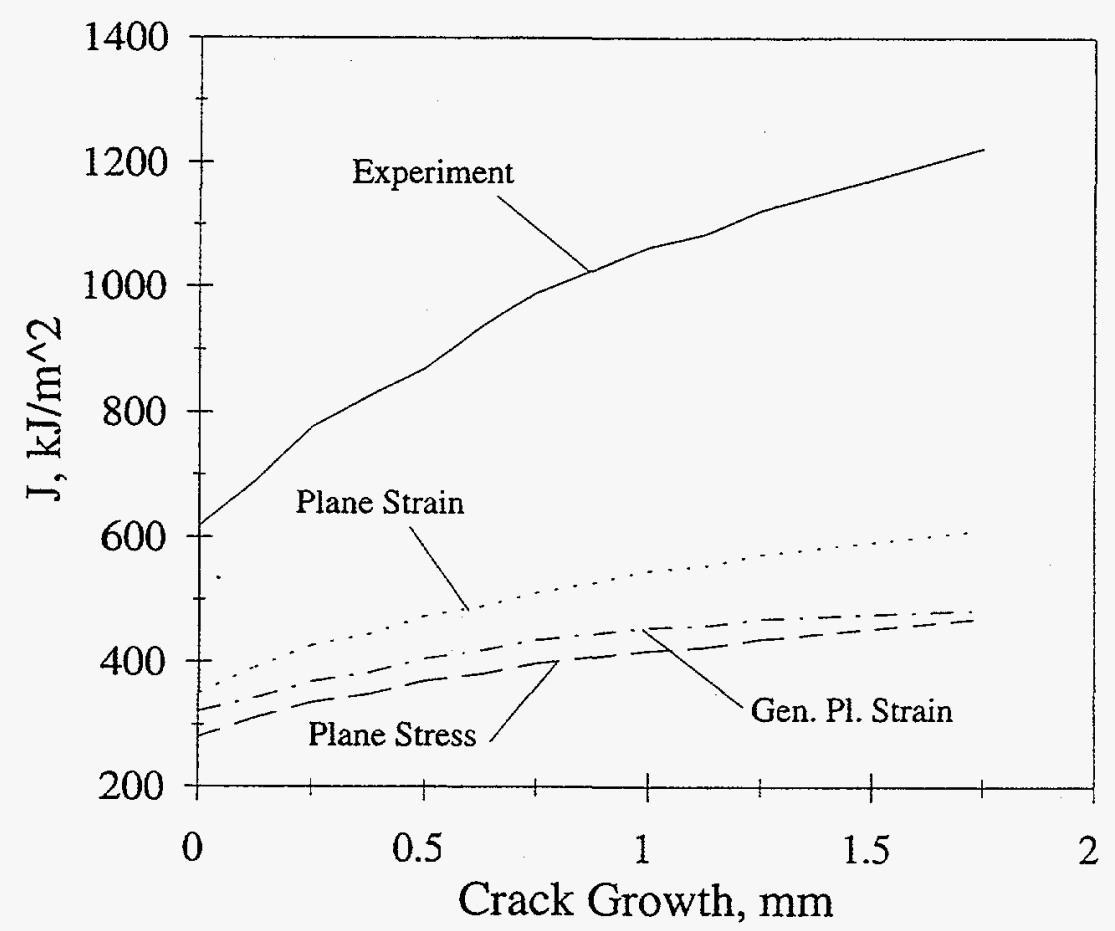

Figure A.8 J-R curves, SENT-2

Finally, Figure A.9 illustrates J versus applied load and applied displacement for the case of no crack growth. It is clear that slight differences in load or displacement can lead to large differences in J. Of course, this is well known since $J$ is proportional to load to the $(n+1)$ power (where $n$ is the RambergOsgood exponent). For the DP2-A8II material, $\mathrm{n}$ is about 5. For this value of hardening exponent, the differences are magnified to a considerable extent.

\section{A.5.2 SENT-6 Analysis}

The SENT-6 specimen had a loading history similar to that of the SENT-2 specimen; however, the SENT-6 specimen had a much deeper initial crack $(a / w=0.71$ versus 0.62$)$. As with the analysis for the SENT-2 specimen, the experimental displacement-versus-crack growth curve was used as input to the analysis. This curve is shown in Figure A.10. The predicted load-versus-displacement curve is shown in A.11. Here, the prediction using generalized plane strain again compares reasonably well with the experimental results. However, the plane strain solution also agrees well with the experiment, while the plane stress solution slightly underpredicts the maximum load. As seen in Figure A.10, crack initiation occurred at a displacement of $1.12 \mathrm{~mm}(0.044 \mathrm{in})$. Overall, the predictions are considered to be adequate.

The predicted J-integral versus displacement curves are compared with the experimental results in Figure A.12. The J-integral versus load curves are compared in Figure A.13. The finite element predicted J-R curves are compared with the Ahmad J-estimation J-R curve in Figure A.14. As was seen in Figures A.6, A.7, and A.8 for the SENT-2 specimen, the Ahmad J values, as evaluated using the method outlined 


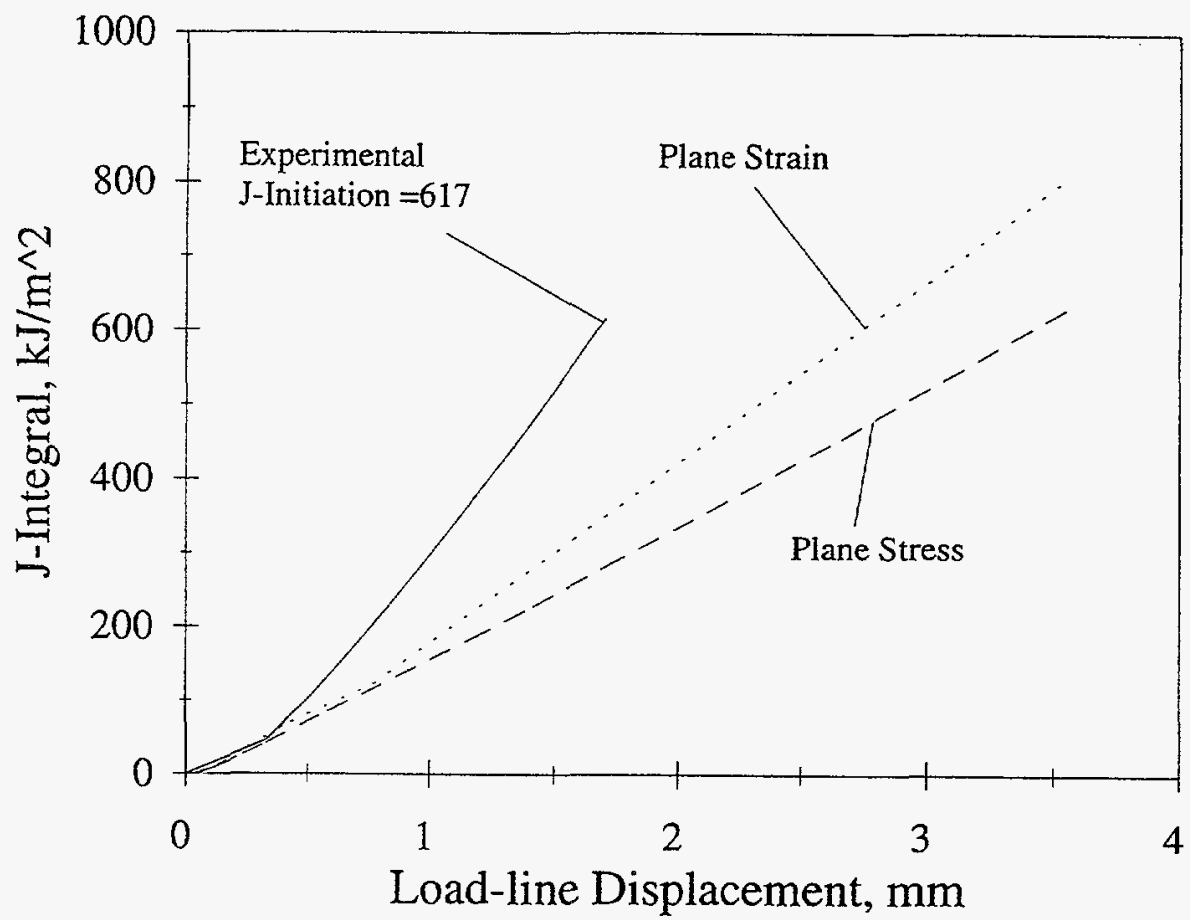

(a) $\mathbf{J}$ versus displacement

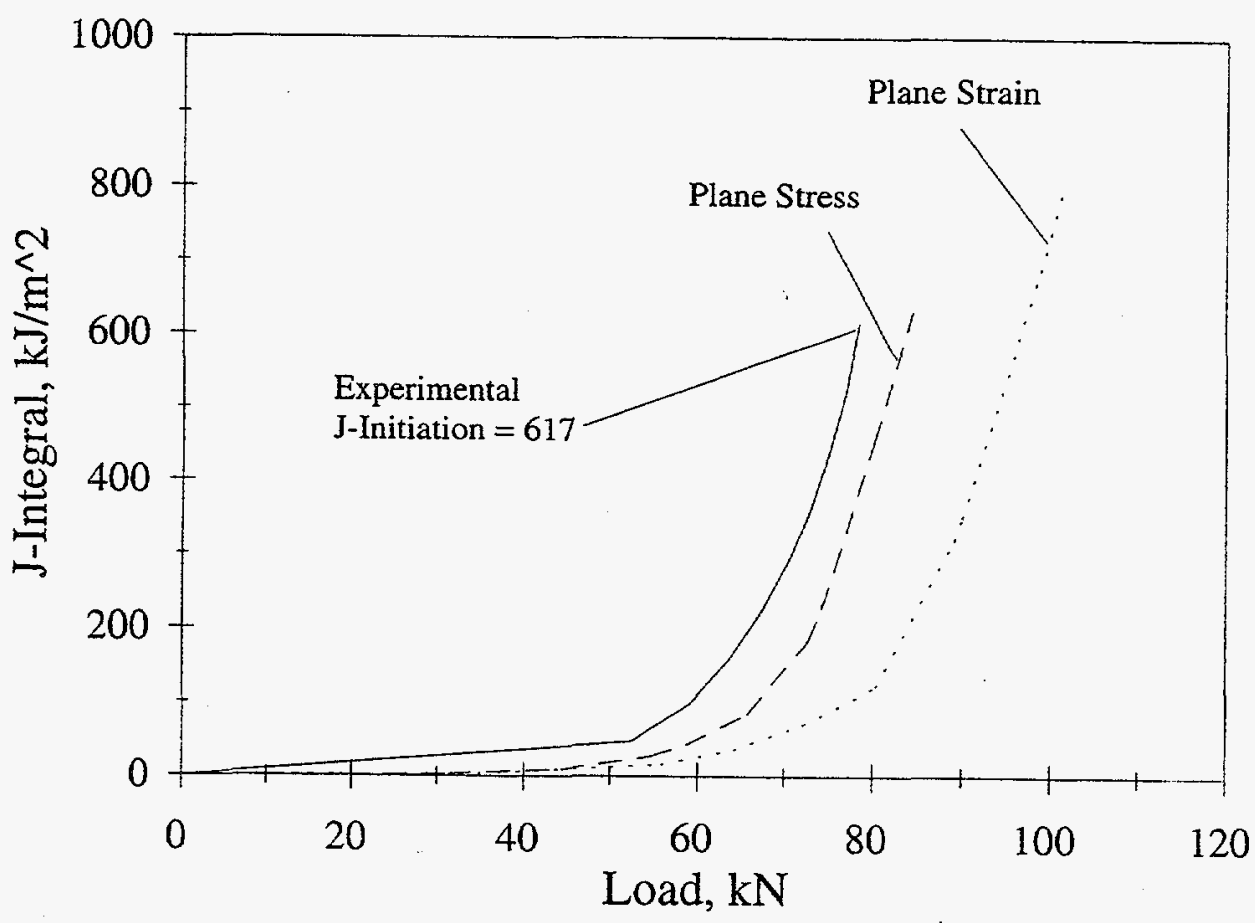

(b) J versus load

Figure A.9 Analysis results with no crack growth, SENT-2 


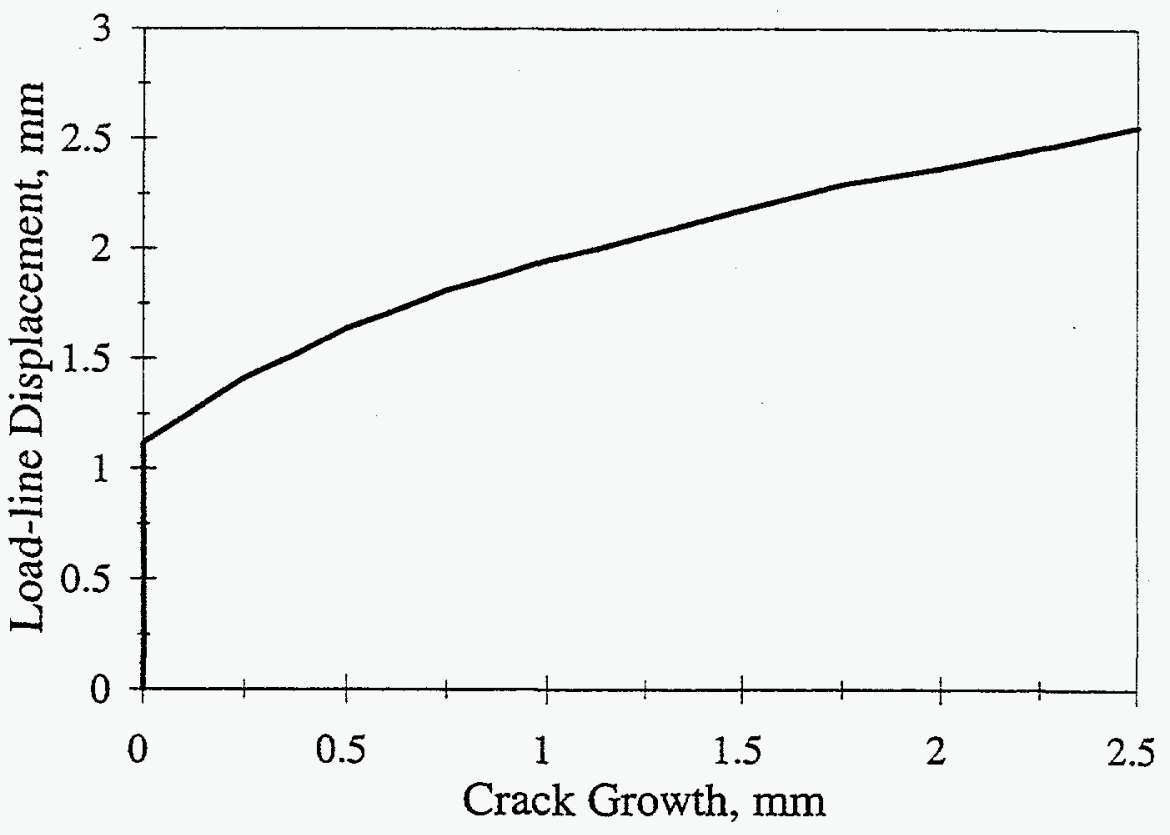

Figure A.10 Displacement versus crack growth experimental record used as input for SENT-6 analyses

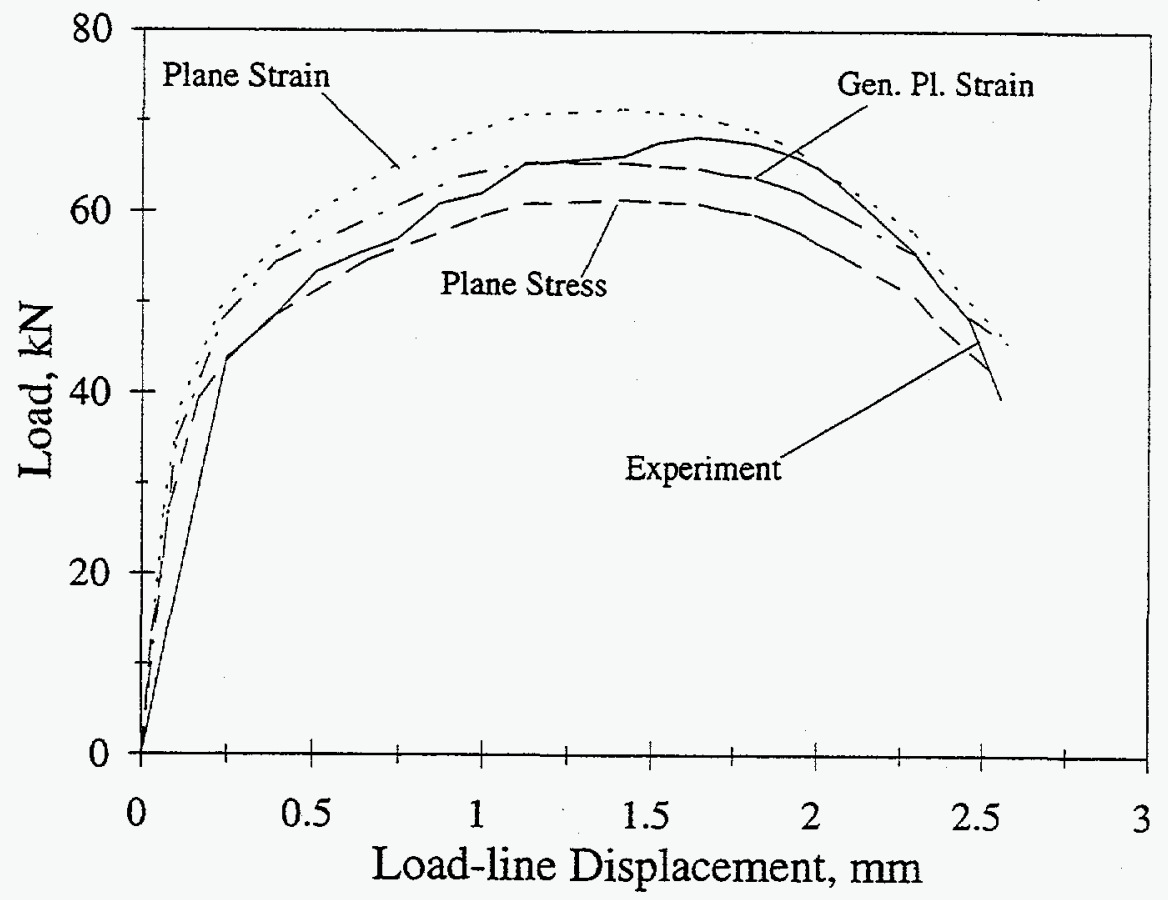

Figure A.11 Predicted load displacement curve, SENT-6 


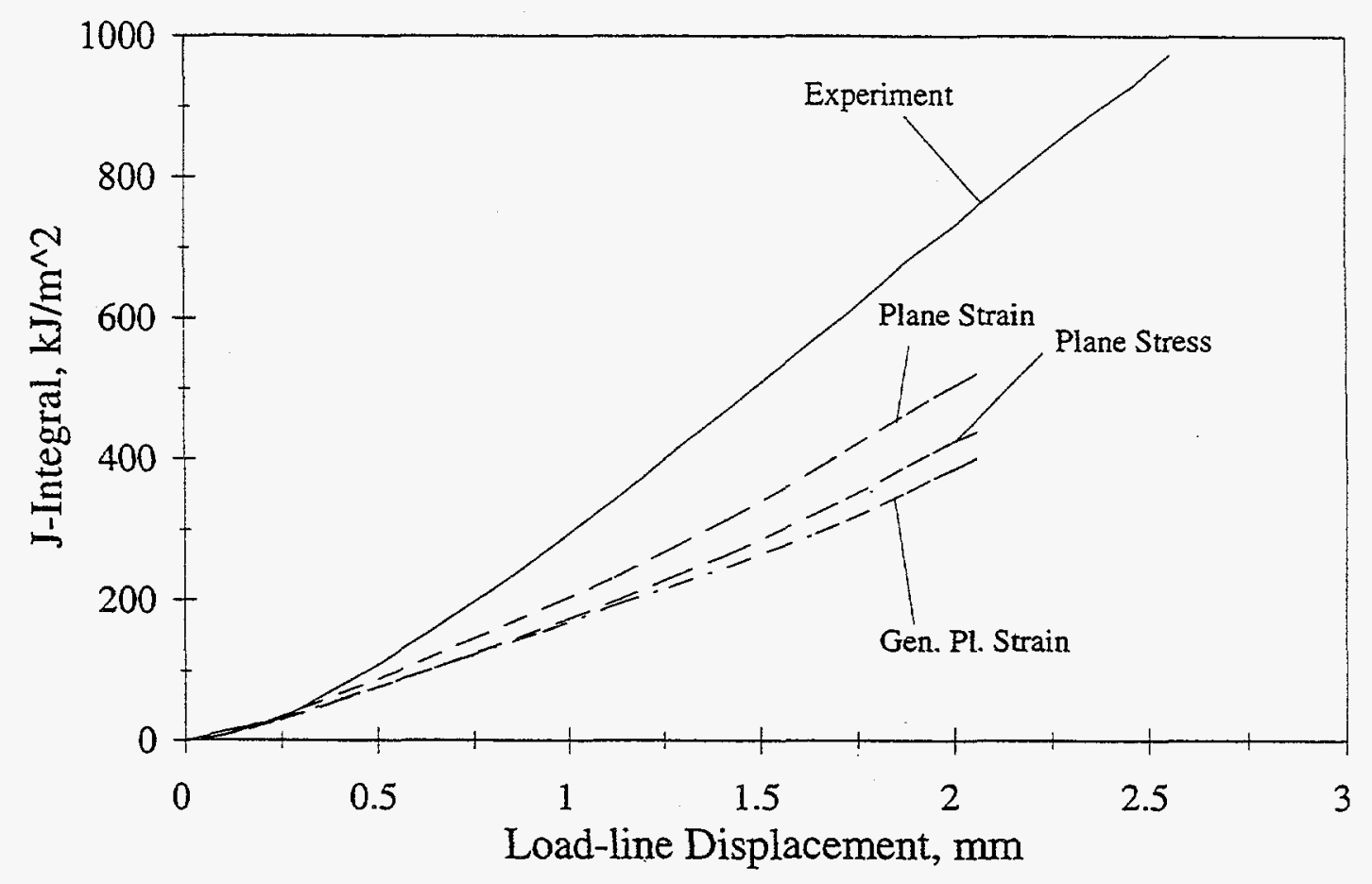

Figure A.12 J versus load-line displacement, SENT-6

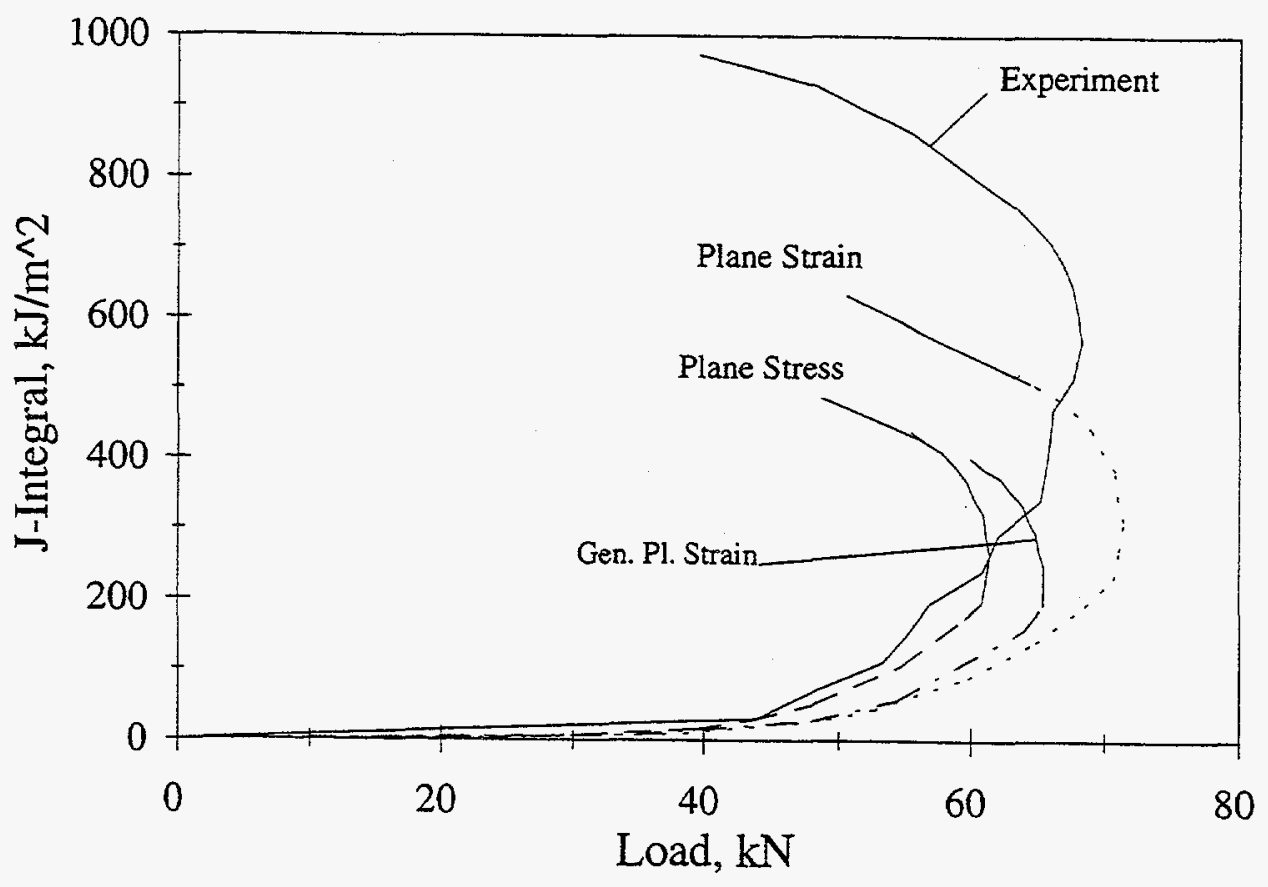

Figure A.13 J versus load, SENT-6 


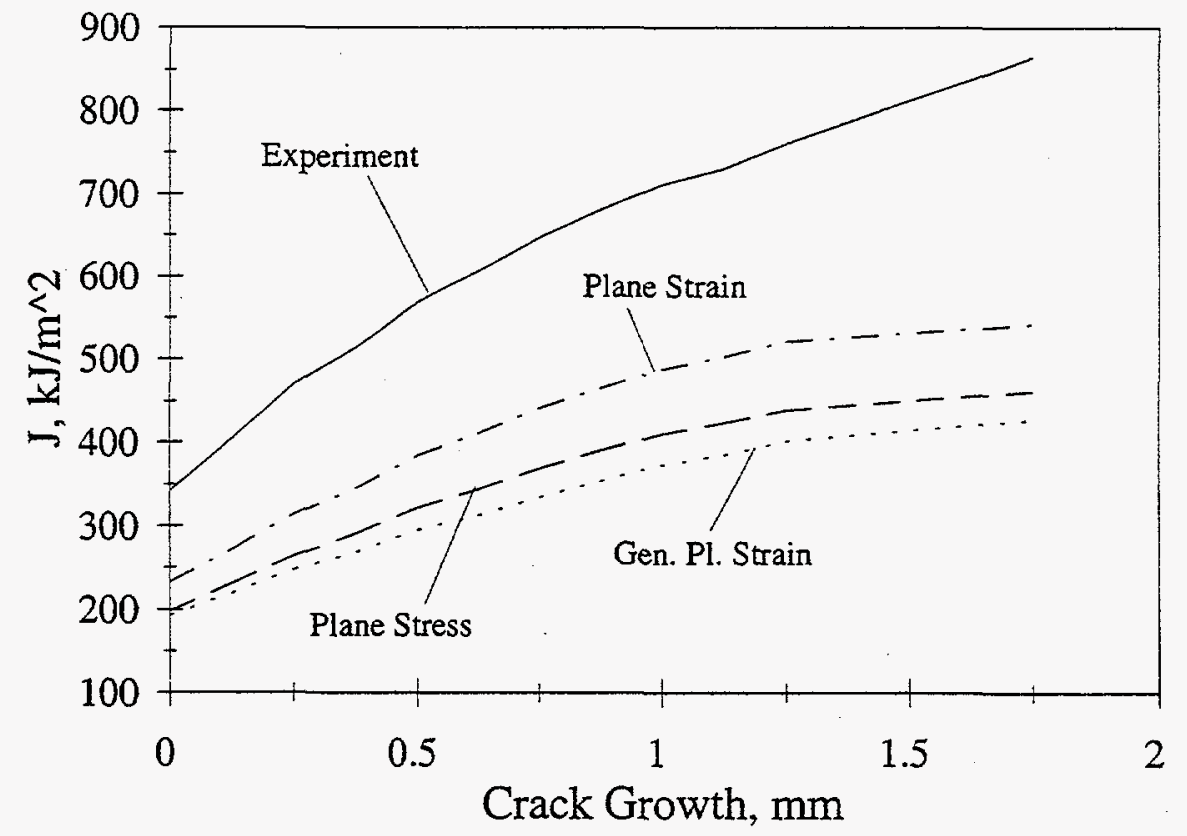

Figure A.14 Predicted J-R curves compared with Experiment SENT-6; the experimental $J$ values were calculated from the load-displacement curve based on the method of Reference A.2

in Reference A.2, overestimates the J values from finite element analyses by a factor of about two for the SENT-6 case as well.

It is also instructive to observe the predictions of $J$ up to the crack-initiation value. Figure A.15a and A.15b illustrate the $J$ versus displacement and $J$ versus load curves, respectively. In these figures, the last value plotted represents the crack-initiation value. It is seen that the predicted J-versus-load (Figure A.15b) compares best with the experimental curve (based on the method of Reference A.2) for the plane stress case. However, the comparison of $J$ versus load-line displacement (Figure A.15a) is poor for all cases considered. The same conclusion was drawn for the SENT-2 case (Figures A.9a, A.9b).

For the SENT-6 specimen, the values of $\mathrm{J}$ at crack initiation are:

- $\mathrm{J}_{\mathrm{i}}=198 \mathrm{~kJ} / \mathrm{m}^{2}(1,130 \mathrm{lb} / \mathrm{in})$

- $\mathrm{J}_{\mathrm{i}}=193 \mathrm{~kJ} / \mathrm{m}^{2}(1,100 \mathrm{lb} / \mathrm{in})$

- $\mathrm{J}_{\mathrm{i}}=232 \mathrm{~kJ} / \mathrm{m}^{2}(1,320 \mathrm{lb} / \mathrm{in})$

- $\mathrm{J}_{\mathrm{i}}=342 \mathrm{~kJ} / \mathrm{m}^{2}(1,950 \mathrm{lb} / \mathrm{in})$
Plane stress

Generalized plane strain

Plane strain

Ahmad J-estimation scheme

As was the case for the SENT-2 analysis, the J values are lower from the analysis results than the J-values from the Ahmad J-estimation scheme. Again, it is emphasized that the experimental J-values were calculated from the load-displacement record using the method and formulas from Reference A.2. 


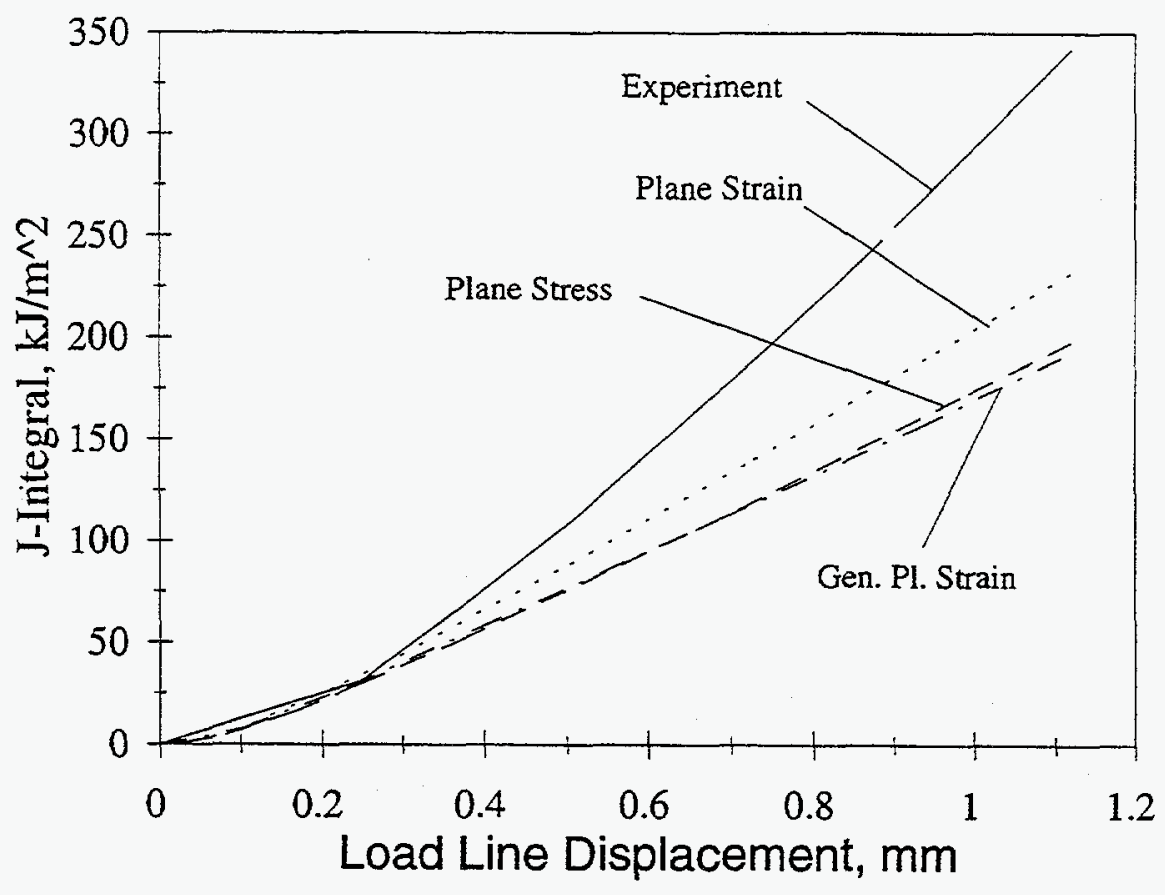

(a) J versus load-line displacement

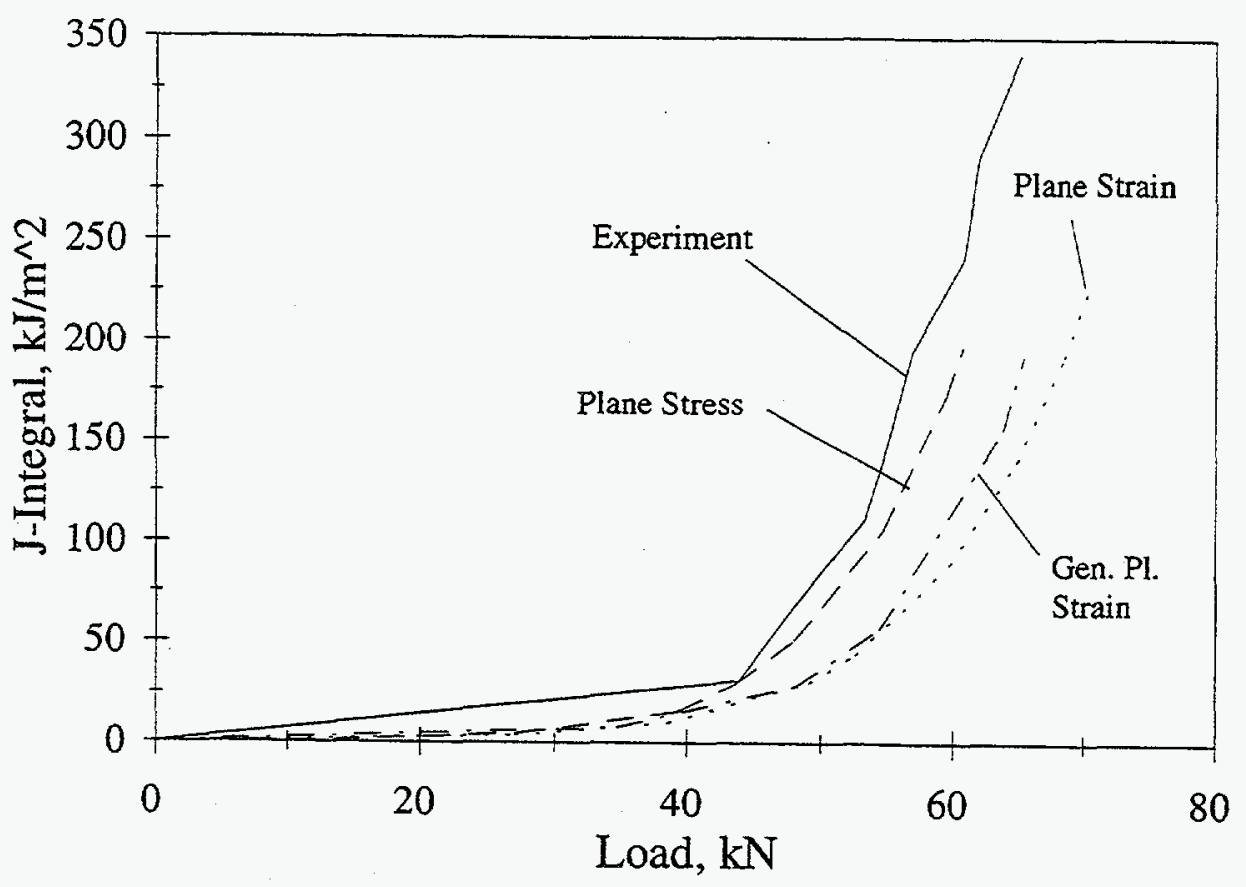

(b) J versus load

Figure A.15 Analysis results with no crack growth, SENT-6 


\section{A.5.3 Specimen PB4 $(\mathrm{a} / \mathrm{w}=\mathbf{0 . 8 2})$}

Observe from Table A.1 that analyses were also performed for two monotonic load cases having cracksize-to-width ratios $(\mathrm{a} / \mathrm{w})$ different from the SEN(T) experimental cases. These analyses, which do not have experimental data for comparison, were performed to determine the effect of initial crack size on the J-Integral for the SEN(T) specimen. Specimen PB4 represents the case of a deep surface crack in a pipe that is very close to breaking through the pipe wall and becoming a through-wall-crack.

The load versus load-line displacement curves are plotted for the three analyses in Figure A.16, these curves are for the no-crack-growth case ${ }^{*}$. It is seen that for this very deep crack, the differences between the plane strain and generalized plane strain curves are not as large as they were for the SENT-2 and SENT-6 curves (Figures A.5 and A.11, respectively). However, the plane stress curve is significantly lower, likely due to the fact that the plastic zone for the plane stress case rapidly engulfs the uncracked ligament, and hooks around above and behind the crack. The generalized plane strain and plane strain cases permit much more constraint since the out-of-plane stress is non-zero. This constraint results in a smaller plastic zone and magnitude compared with the plane stress case. Hence, for the same load, the displacement is much larger for the plane stress condition. While this same effect occurs for the smaller crack cases, it is apparently more important as the crack depth-to-specimen thickness ratio increases.

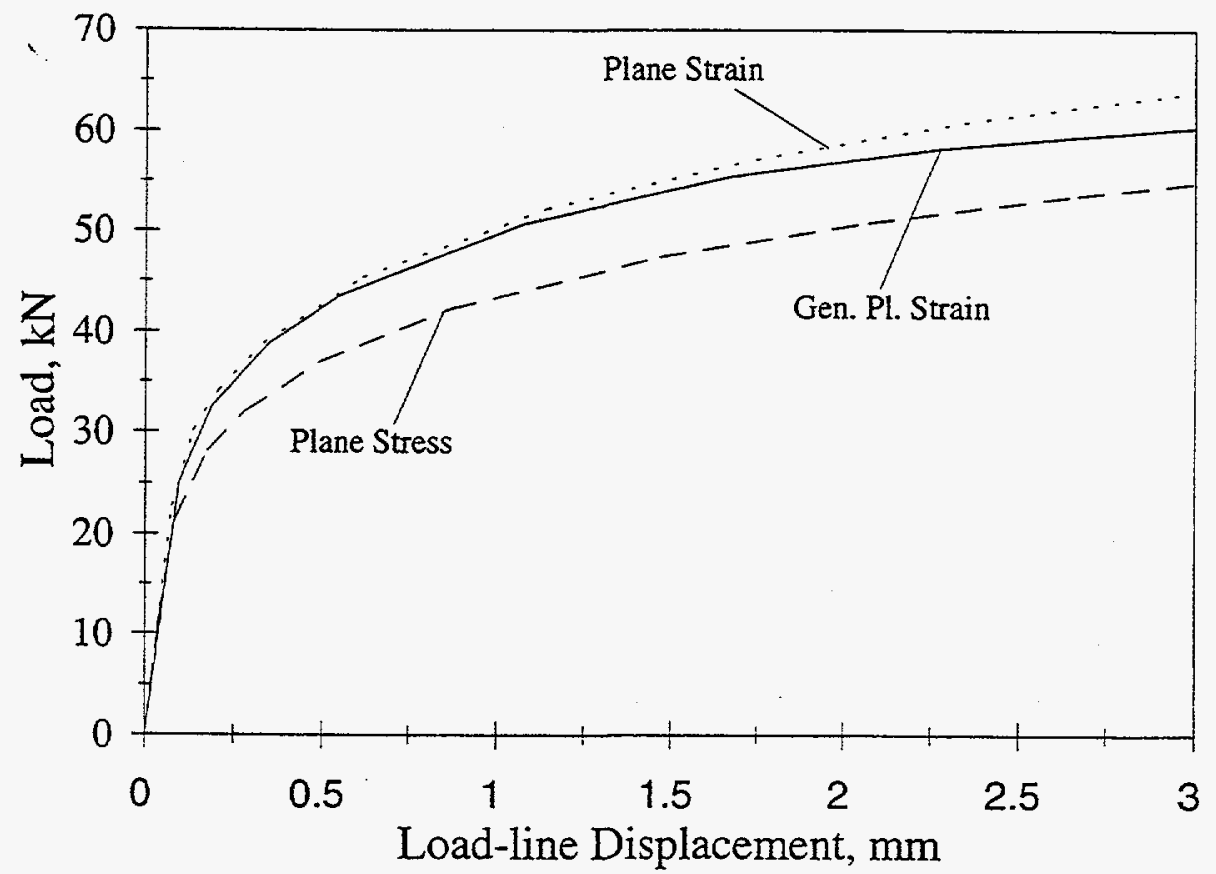

Figure A.16 Predicted load versus load-line displacement curve for Specimen PB4

* No crack growth was permitted for this case (and for Specimen PB5a) since the displacement versus crack growth record (of the type from Figures A.4 and A.10) are not available. 
The calculated J-integral is plotted versus load in Figure A.17. The plane strain and generalized plane strain results are close to each other while the plane stress J-values are much higher for a given load. Since $\mathbf{J}$ is related to the area under the load-versus-displacement curve (actually the derivative of this area with respect to crack size) this result is not unexpected. Note from Figure A.17 that J begins to rise more sharply for the generalized plane strain case compared with plane strain at larger load values. This finding is consistent with Figure A.16, where the load-versus-displacement curves show increasing separation.

\section{A.5.4 Specimen PB5 $(\mathrm{a} / \mathrm{w}=0.50)$}

Finally, the results for the fourth and final monotonic load case $(R=1)$ in which $a / w=0.50$ are presented. Again, no crack growth was permitted since experimental data were not available. The calculated loadversus-displacement curves are shown in Figure A.18. The J-integral is plotted versus load-point displacement and versus load in Figures A.19 and A.20, respectively. Again, the observed trends are consistent with the $\eta$-factor approach of Reference A.2 in that $J$ is related to the areas under the loaddisplacement curves.

\section{A.5.5 Summary - Monotonic Load Case}

Comparisons are made between the four monotonic analyses in this section to summarize the results. Figure A.21 compares the predicted load-versus-displacement curves, representing the plane stress case for the four different crack-size-to-width ratios. All other dimensions for the specimens are identical. The trends for the plane strain and generalized plane strain cases follow trends similar to those shown here. Figure A.22 compares the J-integral-versus-load curves for the plane stress case. Clearly, the toughness calculated from this SEN(T)-specimen geometry is highly dependent on the initial crack depth.

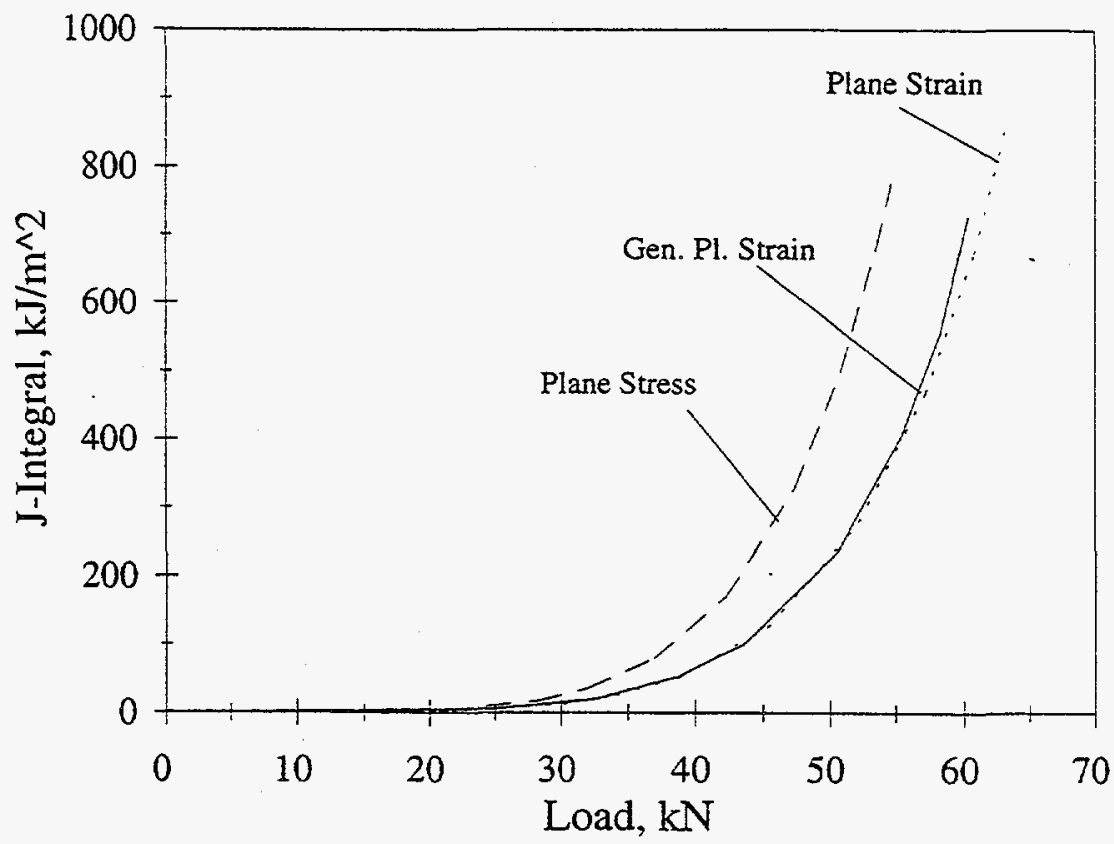

Figure A.17 J versus load, Specimen PB4, a/w $=0.82$ 


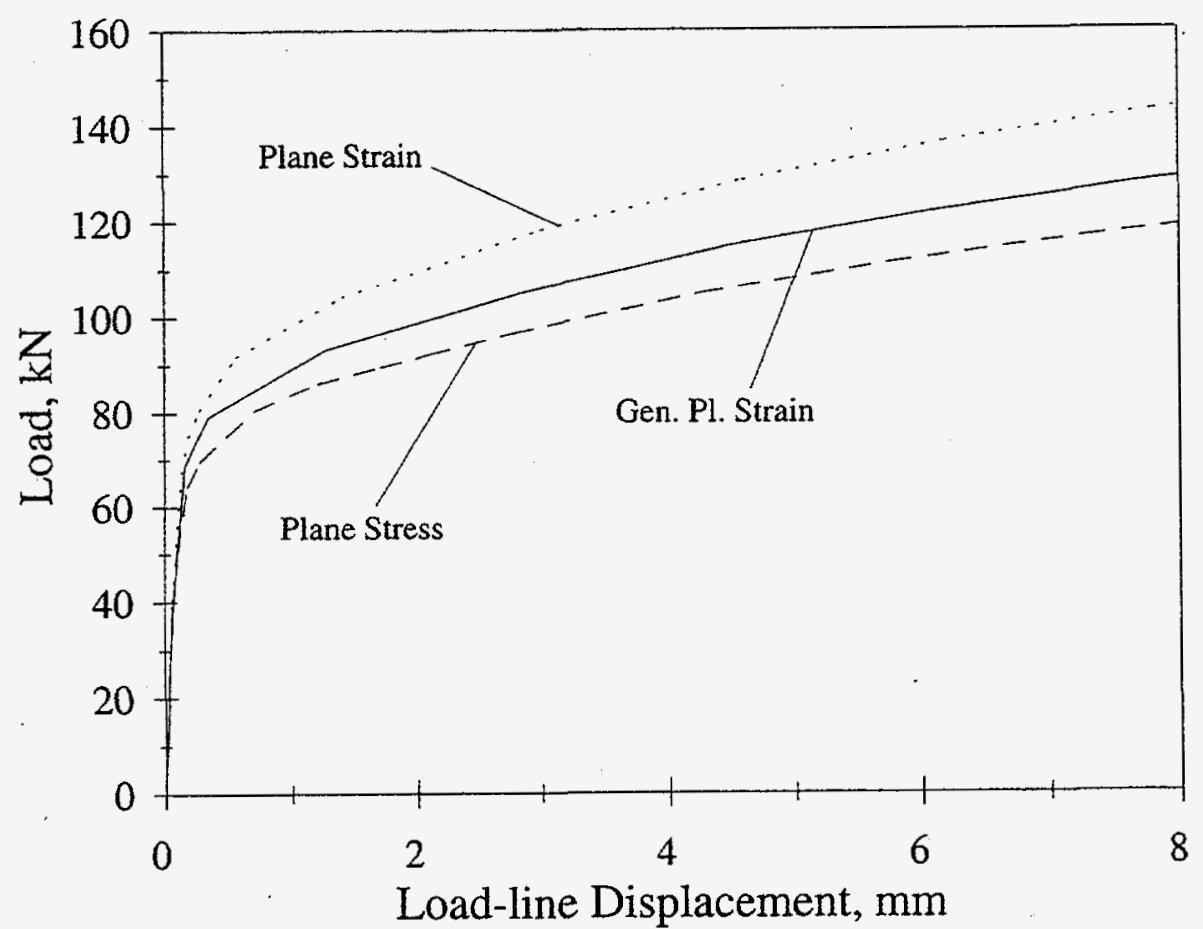

Figure A.18 Load-displacement curve, Specimen PB5, a/w $=0.5$

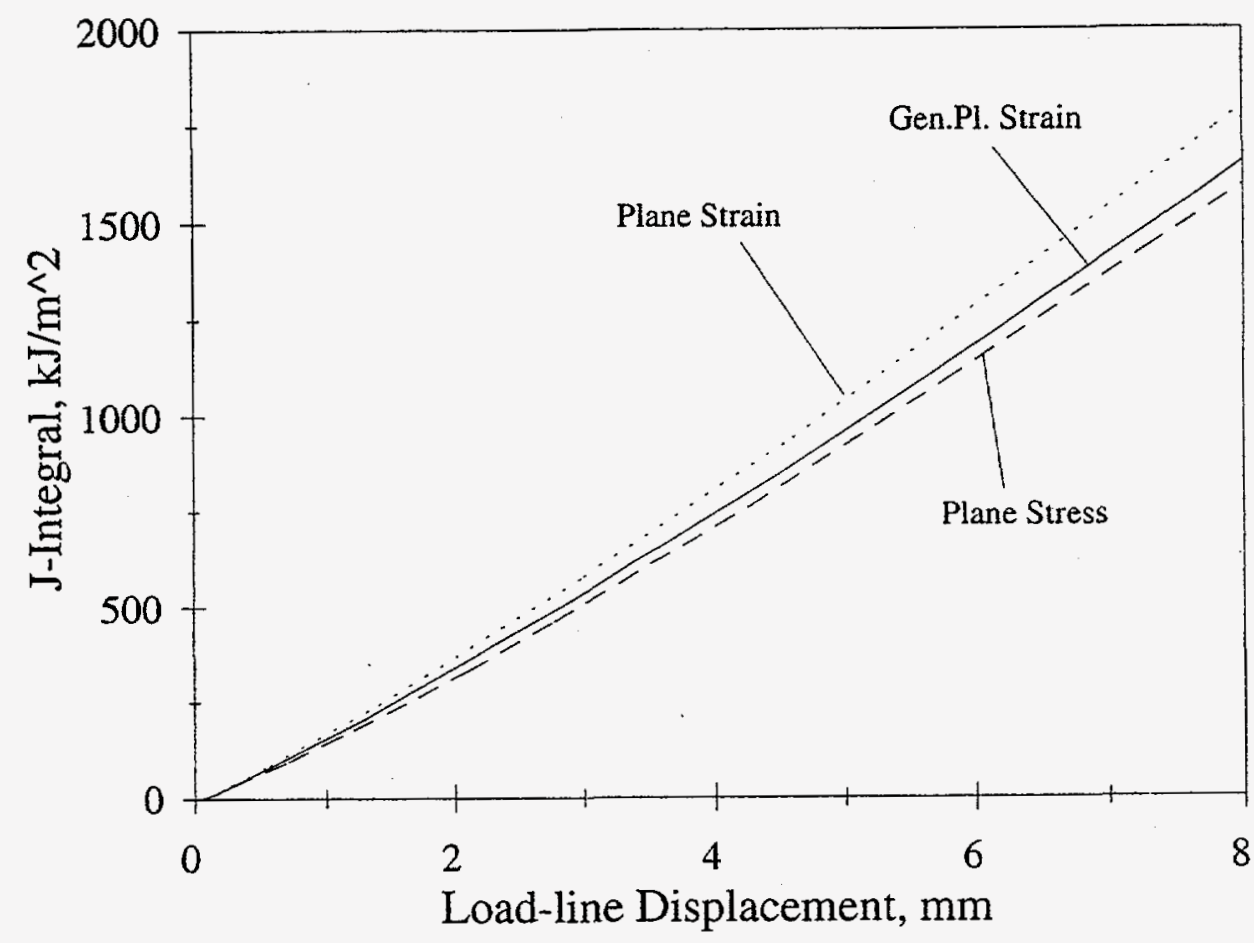

Figure A.19 J-integral versus displacement, Specimen PB5, $a / w=0.5$ 


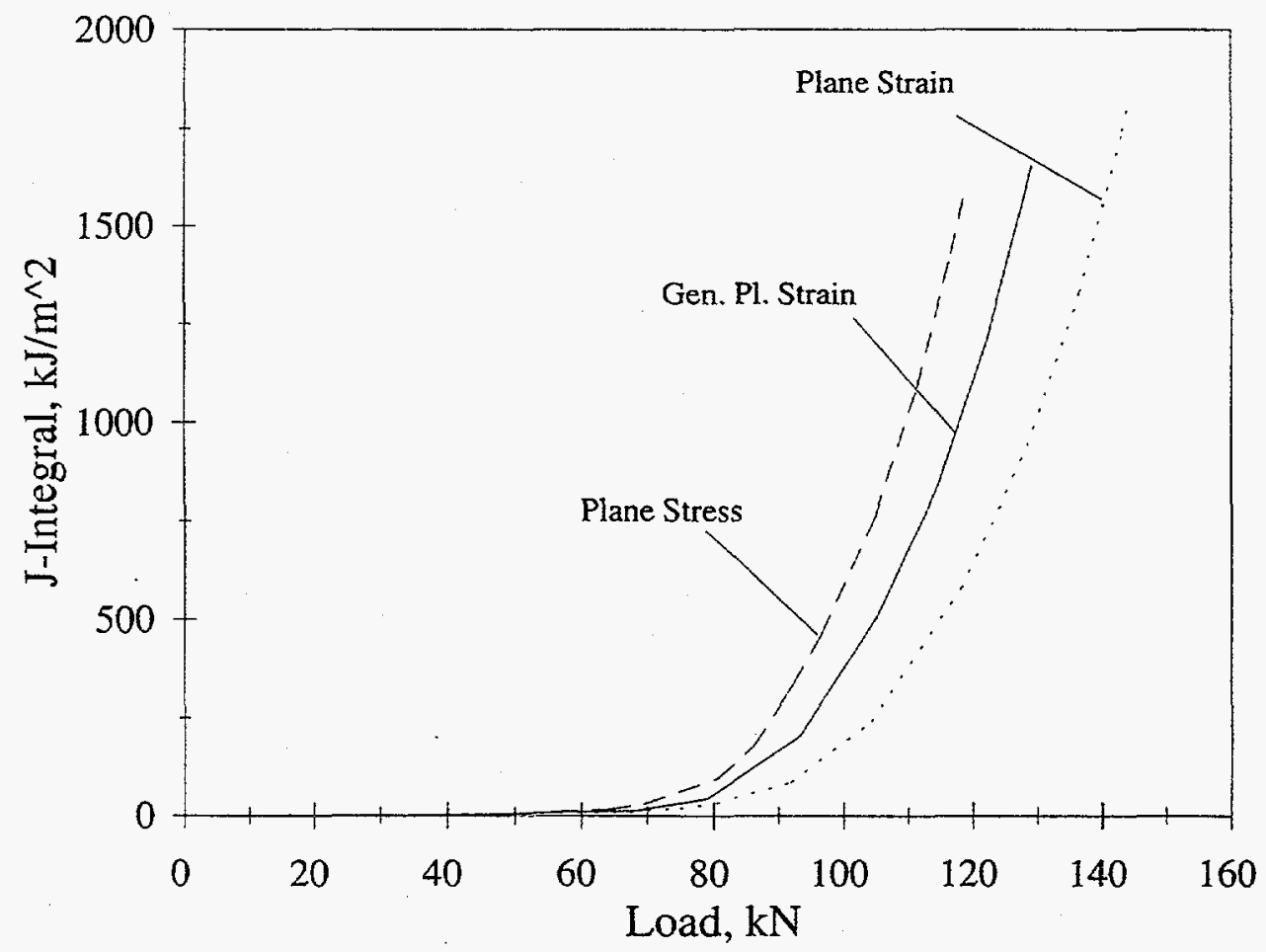

Figure A.20 J-integral versus load, Specimen PB5, a/w $=0.5$

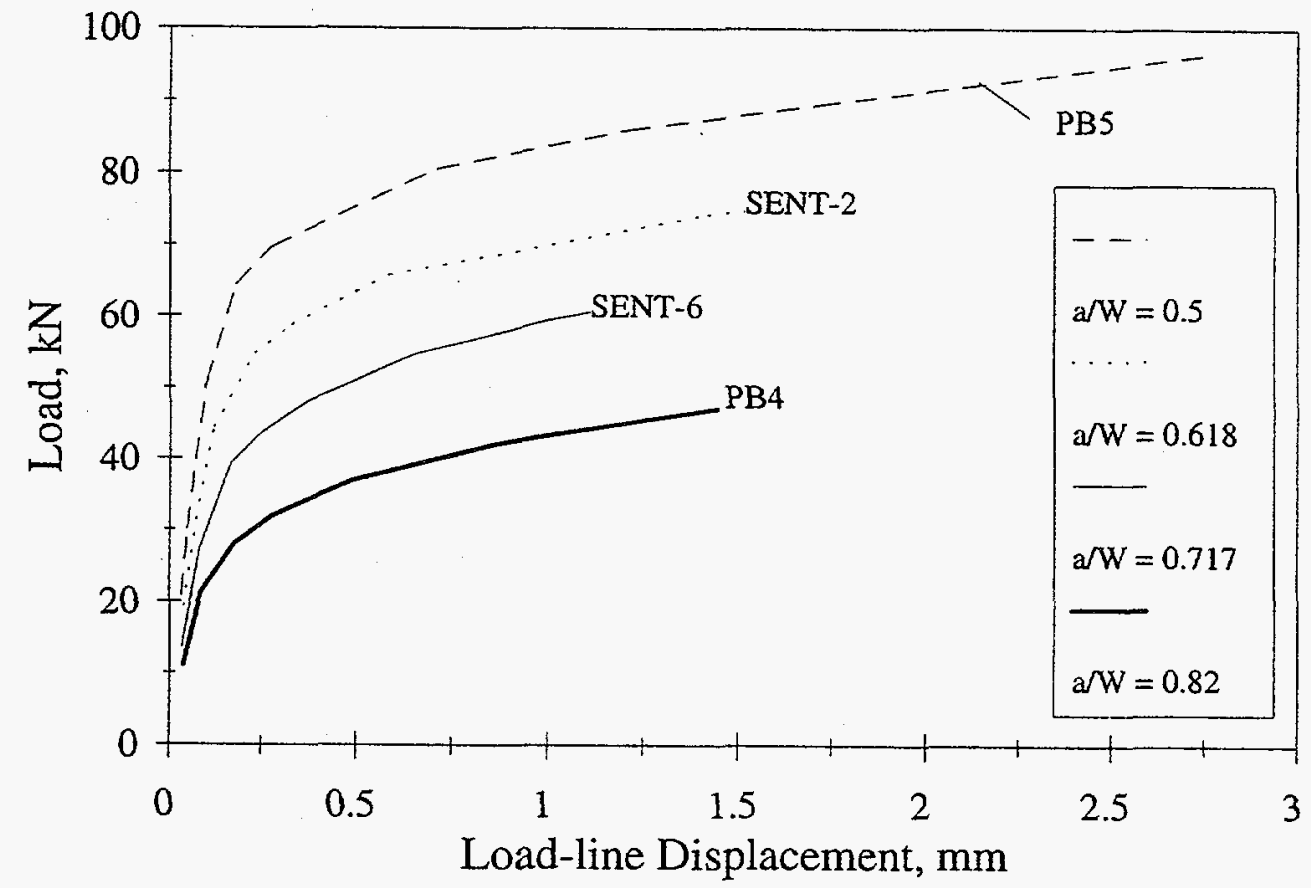

Figure A.21 Load versus displacement comparison, no crack growth 


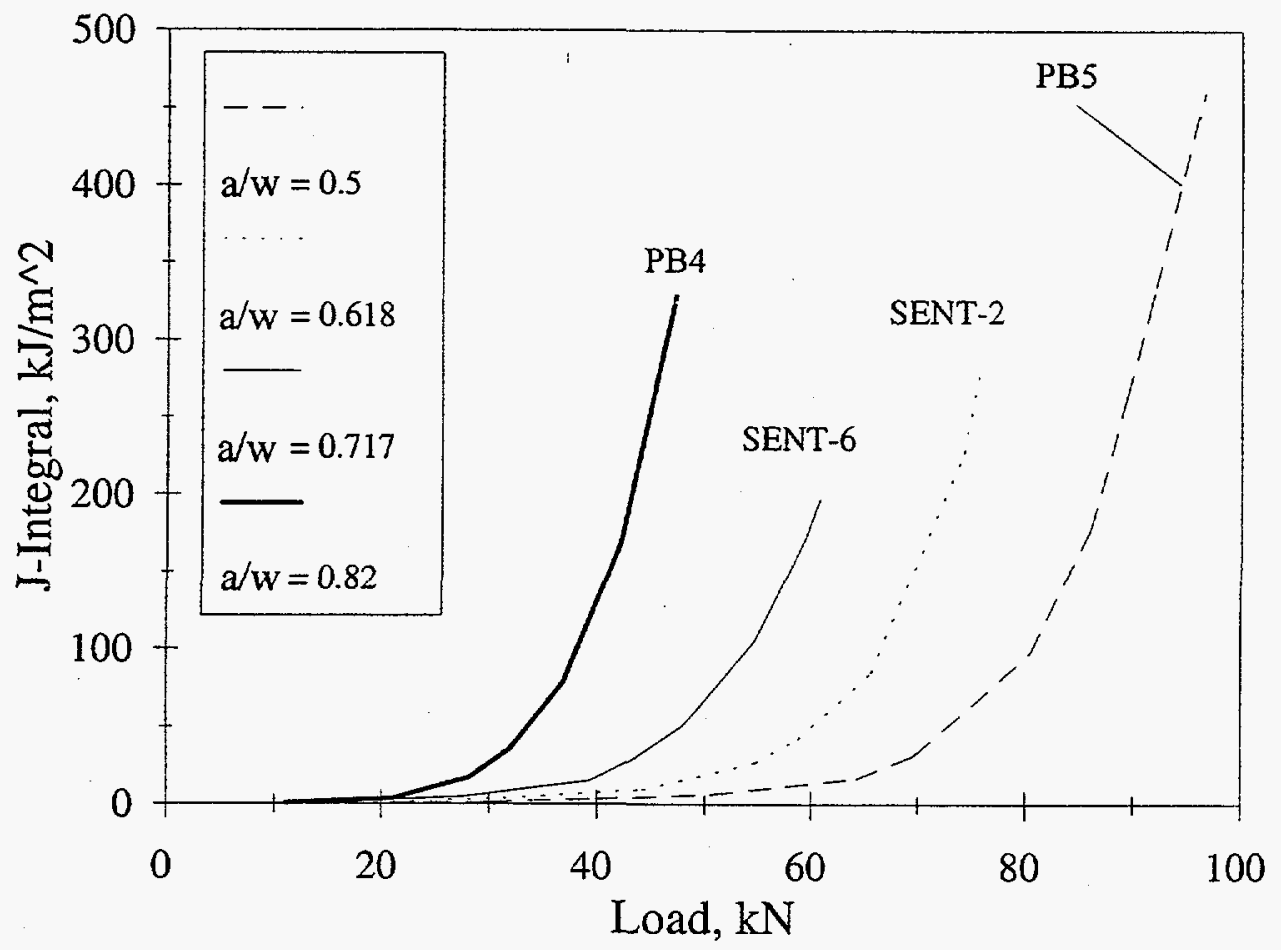

Figure A.22 J-integral versus load comparison, no crack growth

\section{A.6 Analysis Results for Cyclic Loading, SENT-4 (a/w = 0.635)}

The finite element analyses for the SENT-4 specimen required some different considerations compared with the monotonic-loading analyses. For the cyclic-loading analyses, it is possible for the crack faces to contact each other during an unloading cycle. However, it is not possible for the machined starter-notch portion of the "crack" to close because its faces are two widely separated. Hence, the only possible contact points (for the magnitude of the loads applied to the SENT-4 specimen) are along the region of the EDM notch and the fatigue precrack region behind the initial crack tip. This total distance is about 3 to $4 \mathrm{~mm}$ ( 0.12 to 0.16 in). To account for contact effects, a rigid surface was defined in the ABAQUS model which prevents overlap of the mesh by forcing compressive stresses at the contact points*. It turned out that the effect of contact is small, so that only some analyses included this effect. For analyses which included the possibility for contact, the ' $C$ ' designation is used for contact, while for analyses which did not include the possibility for contact, the ' $\mathrm{NC}$ ' designation was used for no contact. Figure A.2b illustrates the deformed shape of an SEN(T) specimen at the peak tensile load. Note the crack opening region. During unloading,

- Note that the finite element mesh did not include the width of the machined notch. The rigid zone was defined for $3.5 \mathrm{~mm}(0.14 \mathrm{in})$ behind the original crack tip. Accordingly, crack face contact can occur only over $3.5 \mathrm{~mm}$ $(0.14 \mathrm{in})$ behind the original crack tip so that the geometry of Figure 3.4 is modeled adequately. 
the region behind the original crack tip (within $3.5 \mathrm{~mm}$ [0.14 in]) could come into contact. Note that as the crack grows, the new crack surfaces can come into contact during unloading. This possibility is also taken into account.

Also, for all of these analyses, isotropic hardening is used to define the evolution of the yield surface. The original plan was to use both isotropic and kinematic hardening, but as will be seen, isotropic hardening produced excellent results. This finding is not unusual. Stainless steel is better represented by isotropic hardening than by kinematic hardening, based on previous experience.

The experimental displacement versus crack growth curve, which serves as input for all of the analysis cases, is illustrated in Figure A.23 for the SENT-4 specimen. With this curve as input, the loads,

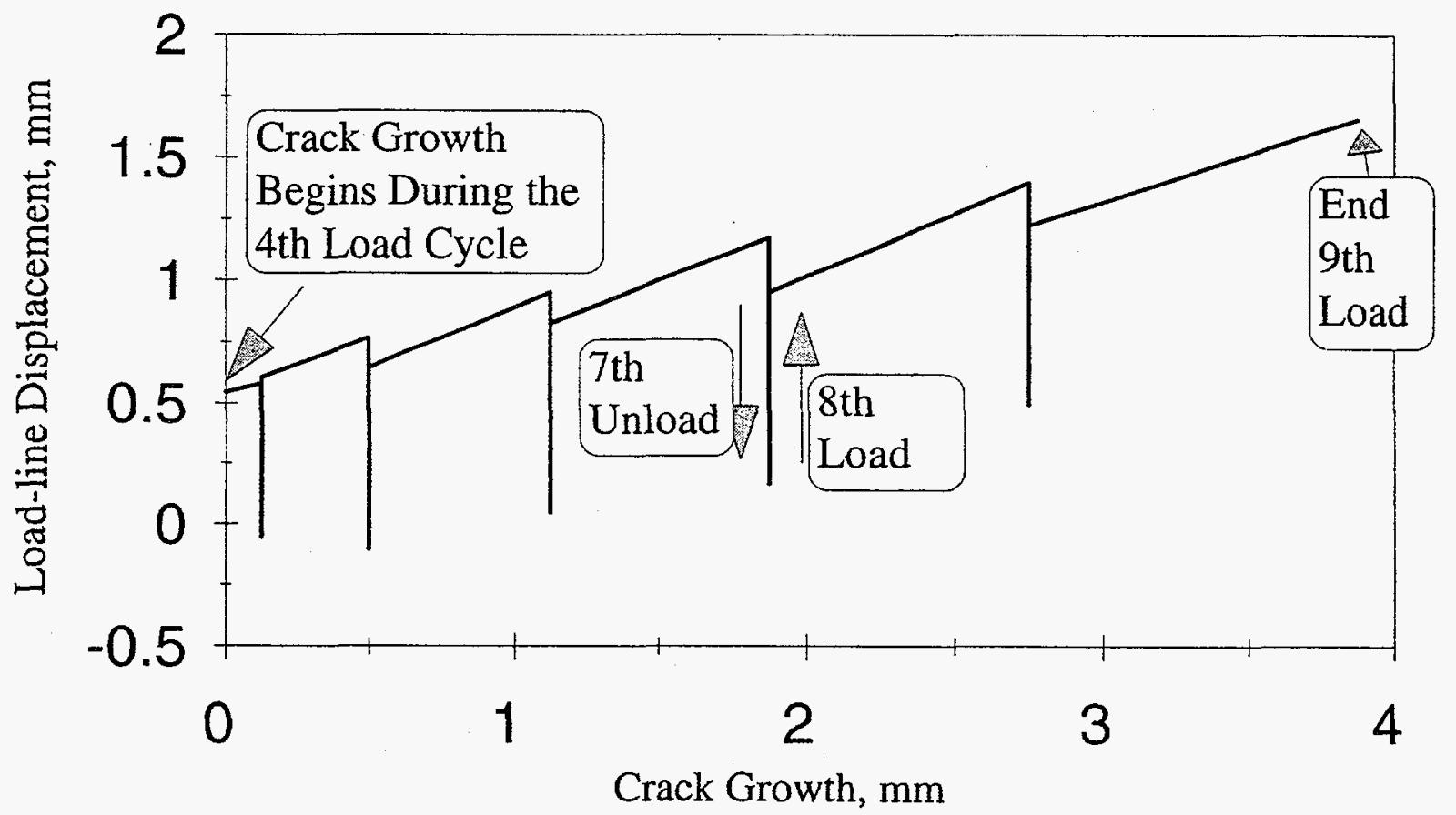

Figure A.23 Experimental displacement versus crack growth for SENT-4, used as input to analysis 
J-integral, etc., are predicted from the analyses. The predicted load-versus-displacement curve for the plane stress analysis without crack-face contact permitted during unloading is illustrated in Figure A.24. It is seen that the predictions compare remarkably well with the experimental data throughout the entire history. A blow-up of these comparisons is provided in Figure A.25a over the first three-and-one-half loading cycles, and in Figure A.25b over cycles four to six. Recall from Figure A.23 that a total of nine cycles were applied to this test and crack growth began during the fourth load cycle.

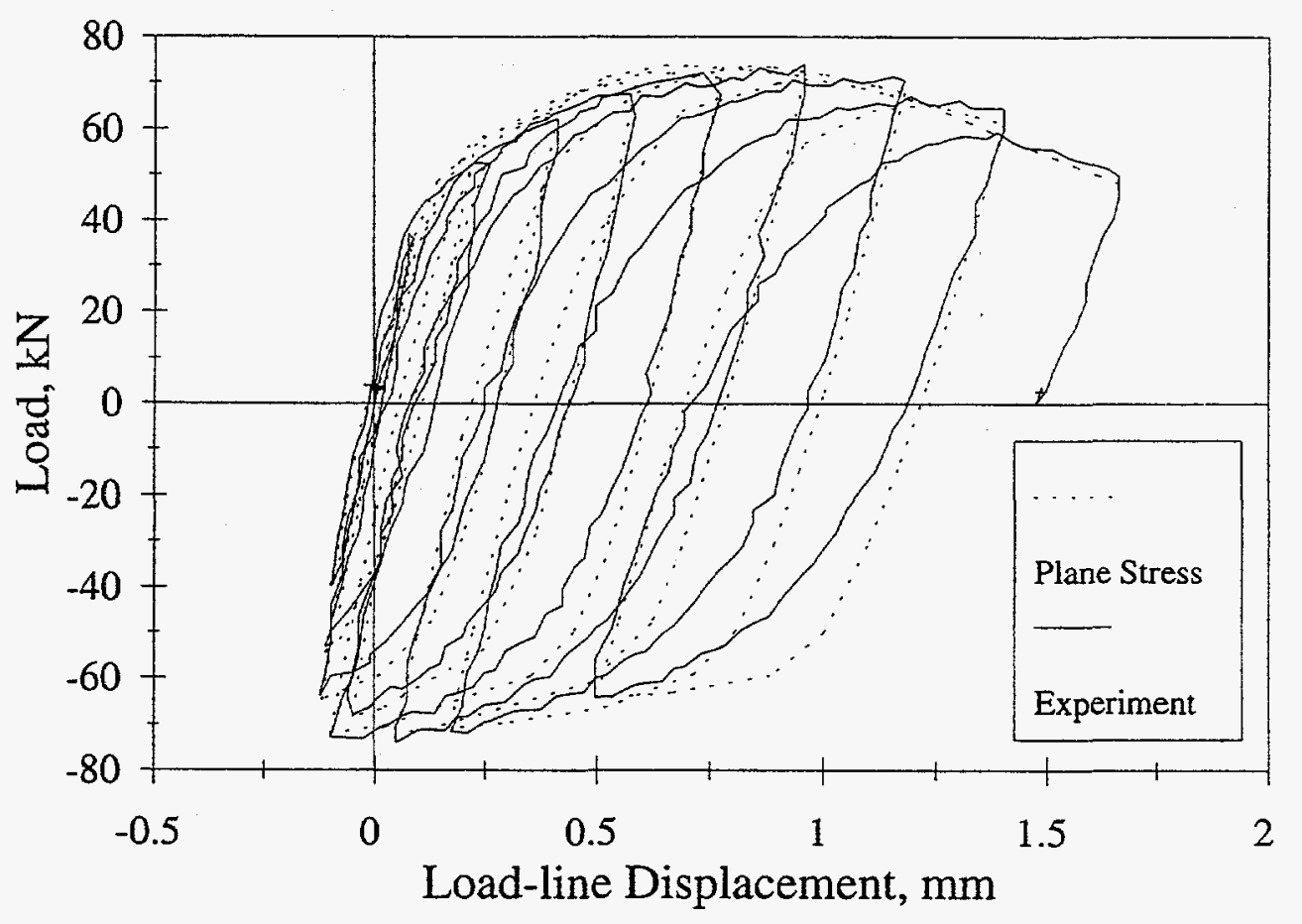

Figure A.24 Predicted load-displacement curve SENT-4, no contact permitted 


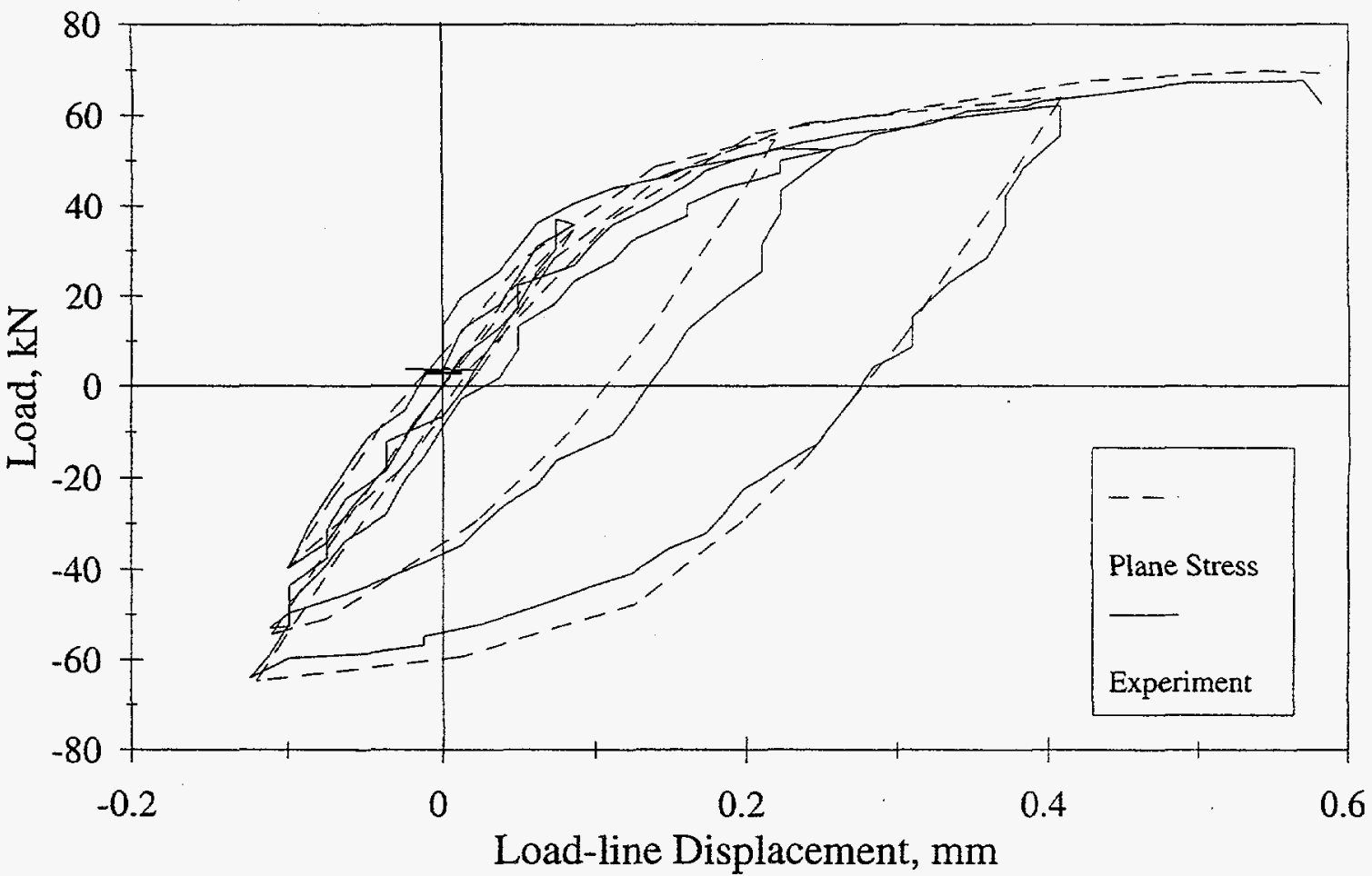

(a) First $3 \frac{1}{2}$ cycles

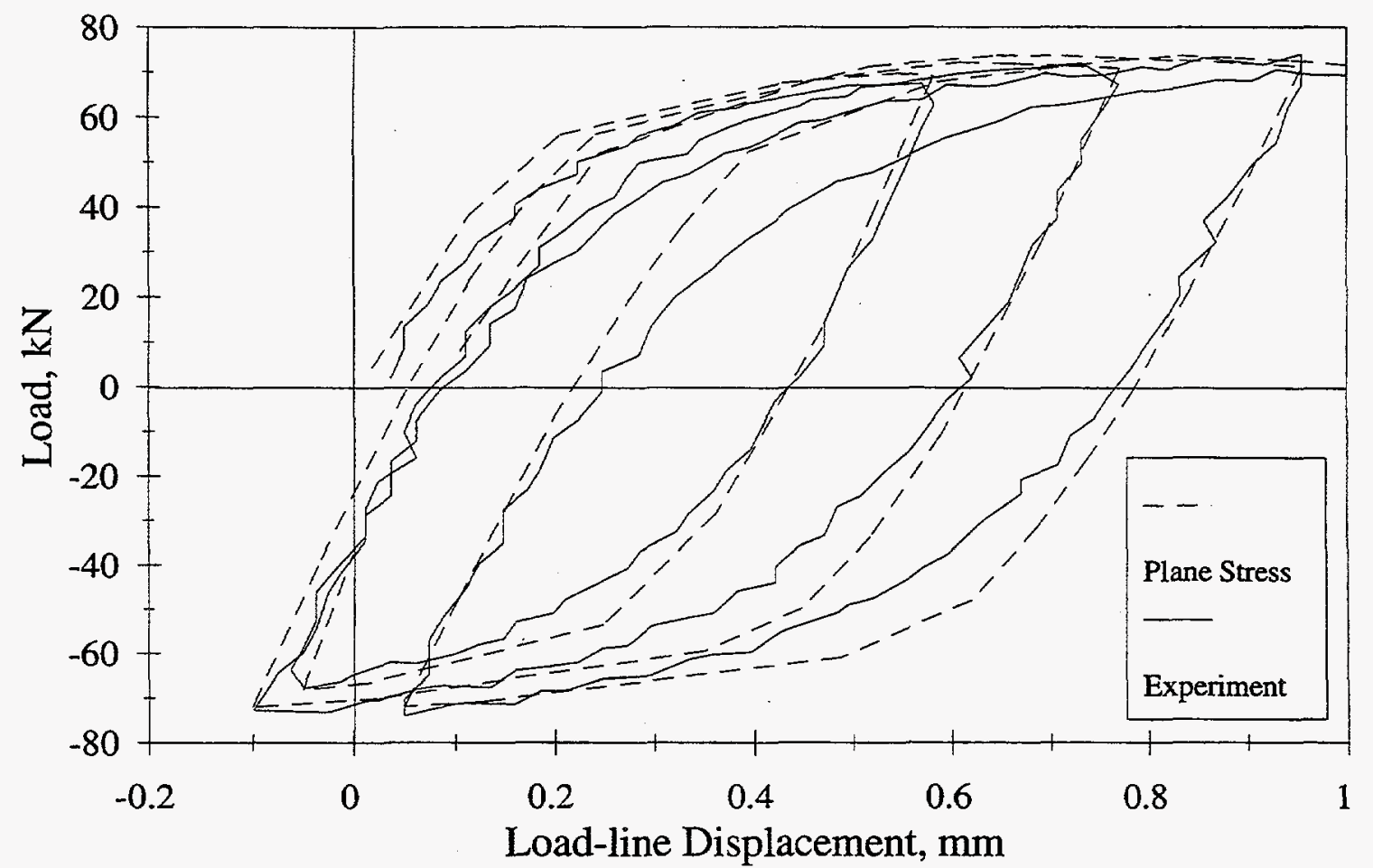

(b) Cycles 4 to 6

Figure A.25 Predicted versus experimental load-displacement curve, SENT-4, no contact permitted 
The results of this analysis when contact behind the crack tip is permitted during unloads is illustrated in Figure A.26. The effect of permitting contact is seen to be small, especially in the tensile-load regime. A blow-up of these predictions in the compressive-load regime is illustrated in Figure A.27. It is seen that, when contact is permitted, the maximum compressive load is increased slightly for each cycle compared with the analysis which neglects contact (Figures A.24 and A.25). It is interesting to note that the results compare more favorably with the experimental data when contact is neglected. A direct comparison of the results for the plane stress contact- and no-contact analyses is illustrated in Figure A.28. While the differences are not important here, it should be pointed out that, in a cracked pipe in service, the contact behind the crack faces could be important because contact is possible behind the entire crack. Since the

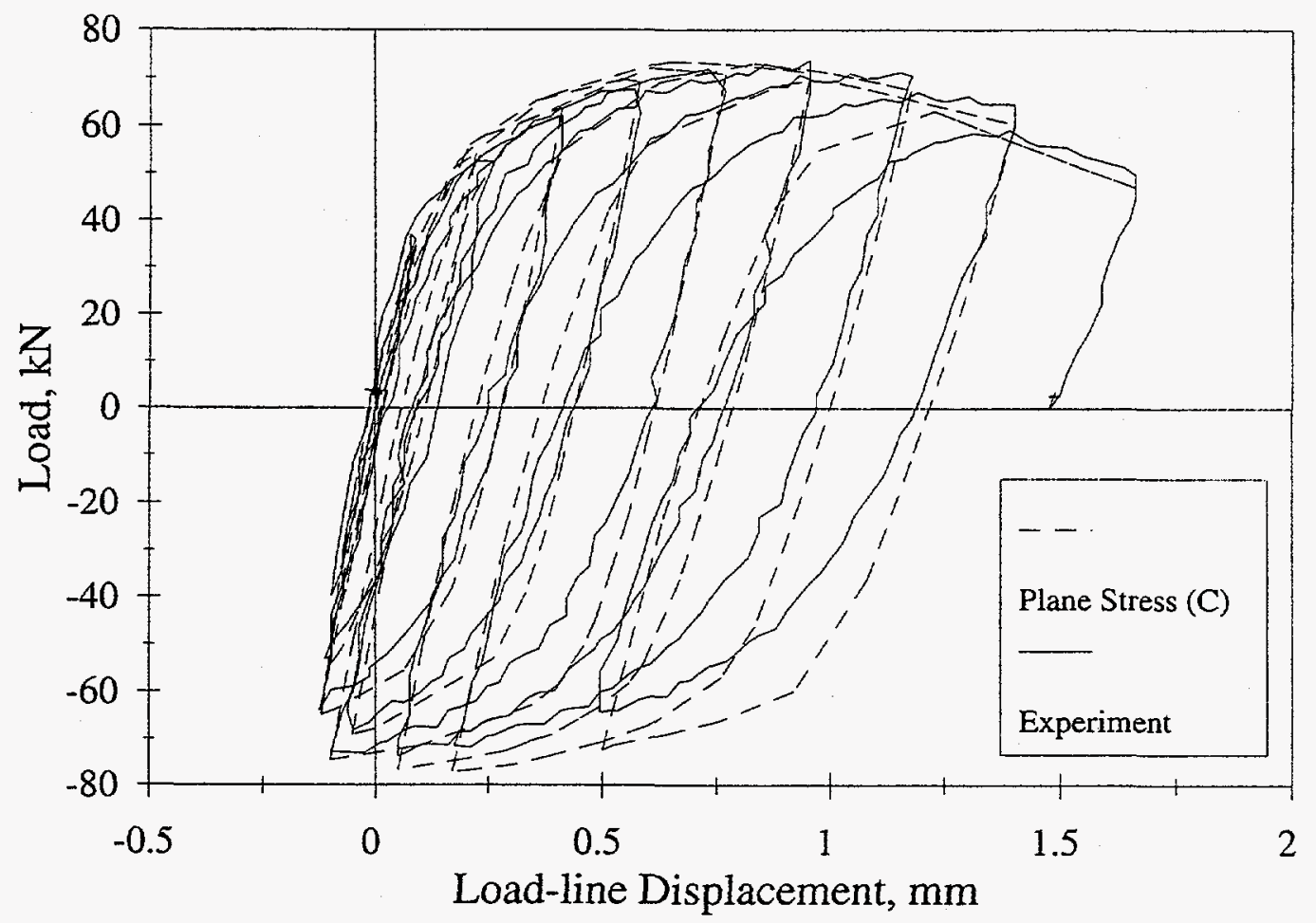

Figure A.26 Predicted versus experimental load-displacement curve, SENT-4; contact permitted 


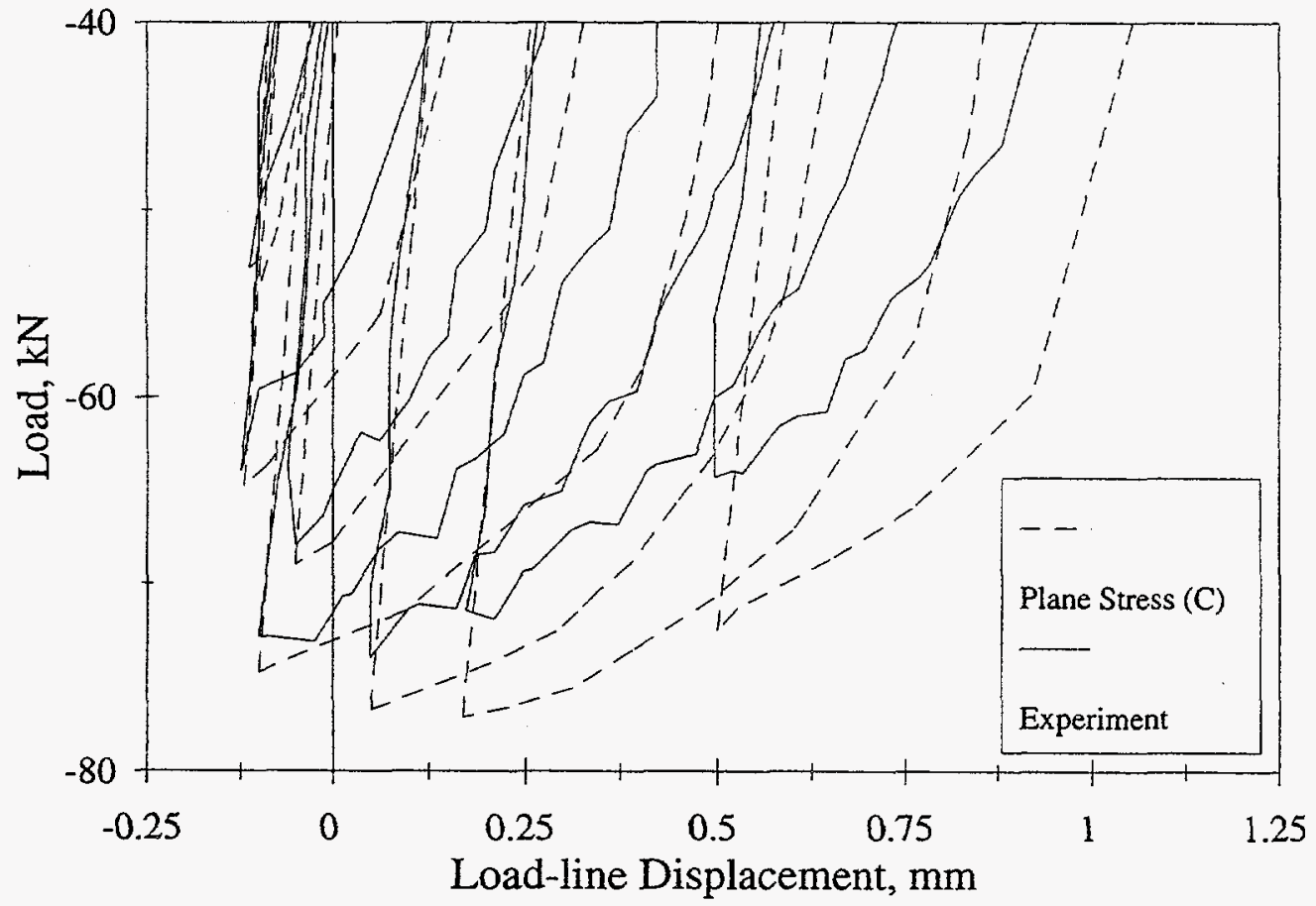

Figure A.27 Predicted versus experimental load-displacement curve near the compressive peaks, SENT-4; contact permitted

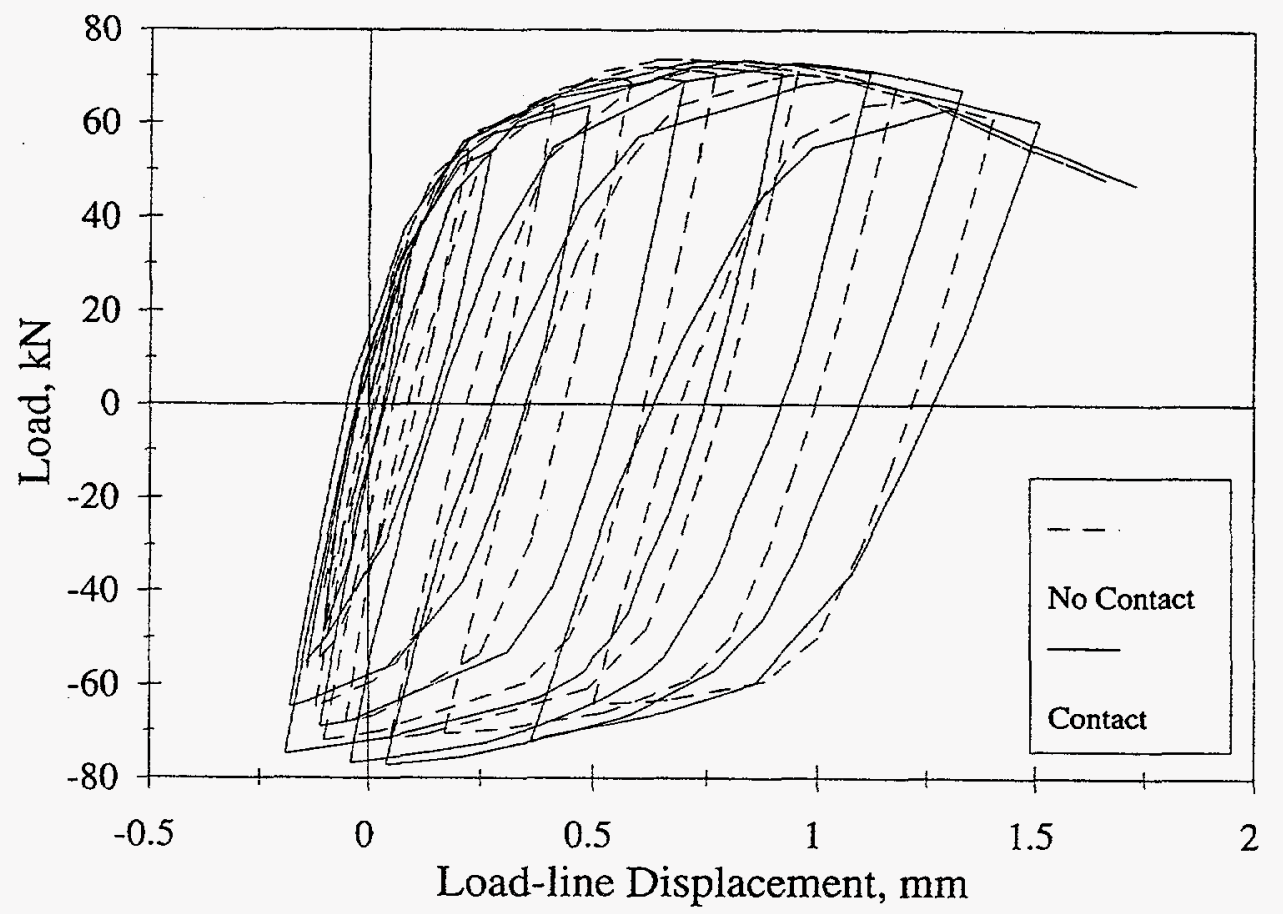

Figure A.28 Comparison of load-displacement predictions between the contact and no-contact plane stress solutions, SENT-4 
specimens are machined with a large separation between the crack faces, except over a small distance of 3 to $4 \mathrm{~mm}(0.12$ to $0.16 \mathrm{~m})$ behind the crack tip, the effect of contact is diminished.

A comparison of the load-versus-displacement predictions for the plane strain case is illustrated in Figure A.29. As is seen, the predictions are larger in absolute magnitude compared with experiment in both the tensile and compressive load regimes. This finding is consistent with the analyses of the monotonic-load tests discussed in Sections A.5.1 and A.5.2. A blow-up of these predictions over the first three cycles is illustrated in Figure A.30. It is seen that the errors develop early in the load history and become larger as more cycles are modeled. In fact, comparing the errors for this analysis with those for the monotonic plane strain cases (Figures A.5 and A.11), it becomes apparent that the plane strain assumption is worse for the cyclic-load case than for the monotonic-load case.

The J-resistance curves for Specimen SENT-4 are illustrated in Figure A.31. Several important points about the J-R curves can be made:

- The Ahmad J-estimation scheme and finite element predicted J-R curves for the cyclic load case are closer than the corresponding comparison for the monotonic-load cases (Figures A.8 and A.14). Recall that the cyclic-load J-R curves are experimentally evaluated using the method of Reference A.2 and the upper envelope of the load-displacement record.

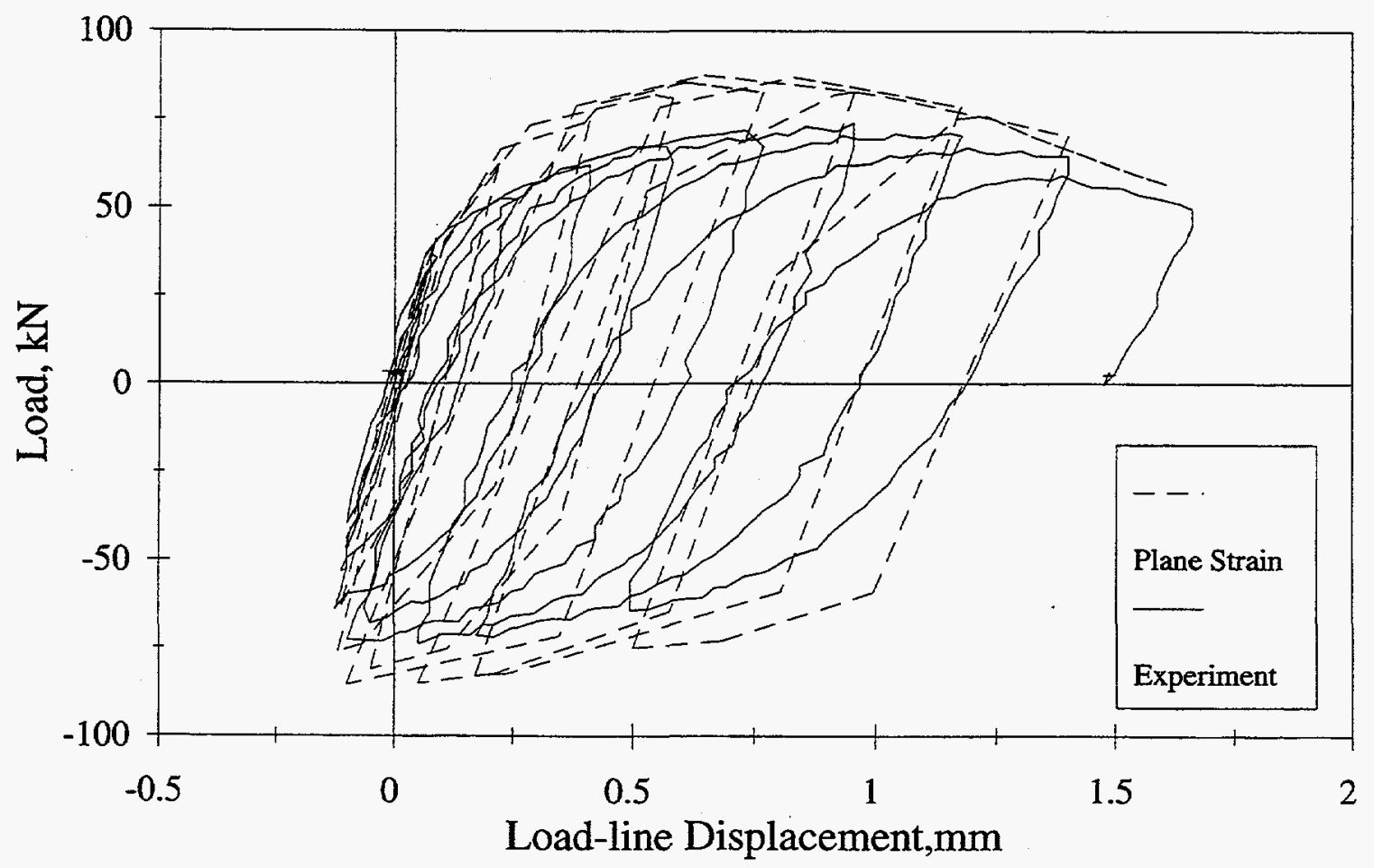

Figure A.29 Predicted versus experimental load-displacement curve, plane strain, SENT-4 


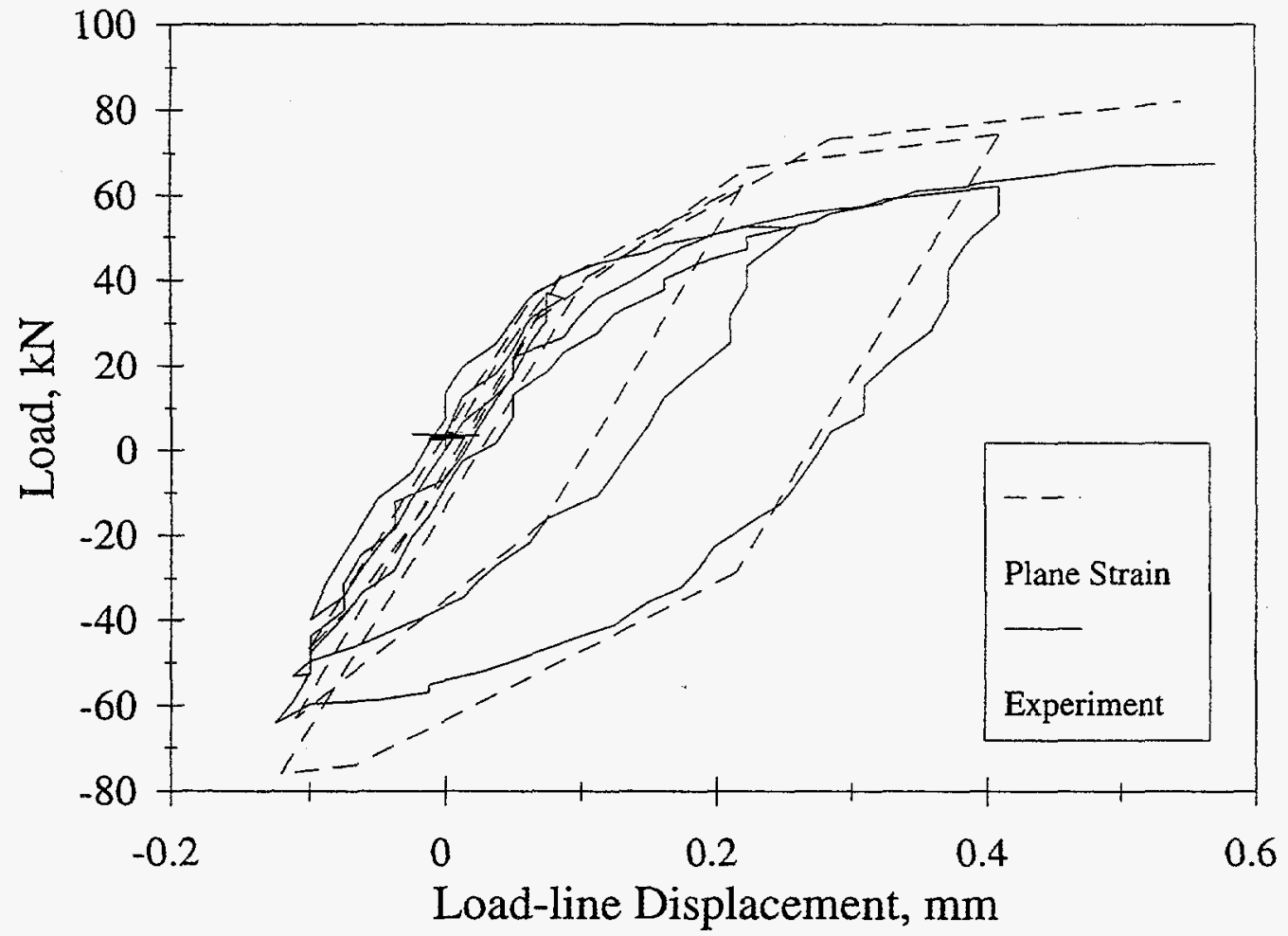

Figure A.30 Predicted versus experimental load-displacement curve over the first three cycles, plane strain, SENT-4

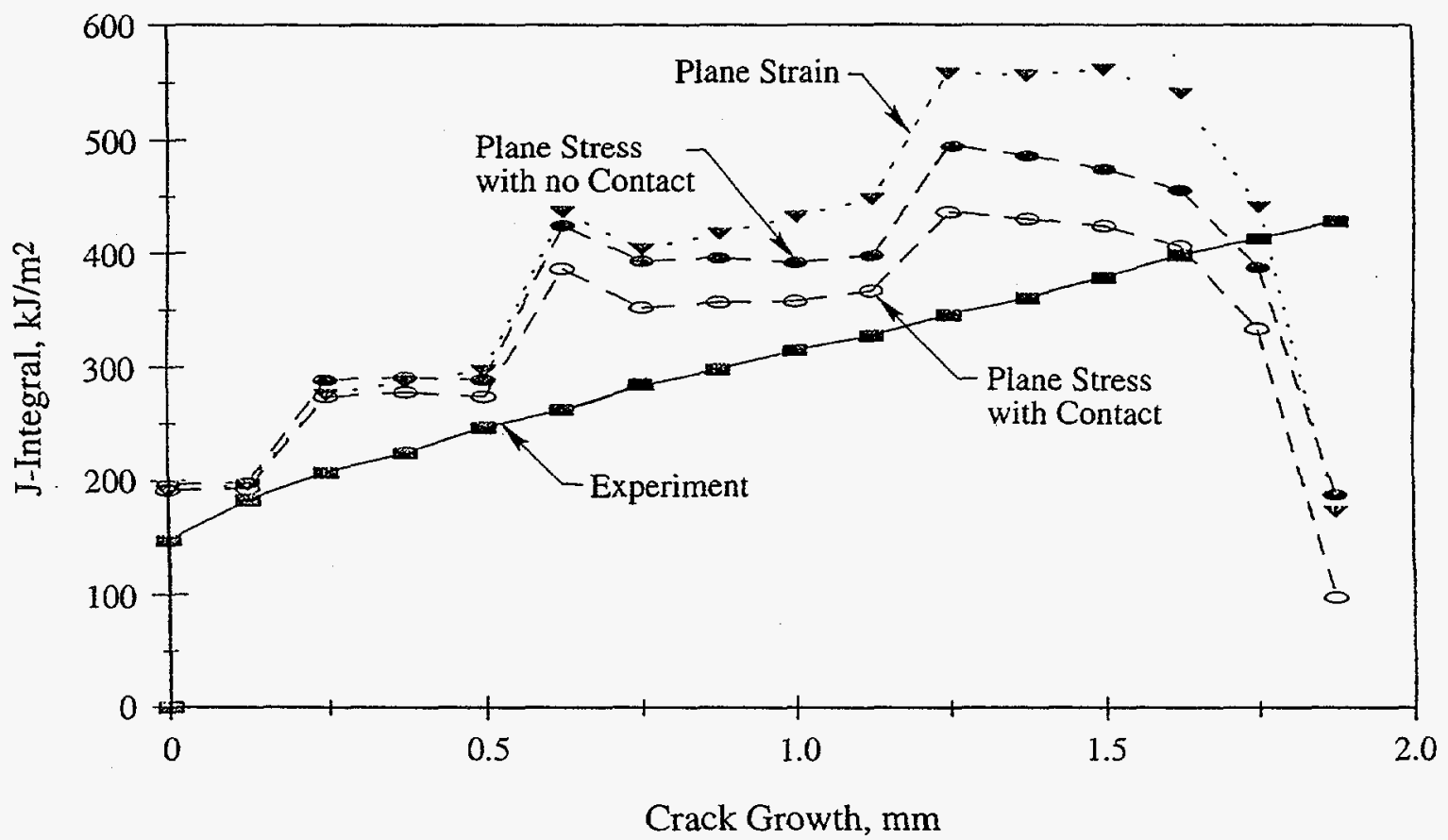

Figure A.31 J-resistance curves, SENT-4 
- The finite element predicted curves are plotted only through part of the seventh load cycle. Beyond this point, the largest path definition for $J$, as defined by ABAQUS, goes through the wake of the crack growth. At this point, $J$ can no longer be calculated accurately. In Figure A.31, this restriction means that the calculated values for $J$ should be disregarded for crack growth beyond about $1.75 \mathrm{~mm}$ ( $0.07 \mathrm{in})$, corresponding to the point where the curve drops sharply.

- Crack growth began during the 4th load cycle. The total crack growth amount at the end of the load cycles was:

- 4th load cycle $0.125 \mathrm{~mm}(0.005 \mathrm{in})$

- 5th load cycle $0.500 \mathrm{~mm}(0.020 \mathrm{in})$

- 6th load cycle $1.125 \mathrm{~mm}(0.044 \mathrm{in})$

- 7th load cycle $1.875 \mathrm{~mm}(0.074 \mathrm{in})$

- 8th load cycle $2.750 \mathrm{~mm}$ ( $0.108 \mathrm{in})$

- 9 th load cycle $3.875 \mathrm{~mm}(0.153 \mathrm{in})$

The different load cycles can be identified in Figure A.31 as each data point represents crack growth through one element (the finite element dimension along the crack growth region was $0.125 \mathrm{~mm}[0.005 \mathrm{in}]$ ). For each load cycle, the finite element predicted J-R curve appears to have a plateau. For instance, the fifth load cycle, with crack growth through three elements, is at a plateau $J$ value of about $275 \mathrm{~kJ} / \mathrm{m}^{2}\left(1,570 \mathrm{in}-\mathrm{lb} / \mathrm{in}^{2}\right)$. These plateaus are not believed to be real. Rather, the experimental determination of crack growth reinitiation after an unload cycle is difficult, and is not necessarily accurate. If, in Figure A.23, crack growth after a reload cycle occurs at a lower value of load-line displacement, then the predicted J-R curves of Figure A.31 will rise smoothly (like the experimental curve) rather than have plateaus. Hence, the final value of $\mathrm{J}$ at the end of the load cycle is believed to be more representative. If that is true, the comparison between Ahmad J-estimation $\mathrm{J}$ values and the finite element analysis $\mathrm{J}$ values is closer than it appears in Figure A.31.

- The differences between the J-R curves for the plane stress analyses with and without permitting contact, become larger as cycles accumulate. However, for the specimen examined here, where the contact zone behind the crack tip is small ( $3.5 \mathrm{~mm}$ [0.14 in]), the differences are small. Nonetheless, it should be clear that if the contact zone is larger, as in a service crack in a pipe rather than in a fabricated laboratory specimen, the importance of closure on the J-R curve is expected to be more important.

- Finally, and perhaps most importantly, the meaning of $\mathrm{J}$ is unclear for cyclic loading. The intent here is to provide an operational definition of the J-R curve, which, when combined with an estimation scheme based on deformation theory, provides adequate engineering estimates of the load reduction caused by cyclic tearing.

Figure A.32 compares the J-resistance curves for the SENT-2 (monotonic loading) and SENT-4 (cyclic loading) Ahmad J-estimation analyses and finite element analyses (plane stress only). SENT-2 and SENT-4 have nearly the same initial crack size so that the crack tip constraint between the two is nearly 


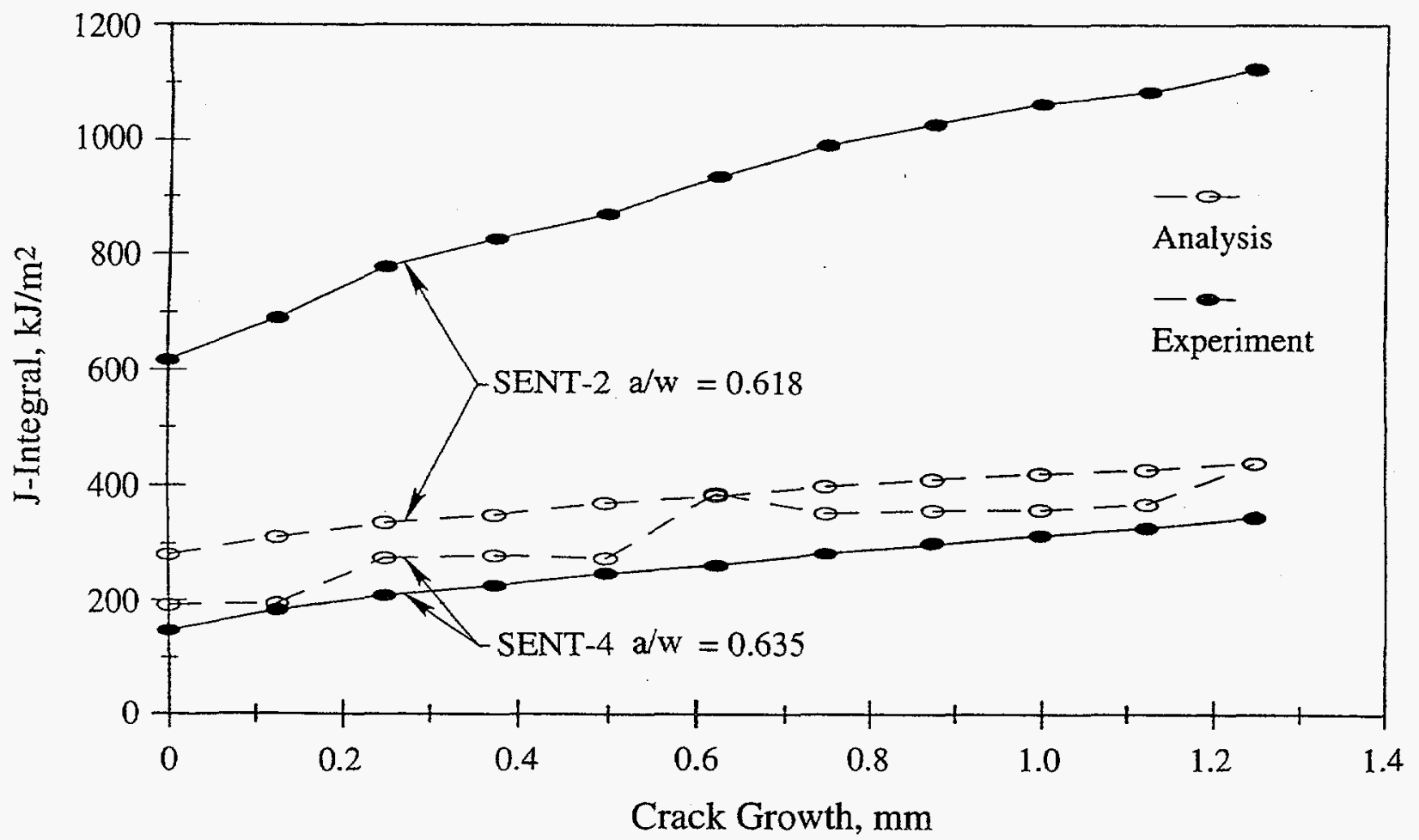

Figure A.32 J-resistance curves for SENT-2 and SENT-4, plane stress; the SENT-4 analysis included contact

identical. It is apparent that the estimate of $J$ using the procedure of Reference A.2 is poor for the monotonic-loading case, but better for the cyclic-loading case. In addition, the reduction in the J-R curve due to cyclic loading is much larger when using the Ahmad estimation than for the finite element predictions.

The J-integral from the plane stress analysis throughout the load history is plotted in Figure A.33 versus displacement and in Figure A.34 versus load. The behavior of $J$ during the unload portions can be observed. Again, results are plotted only through part of the seventh load cycle since $J$, as calculated, is inaccurate beyond this point.

Finally, it is useful to observe the crack profiles through a cycle as determined from plane stress analysis. Figure A.35 shows the crack profile at the end of the 8th load cycle followed by the profile after the 8th unload cycle. It is seen that at the end of the 8 th load cycle, the crack has grown $2.75 \mathrm{~mm}(0.108 \mathrm{in})$. Note that the region of contact (or crack closure) is pointed out in Figure A.35. Here it is seen that the size of the crack closure is about $1 \mathrm{~mm}(0.04 \mathrm{in})$. By following the 'steps' in this plot, the contact region after the 7th, 6th, 5th, and 4th unload steps can be observed. In addition, the amount of closure for the first three unloads, before crack growth, can be observed. The amount of crack closure before crack growth was about $3 \mathrm{~mm}(0.118 \mathrm{in})$, larger than that after crack growth. Note that the 'step' structure of the crack profiles persist after reloading, although it is deformed. This finding should make it clear that a geometric parameter such as crack-tip-opening angle cannot be useful to predict crack growth under cyclic-loading conditions. 


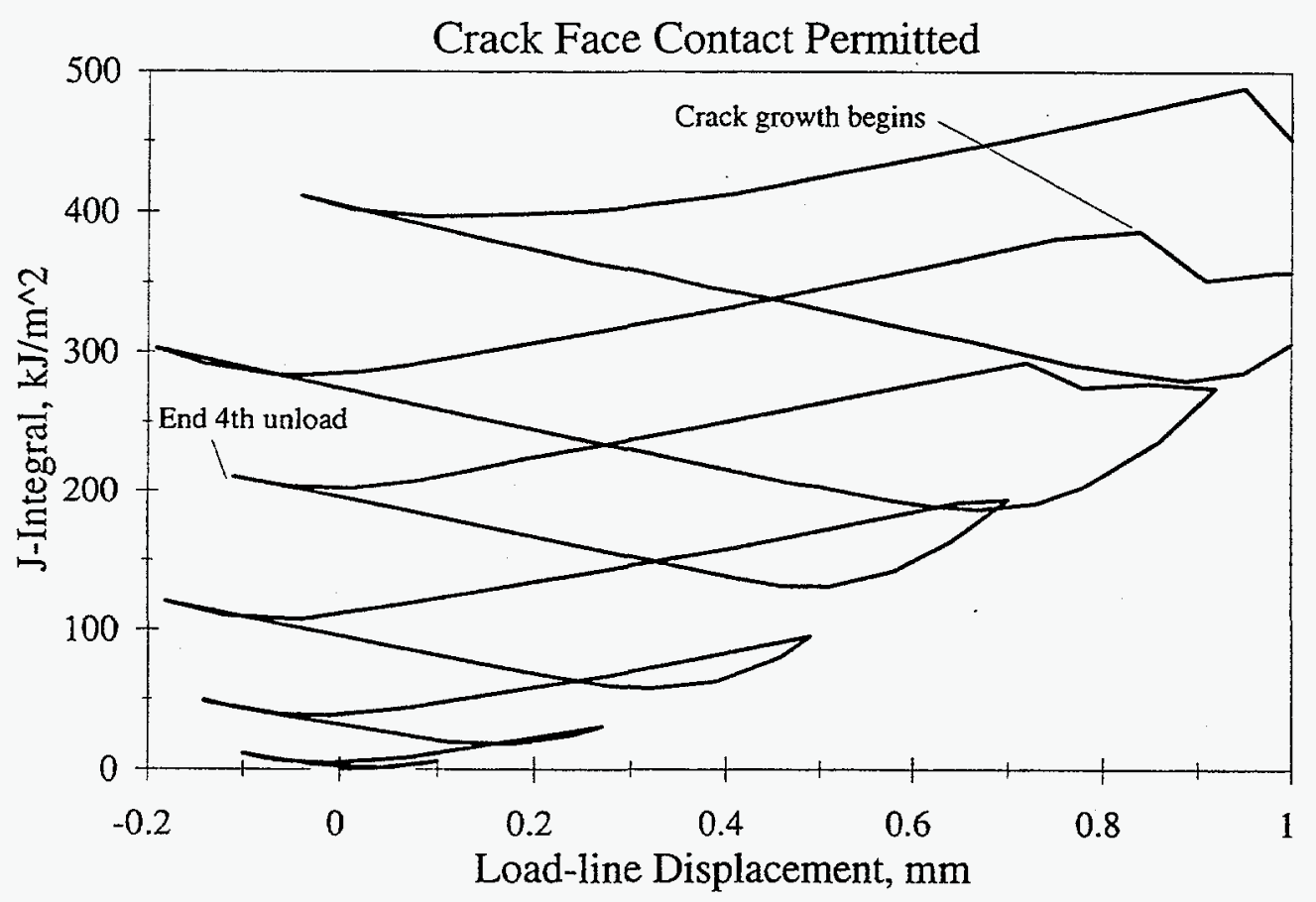

Figure A.33 J versus displacement, SENT-4, plane stress, contact permitted

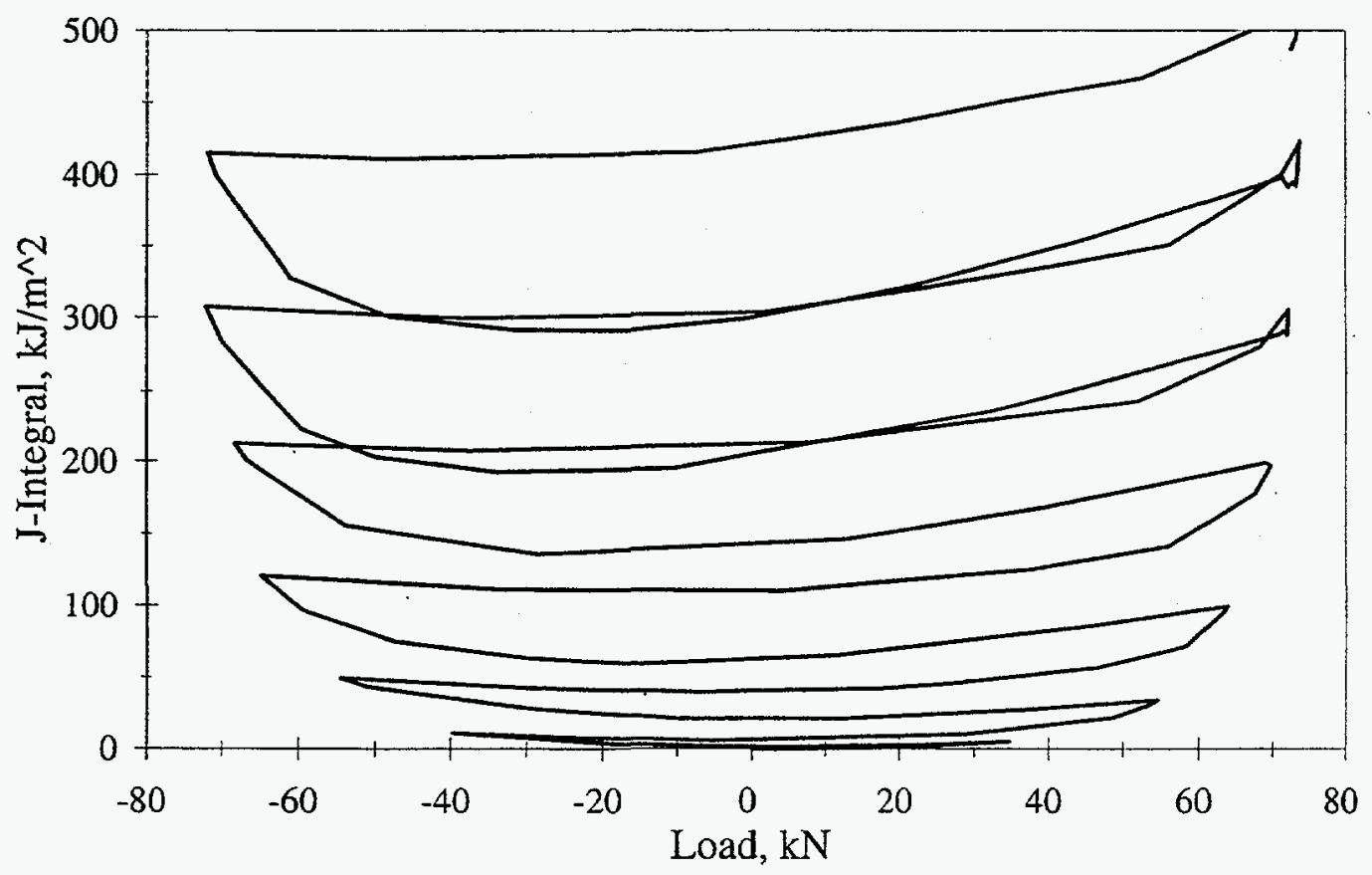

Figure A.34 J versus load, SENT-4, plane stress, contact permitted 


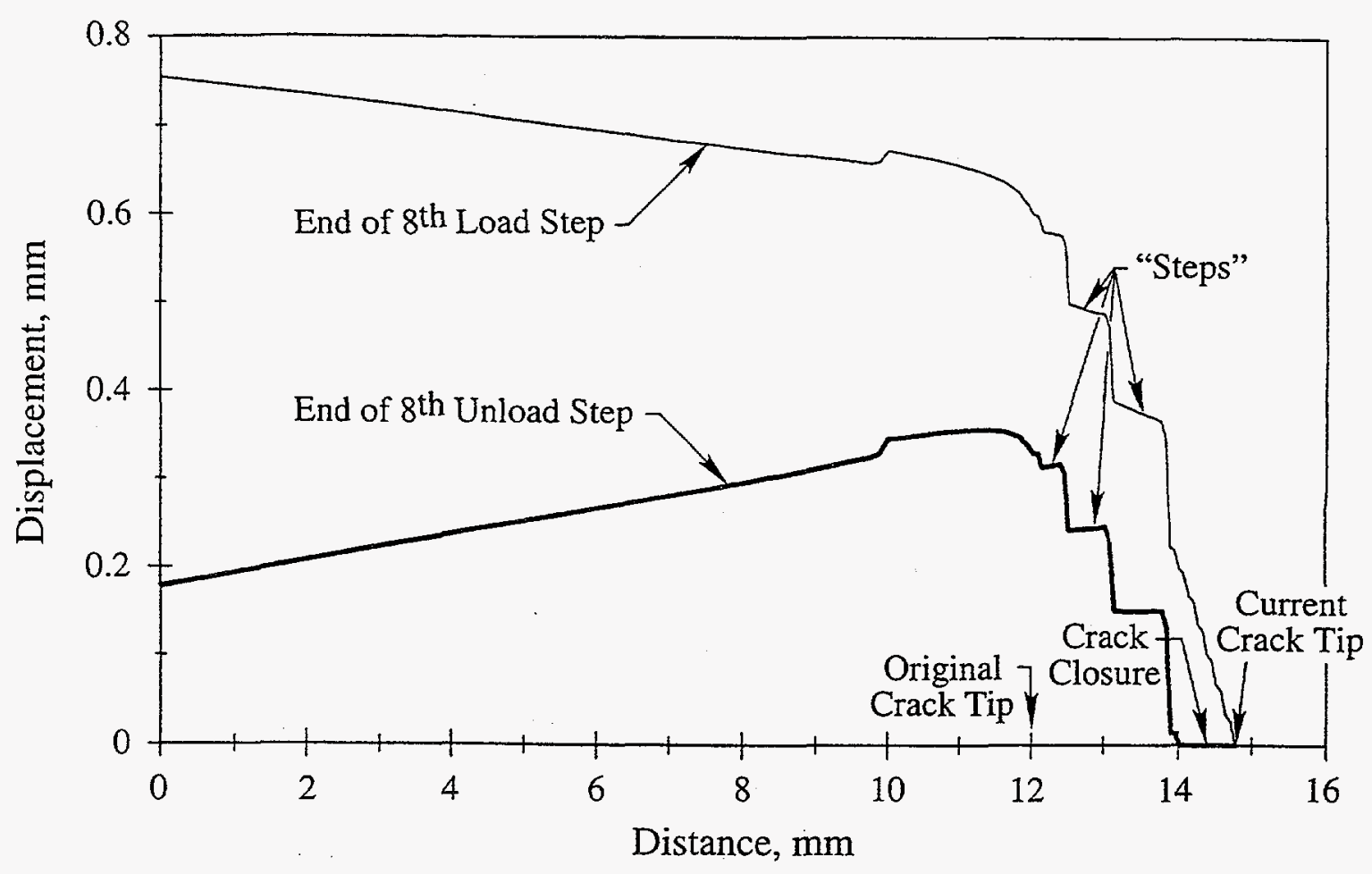

Figure A.35 Crack profiles, 8th load and unload cycle, SENT-4, plane stress

\section{A.7 Analysis Conclusions}

For the monotonic-load case, three finite element analyses of SEN(T) specimens were performed; plane stress, plane strain, and generalized plane strain. Load predictions are largest with the plane strain assumption and lowest with the plane stress assumption. The generalized plane strain analyses were between the extremes of plane stress and plane strain, and in general appear to provide the best comparison with experimental data.

The values of the J-integral determined from the analyses appear to be about one half those calculated from the experimental results using the method of Reference A.2. Although not conclusively proven here, it appears that the estimation method of Reference A. 2 for the fixed-grip conditions may need to be modified, perhaps for larger hardening exponents or higher toughness materials.

\section{A.8 References}

A.1 Kumar, V., German, M., and Shih, C., "An Engineering Approach for Elastic-Plastic Fracture Analysis," EPRI Report No. NP-1931, July 1981. 
A.2 Ahmad, J., Papaspyropoulos, V., and Hopper, A. T., "Elastic-Plastic Analysis of Edge-Notched Panels Subjected to Fixed Grip Loading," Engineering Fracture Mechanics, Vol. 38, No. 4/5, pp 283-294, 1991.

A.3 Schwalbe, K. H., and Hellman, D., "Application of the Electric Potential Method to Crack Length Measurements Using Johnson's Formula," Journal of Testing and Evaluation, Vol. 9, No. 3, pp 218-221, 1981.

A.4 Landow, M. P., and Marschall, C. W., "Experience Using Direct Current Electric Potential to Monitor Crack Growth in Ductile Metals," ASTM STP1114, pp 163-172, 1991.

A.5 Tada, H., Paris, P. C., and Irwin, G. R., "The Stress Analysis of Crack Handbook," pp 2.10-2.15, Del Research Corporation, Hellertown, PA, USA, 1973.

A.6 Landes, J. D., and McCabe, D. E., "Load History Effects on the J-R Curve," Elastic Plastic Fracture: Second Symposium, Volume II-Fracture Resistance Curves and Engineering Applications, ASTM STP 803, C. F. Shih and J. P. Gudas, Eds., American Society for Testing and Materials, pp II723-II738, 1983.

A.7 Landes, J. D., and Liaw, P. K., "Effect of Cyclic Loading on Fracture Toughness of a Modified 4340 Steel," Effect of Load and Thermal Histories on Mechanical Behavior of Materials, P. K. Liaw and T. Nicholas, Eds., a publication of the Metallurgical Society, Inc. 1987. 
APPENDIX B

LISTING OF ALL DP2-A8 SPECIMENS 


\section{APPENDIX B: LISTING OF ALL DP2-A8 SPECIMENS}

Table B.1 Full-scale pipe experiments with crack in base metal

\begin{tabular}{cccc}
$\begin{array}{c}\text { Experiment } \\
\text { Number }\end{array}$ & Crack Type $^{(\text {a) }}$ & Loading History & Material Heat \\
\hline EPRI-8T & TWC pipe & Quasi-static bending & Unknown $^{(\text {b) }}$ \\
EPRI-13S & SC pipe & Quasi-static bending & Unknown $^{(\text {b) }}$ \\
$4114-3$ & CC pipe & Quasi-static bending & Unknown $^{(\mathrm{c})}$ \\
$4114-4$ & CC pipe & Quasi-static bending & Unknown $^{(\mathrm{c})}$ \\
$1.3-3$ & SC pipe & Single Frequency & DP2-A8II \\
$1-1$ & SC pipe & Simulated Seismic & DP2-A8I \\
\hline
\end{tabular}

(a) TWC = Through-wall crack; $\mathrm{SC}=$ surface crack; $\mathrm{CC}=$ complex crack.

(b) Unable to locate fracture surface.

(c) No chemical analysis performed.

Table B.2 Tensile specimens

\begin{tabular}{lll}
\hline Specimen ID & Loading History & Material Heat $^{(\mathrm{a})}$ \\
\hline A8-1-4 & Quasi-static & Unknown $^{(\mathrm{a})}$ \\
A8-1-1 & Quasi-static & Unknown $^{(\mathrm{a})}$ \\
A8-1-2 & Quasi-static & Unknown $^{(\mathrm{a})}$ \\
A8-35 & Quasi-static & DP2-A8I ${ }^{(\mathrm{b})}$ \\
A8-36 & Quasi-static & DP2-A8I \\
A8-37 & Quasi-static & DP2-A8I \\
A8-38 & Quasi-static & DP2-A8I \\
A8-39 & Quasi-static & DP2-A8I \\
A8-40 & Quasi-static & DP2-A8I \\
A8-101 & Dynamic, $1 /$ sec & DP2-A8II \\
A8-102 & Dynamic, $1 /$ sec & DP2-A8II \\
A8-103 & Dynamic, 10/sec & DP2-A8II \\
A8-104 & Dynamic, 10/sec & DP2-A8II \\
A8-105 & Quasi-static & DP2-A8II \\
\hline
\end{tabular}

(a) No chemical analysis performed.

(b) Machined from same section of pipe as specimen A8-39.

(c) Chemical analysis performed.

(d) Machined from same section of pipe as specimen A8-105. 
Table B.3 C(T) specimens

\begin{tabular}{|c|c|c|}
\hline Specimen D & Loading History & Material Heat \\
\hline A8-41 & Quasi-static, monotonic & DP2-A8I ${ }^{(a)}$ \\
\hline A8-42 & Quasi-static, monotonic & $\mathrm{DP} 2-\mathrm{A} 8 \mathrm{I}^{(\mathrm{a})}$ \\
\hline A8-43 & Quasi-static, monotonic & $\mathrm{DP} 2-\mathrm{A} 8 \mathrm{I}^{(\mathrm{a})}$ \\
\hline A8-44 & Quasi-static, monotonic & $\mathrm{DP} 2-\mathrm{A} 8 \mathrm{I}^{(\mathrm{b})}$ \\
\hline A8-47 & Quasi-static, monotonic & $\mathrm{DP} 2-\mathrm{A} 8 \mathrm{I}^{(\mathrm{a})}$ \\
\hline A8-48 & Quasi-static, monotonic & $\mathrm{DP} 2-\mathrm{A} 8 \mathrm{I}^{(\mathrm{a})}$ \\
\hline A8-49 & Quasi-static, monotonic & $\mathrm{DP} 2-\mathrm{A} 8 \mathrm{I}^{(\mathrm{a})}$ \\
\hline A8-52 & Quasi-static, monotonic & $\mathrm{DP} 2-\mathrm{A} 8 \mathrm{I}^{(\mathrm{c})}$ \\
\hline A8-54 & Quasi-static, monotonic & $\mathrm{DP} 2-\mathrm{A} 8 \mathrm{I}^{(\mathrm{c})}$ \\
\hline A8-55 & Quasi-static, monotonic & $\mathrm{DP} 2-\mathrm{A} 8 \mathrm{I}^{(\mathrm{c})}$ \\
\hline A8-56 & Quasi-static, monotonic & $\mathrm{DP} 2-\mathrm{A} 8 \mathrm{I}^{(\mathrm{c})}$ \\
\hline A8-57 & Quasi-static, monotonic & DP2-A8I ${ }^{(\mathfrak{b})}$ \\
\hline A8-71 & Quasi-static, monotonic & $\mathrm{DP} 2-\mathrm{A} 8 \mathrm{I}^{(\mathrm{d})}$ \\
\hline A8-72 & Quasi-static, monotonic & $\mathrm{DP} 2-\mathrm{A} 8 \mathrm{I}^{(\mathrm{b})}$ \\
\hline A8-9a & Dynamic, monotonic & $\mathrm{DP} 2-\mathrm{A} 8 \mathrm{I}^{(\mathrm{e})}$ \\
\hline A8-10a & Dynamic, monotonic & DP2-A8I ${ }^{(e)}$ \\
\hline A8-11a & Dynamic, monotonic & $\mathrm{DP} 2-\mathrm{A} 8 \mathrm{I}^{(\mathrm{e})}$ \\
\hline A8-12a & Quasi-static, monotonic & $\mathrm{DP} 2-\mathrm{A} 8 \mathrm{I}^{(\mathfrak{b})}$ \\
\hline A8I-13 & Quasi-static, $R=-0.3$ & $\mathrm{DP} 2-\mathrm{A} 8 \mathrm{I}^{(\mathrm{e})}$ \\
\hline A8I-14 & Quasi-static, $R=-1$ & $\mathrm{DP} 2-\mathrm{A} 8 \mathrm{I}^{(\mathrm{e})}$ \\
\hline A8II-15 & Dynamic, $R=-0.3$ & DP2-A8 $\Pi^{(f)}$ \\
\hline A8II-16 & Dynamic, $R=-0.3$ & DP2-A8II \\
\hline A8II-17 & Quasi-static, monotonic & DP2-A8II ${ }^{(b)}$ \\
\hline A8II-18 & Quasi-static, $R=-1$ & DP2-A8 $\Pi^{(\mathfrak{f})}$ \\
\hline A8II-20 & Dynamic, monotonic & $\mathrm{DP} 2-\mathrm{A} 8 \mathrm{I}^{(\mathfrak{)})}$ \\
\hline A8II-21 & Quasi-static, $R=-0.3$ & $\mathrm{DP} 2-\mathrm{A} 8 \mathrm{II}^{(f)}$ \\
\hline A8I-22 & Dynamic, $R=-0.3$ & $\mathrm{DP} 2-\mathrm{A} 8 \mathrm{I}^{(\mathrm{b})}$ \\
\hline A8I-23 & Dynamic, $R=-0.3$ & $\mathrm{DP} 2-\mathrm{A} 8 \mathrm{I}^{(\mathrm{b})}$ \\
\hline
\end{tabular}

(a) Machined from same section of pipe as specimen A8-44.

(b) Chemical analysis performed.

(c) Machined from same section of pipe as specimen A8-57.

(d) Machined from same section of pipe as specimen A8-72.

(e) Machined from same section of pipe as specimen A8-12a.

(f) Machined from same section of pipe as specimen A8II-17. 
Table B.4 Single-edge notched specimens

\begin{tabular}{|c|c|c|}
\hline Specimen ID & Specimen Type/Loading History & Material Heat \\
\hline A8-2 & $\begin{array}{c}\text { 3-point bend } \\
\text { Quasi-static, monotonic }\end{array}$ & Unknown $^{(a)}$ \\
\hline A8-3 & $\begin{array}{l}\text { 3-point bend } \\
\text { Quasi-static, monotonic }\end{array}$ & Unknown $^{(a)}$ \\
\hline SENT-2 & $\begin{array}{l}\text { Fixed grip tension } \\
\text { Quasi-static, monotonic }\end{array}$ & DP2-A8II \\
\hline SENT-3 & $\begin{array}{l}\text { Fixed grip tension } \\
\text { Quasi-static, } R=-0.3\end{array}$ & DP2-A8II ${ }^{(c)}$ \\
\hline SENT-4 & $\begin{array}{l}\text { Fixed grip tension } \\
\text { Quasi-static, } R=-1\end{array}$ & DP2-A8II ${ }^{(c)}$ \\
\hline SENT-5 & $\begin{array}{l}\text { Fixed grip tension } \\
\text { Quasi-static, } R=-0.8\end{array}$ & DP2-A8II \\
\hline SENT-6 & $\begin{array}{l}\text { Fixed grip tension } \\
\text { Quasi-static, monotonic }\end{array}$ & DP2-A81I ${ }^{(c)}$ \\
\hline A8-14 & $\begin{array}{l}\text { Fixed grip tension } \\
\text { Quasi-static, monotonic }\end{array}$ & Unknown $^{(\mathrm{a})}$ \\
\hline A8-19 & $\begin{array}{l}\text { Fixed grip tension } \\
\text { Quasi-static, monotonic }\end{array}$ & Unknown $^{(a)}$ \\
\hline A8-23 & $\begin{array}{l}\text { Fixed grip tension } \\
\text { Quasi-static, monotonic }\end{array}$ & Unknown $^{(a)}$ \\
\hline A8-59 & $\begin{array}{c}\text { Fixed grip tension } \\
\text { Quasi-static, monotonic }\end{array}$ & Unknown ${ }^{(a)}$ \\
\hline A8-60 & $\begin{array}{l}\text { Fixed grip tension } \\
\text { Quasi-static, monotonic }\end{array}$ & Unknown $^{(a)}$ \\
\hline A8-25 & $\begin{array}{l}\text { Fixed grip tension } \\
\text { Quasi-static, monotonic }\end{array}$ & Unknown $^{(\mathrm{a})}$ \\
\hline A8-27 & $\begin{array}{l}\text { Fixed grip tension } \\
\text { Quasi-static, monotonic }\end{array}$ & Unknown $^{(a)}$ \\
\hline A8-29 & $\begin{array}{c}\text { Fixed grip tension } \\
\text { Quasi-static, monotonic }\end{array}$ & Unknown $^{(\mathrm{a})}$ \\
\hline A8-9 & $\begin{array}{l}\text { Fixed grip tension } \\
\text { Quasi-static, monotonic }\end{array}$ & Unknown $^{(\mathrm{a})}$ \\
\hline A8-10 & $\begin{array}{l}\text { Fixed grip tension } \\
\text { Quasi-static, monotonic }\end{array}$ & Unknown $^{(2)}$ \\
\hline A8-12 & $\begin{array}{c}\text { Fixed grip tension } \\
\text { Quasi-static, monotonic }\end{array}$ & Unknown $^{(a)}$ \\
\hline
\end{tabular}

(a) No chemical analysis performed.

(b) Chemical analysis performed.

(c) Machined from the same section of pipe as SENT-2. 


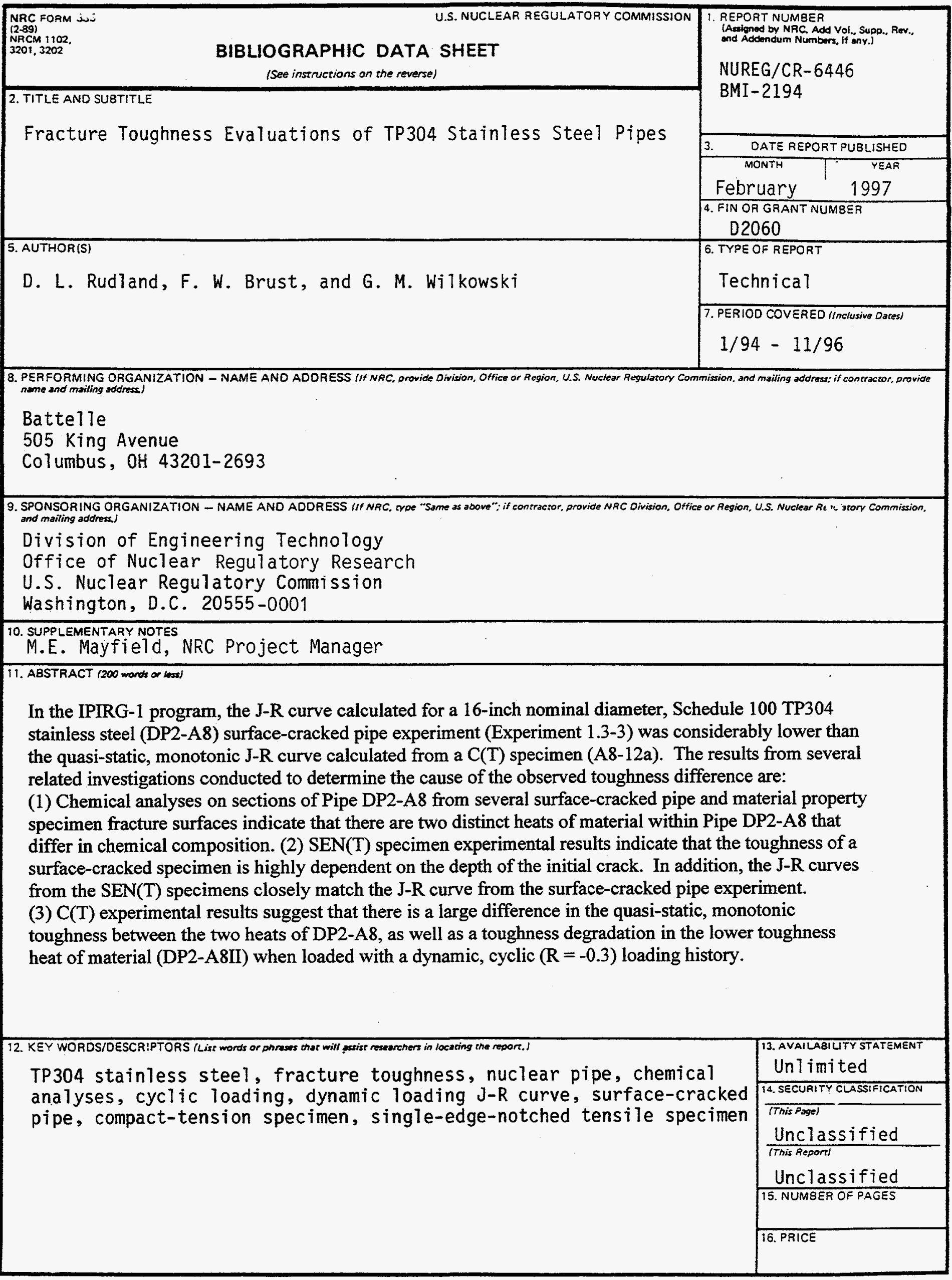

